\title{
Pluripotent stem cell SOX9 and INS reporters facilitate differentiation into insulin-producing cells
}

\author{
Rabea Dettmer, Isabell Niwolik, Ilir Mehmeti, Anne Jörns and Ortwin Naujok* \\ Institute of Clinical Biochemistry, Hannover Medical School, Hannover, Germany
}

Author contributions

Conceptualization: Ortwin Naujok

Formal analysis: Rabea Dettmer and Ortwin Naujok

Funding acquisition: Ortwin Naujok

Investigation: Rabea Dettmer, Isabell Niwolik, Ilir Mehmeti, Anne Jörns and Ortwin Naujok Methodology: Rabea Dettmer, Isabell Niwolik, Ilir Mehmeti

Project administration: Ortwin Naujok

Supervision: Ortwin Naujok

Visualization: Rabea Dettmer, Anne Jörns and Ortwin Naujok

Writing - original draft: Rabea Dettmer, Isabell Niwolik, Ilir Mehmeti, Anne Jörns and Ortwin Naujok

Writing - review \& editing: Anne Jörns and Ortwin Naujok

\section{*Corresponding author}

\section{Dr. Ortwin Naujok}

Institute of Clinical Biochemistry

Hannover Medical School

30625 Hannover

Germany

Phone: $+49 / 511 / 532-3544$

Fax: $+49 / 511 / 532-3584$

33 E-mail: naujok.ortwin@mh-hannover.de 


\section{Abstract}

45 Differentiation of human pluripotent stem cells into insulin-producing stem cell-derived beta cells harbors great potential for research and therapy of diabetes. The SOX9 gene plays a crucial role during development of the pancreas and particularly in the development of insulin-producing cells as SOX9+ cells form the source for NEUROG3+ endocrine progenitor cells. For the purpose of easy monitoring of differentiation efficiencies into pancreatic progenitors and insulin-producing cells, we generated new reporter lines by knocking in a $\mathrm{P} 2 \mathrm{~A}-\mathrm{H}-2 \mathrm{~K}^{\mathrm{k}}-\mathrm{F} 2 \mathrm{~A}-\mathrm{GFP} 2$ reporter genes into the SOX9 locus and a P2A-mCherry reporter gene into the INS locus mediated by CRISPR/CAS9-technology. The knock-ins enable coexpression of the endogenous genes and reporter genes, report the endogenous gene expression and enable the purification of pancreatic progenitors and insulin-producing cells using FACS or MACS. Using these cell lines we established a new differentiation protocol geared towards SOX9+ cells to efficiently drive human pluripotent stem cells into glucoseresponsive beta cells. 


\section{Introduction}

60 The SOX9 protein belongs to a large family of high-mobility domain transcription factors with pleiotropic functions during vertebrate development, cellular maintenance and disease development [1]. In humans SOX9 haploinsufficiency leads to campomelic dysplasia with

pancreatic dysmorphogenesis [2]. This evidence and other results from several transgenic mouse models $[3,4]$ have led to the conclusion that SOX9 belongs to the group of master regulators of pancreatic development [1].

SOX9 expression during the initial forming of the dorsal and ventral pancreatic buds strongly co-localizes with PDX1 in mouse and man $[4,5]$. In mice, when the early unpolarized epithelium branches into a plexus with proximal trunk and distal tip domains, Sox9 is expressed co-localized with Cpa1 and Pdx1 in the tip domain or with Nkx6.1 and Pdx1 in the trunk domain [4]. The distal tip domain is considered as the cellular pool for acinar differentiation, whereas the proximal trunk domain harbors the development niche for bipotent ductal/endocrine precursor cells [6]. Bipotent precursor then give rise to Neurog3+ cells. Later, during mid second transition, Sox9 expression is receding from the tip domain and becomes restricted to the proximal trunk cells. By late gestation and in adults Sox9 expression is confined to centroacinar and ductal cells $[1,4]$.

Thus, SOX9 is an interesting target for the generation of new human pluripotent stem cell (hPSC) reporter lines in order to target the development niche that gives rise to the endocrine lineage. This would open up new opportunities to develop efficient differentiation protocols for the generation of stem cell-derived beta cells or organoids, respectively (SC-derived beta cells/SC-derived organoids). Therefore, the aims of this study were to generate two types of reporter cell lines, namely a SOX9 and a SOX9/INS knock-in cell line and a differentiation protocol optimized towards the generation of SOX9+ MPCs.

For that purpose, we used CRISPR/Cas9 to knock-in reporter genes, GFP2 and the surface antigen $\mathrm{H}-2 \mathrm{~K}^{\mathrm{k}}$, in frame by homology directed repair (HDR) into the SOX9 locus and 
85 additionally mCherry into the INS locus. This permits monitoring and cell purification of

86 SOX9 and INS expressing populations.

87 We can show that PDX1+ pancreatic-duodenal cells described in earlier studies [7, 8],

88 effectively differentiate into SOX9+ multipotent pancreatic progenitor cells (MPCs) with co-

89 expression of CPA1 or NKX6.1. By use of this triple knock-in cell line we could track the

90 conversion of SOX9 MPCs into SC-derived beta cells. In parallel, we have developed a 3D

91 differentiation protocol to efficiently generate a large number of SC-derived organoids 92 predominantly composed of monohormonal beta cells. 


\section{Results}

In order to generate reporter PSC lines, a knock-in strategy based on CRISPR/Cas9-induced

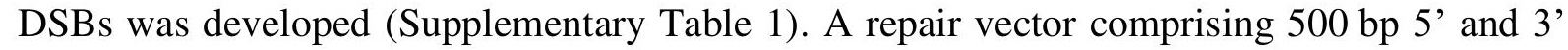
homology arms, two reporter genes, namely $\mathrm{H}-2 \mathrm{~K}^{\mathrm{k}}$ and GFP2, separated by $2 \mathrm{~A}$ cleavage sites, and a floxed selection gene cassette was cloned (Fig 1A). After nucleofection and selection by antibiotics, pluripotent stem cell colonies with typical morphology were expanded and genotyped by PCR. Correct insertion was verified by sequencing. The HES-3 clone SC30 and the Phoenix iPSC clone NSC20, both with homozygous integration, were selected for further work. Our optimized endoderm differentiation protocol [9] robustly produced $>90 \%$ CXCR4-positive cells, which were also predominantly positive for the anterior foregut endoderm markers CD177 and CD275 as recently described [10] (Supplementary Fig. 1A-D). Then six different protocols for differentiation of endoderm into MPC were tested (Supplementary Fig. 2). Protocol \# 6, which is based on our protocol for the differentiation of hPSC into PDX1+ pancreatic-duodenal cells (Supplementary Fig. 1E) [7, 8] expanded by Stage 3 and Stage 4 media from [11] was then selected and termed 2D experimental differentiation protocol (Fig. 1B). This 4-stage protocol, when applied to SC30 and NSC20 cell clones, yielded in an expression peak of $~ 40-50 \%$ GFP2+ cells between day 10 and 13 of differentiation (Fig 1C). GFP2+ positive cells additionally expressed $\mathrm{H}-2 \mathrm{~K}^{\mathrm{k}}$, thereby allowing cell purification by either FACS or MACS (Fig 1D/Supplementary Fig. 3). Next, GFP2+/GFP2- cells were sorted by FACS and analyzed upon expression of MPC marker genes. GFP2+ cells expressed significantly more HNF6, NKX6-1, PDX1 and SOX9 compared to GFP2- cells. Only NEUROG3 was stronger expressed in GFP- cells (Fig. 1E/Supplementary Fig. 4). 
118 SOX9 protein predominately occurred in the nucleus of GFP2+ cells and was low or absent in

119 GFP2- cells (Fig 1F). Consistently to the gene expression data, PDX1, NKX6-1 and HNF6

120 were prominently expressed in GFP2+ cells (Fig 1G). Next, surface markers described to be

121 expressed on MPCs, namely CD200 and CD142 [12] and GP2 [13], were measured by flow

122 cytometry. D12 and d15 GFP2+ cells expressed CD200 and GP2 and faintly CD142, but only

123 GP2 was differently expressed compared to GFP- cells (Fig. 1H).

124 According to the spatiotemporal expression pattern of Sox9 during pancreas organogenesis in mice, we expected to detect CPA1+/SOX9+ and NKX6.1+/SOX9+ cells as representatives of

SOX9 MPC and further differentiated them in 2D using the stage 5-7 media described by

129 Pagliuca and co-workers [14]. Re-seeded and purified SOX9 MPC formed tight clusters/colonies after cell sorting. At d15 mosaic NKX6.1 and CPA1 expressing cells were readily detected and by d18 NKX6.1 was almost homogenously expressed in these colonies.

D18 marked also the expression peak of scattered NEUROG3+ and very few CPA1+ cells (Fig. 2C). The detection of the first NEUROG3+ cells coincided with insulin and C-peptide+

134 cells, which from d18 grew out in clusters. These structures were embedded in CK19+ epithelial colonies. Gene expression changes of sorted and further differentiated cells are presented in Supplementary figure 5. We next analyzed insulin and C-peptide content and whether these SC-derived beta cells would release insulin. We also compared sorted vs non-

138 sorted differentiation experiments. Cell sorting yielded in a $~ 4$-fold increase of insulin and C-

139 peptide content compared to non-sorted cells.

140 However, insulin release was only triggered by $\mathrm{KCl}$ and not by elevated glucose 141 concentrations and mean variation was high (Fig 2E). Since differentiation of hPSCs into 142 polyhormonal SC-beta cells is a common phenomenon, we double stained insulin and 143 glucagon and found to a minor extent polyhormonal cells with both hormones (Fig. 2F). 
144 Next, to take advantage of the SOX9 reporter cells, we tested the impact of stage 3 and stage

1454 media components. In a subtraction assay we compared GFP2 expression in control cells

146 cultured for $24 \mathrm{~h}$ in stage 3 and $72 \mathrm{~h}$ in stage 4 against treatments, where stage 3 was omitted

147 or individual components of stage 4 were left out (Fig 3A). The omission of stage 3 showed

148 the greatest and significant reduction of GFP2+ cells. In descending order, the number of

149 GFP2+ cells was also reduced by omitting LDN, EGF and NA from the stage 4 medium.

150 Addition of a PKC activator as used in some differentiation protocols, however, did not

151 increase the number of GFP2+ cells in our protocol. Then we titrated the amount of EGF in

152 stage 4 medium and were able to determine that the maximum of GFP2 expression was

153 reached for both cell lines from $\sim 100 \mathrm{ng} / \mathrm{ml}$ EGF and on.

154 The SOX9 gene is controlled, amongst other mechanisms, by the FGFR2b signaling pathway

155 and by Wnt/beta-catenin signaling [15]. Therefore we compared the effects of the growth

156 factors FGF7 and FGF10, which signals through FGFR2b, and of EGF and FGF2 used in

157 other beta cell differentiation protocols at this stage of differentation $[11,13,14,16]$. Also the

158 effect of Wnt/beta-catenin inhibition and activation was analyzed (Fig 3C-F). Using the SC30

159 cell clone, it turned out that the incubation with $100 \mathrm{ng} / \mathrm{ml}$ EGF produced the highest number

160 of GFP2+ cells and showed the strongest expression of PDX1, SOX9 and NKX6-1. FGF10 and

161 FGF2 at the same concentration caused a significant decrease of GFP2+ cells compared to

162 EGF (Fig. 3C). Wnt/beta-catenin activation of this pathway by CHIR99021 showed a

163 significant inhibitory effect both on the number of GFP2+ cells and on the expression of

164 PDX1, SOX9, NKX6-1 and NKX2-2. Addition of the inhibitors of Wnt/beta-catenin signaling

165 IWP4 and IWR-1 did, however, not yield in a further increase of GFP2+ cells or enhanced

166 gene expression (Fig 3E/F). The same pattern was found for the NSC20 cell clone

167 (Supplementary Fig. 6A/B). Furthermore, we were able to determine a significant increase in

168 GFP2 expression from $42 \%$ to $74 \%$ for the SC30 cell clone and from $46 \%$ to $77 \%$ for the 
169 NSC20 cell clone after upscaling from 2D differentiation in 12-well cavity format to $10 \mathrm{~cm}$

170 culture dishes (Supplementary Fig. 6C).

171 For simplification of the monitoring process, we knocked-in mCherry into the human INS-

172 locus of the SC30 cell clone. This allowed us to measure SOX9 progenitor generation and

173 their conversion into SC-derived beta cells using flow cytometry. For this, a repair vector

174 similar to the repair vector for the SOX9-locus was cloned. It comprised $500 \mathrm{bp} 5$ ' and 3'

175 homology arms, the reporter gene mCherry and a floxed selection gene cassette (Fig 4A). For

176 the knock-in into the INS locus, CRISPR/Cas9 nickases were used (Supplementary Table 1).

177 After verification of correct insertion by sequencing, the homozygous SC30 ICNC4 cell clone

178 was selected for further work.

179 With recent reports on the improvement of differentiation and maturity through 3D culture we

180 adapted our 2D experimental protocol and introduced 3D orbital shaking from d12 on until

181 the end of differentiation (Stage 4-7). Stage 3 and 4 media were adapted according to our

182 previous findings. For 3D differentiation, d12 cells were gently dissociated and transferred to

183 6-well suspension culture dishes on an orbital shaker. Different rotating speeds from $70 \mathrm{rpm}$

184 to $100 \mathrm{rpm}$ were tested. Finally, we settled with $100 \mathrm{rpm}$ and around 2 x $10^{6}$ cells per ml (5 ml

185 per cavity). To reduce cell clumping the cells were treated with DNase I before seeding,

186 yielding in equally formed, round and small spheroids $24 \mathrm{~h}$ after transition from $2 \mathrm{D}$ to $3 \mathrm{D}$

187 culture. The spheroids were kept in culture for an additional 16-17 days without resizing. (Fig

188 4B, Supplementary Fig. 7).

189 During this time the kinetics of GFP2 and mCherry expression (SOX9 and INS expression,

190 respectively) were monitored by flow cytometry. It could be shown that the increase in INS+

191 cells was accompanied by a parallel decrease in SOX9+ cells starting from d15 (Fig 4C/D).

192 Next, we verified the INS knock-in by comparing gene expression of beta cell genes in

193 mCherry+ vs mCherry- cells. INS gene expression was 31-fold higher in mCherry+ cells and

194 other beta cell markers were between 2.2- and 6.1-fold higher expressed compared to 
195 mCherry- cells verifying functionality of the knock-in (Fig 4E). The gene expression kinetics

196 of various pancreatic and endocrine genes was monitored during the 2D/3D differentiation

197 process (Fig 5A). Of note here was again peak expression of SOX9 and CPA1 at d15 followed

198 by peak NEUROG3 expression three days later. In parallel with the peak in NEUROG3

199 expression, the increase in islet cell hormones and NKX6-1 could be recorded. Typical beta

200 cell genes showed the same pattern in gene expression as insulin (Fig 5A). 
Next, the number of INS+ cells obtained in $2 \mathrm{D}$ culture was compared to 3D culture. 3D yielded in significantly more mCherry+ cells compared to 2D differentiation (mean $44 \%$ for $\mathrm{d} 22$ in $3 \mathrm{D}, 15 \%$ for $\mathrm{d} 22$ in 2D; mean $50 \%$ for d29 in 3D, $12 \%$ for d29 in 2D) (Fig 5B). The different efficiencies of 2D and 3D differentiation could also be observed after immunofluorescence staining of insulin and C-peptide (Fig. 5C). The expression of glucose recognition marker genes GCK, KIR6.2, SUR1 and GLUT2 and the transcription factor NKX61 were significantly higher in $3 \mathrm{D}$ compared to $2 \mathrm{D}$ conditions and, except for $G C K$ expression, comparable to EndoC- $\beta \mathrm{H} 1$ cells (Fig. 5D). Islet hormone expression was also higher in 3D conditions compared to 2D. Since EndoC- $\beta \mathrm{H} 1$ cells are a model cell line for human beta cells, the INS expression is higher compared to the heterogeneous composition of SC-derived organoids. The expression of the transcription factors NEUROG3 and $S O X 9$ were also highest for $3 \mathrm{D}$ culture. This together with the gene expression analysis in $2 \mathrm{D}$ and $3 \mathrm{D}$ compared to

214 EndoC- $\beta \mathrm{H} 1$ cells revealed the improvement of differentiation towards SC-derived organoids 215 in 3D culture (Fig. 5D/Supplementary Fig. 8). The immunostaining of endocrine marker 216 proteins, especially from beta cells, were then compared to those of d15 SC-derived spheroids 217 and beta cells of islets and the surrounding tissue from human non-diabetic pancreas (Fig. 6). 218 D29 SC-derived organoids generated from the SC30 cell clone were typically 200-300 $\mu \mathrm{m}$ in 219 diameter and displayed a cytoplasmic co-localization of insulin and C-peptide in the majority 220 of cells resembling the staining of beta cells in human islets. A polyhormonal staining of 221 insulin or C-peptide with other islet peptides was rarely detected in these cells (Fig. 222 6/Supplemental Figure 9). Also the number of glucagon-positive cells was lower compared to 223 2D culture. NKX6.1 and PDX1 were in parallel localized in the nucleus of the insulin-positive 224 cells in d29 SC-derived organoids. In comparison with human tissue, the only difference of 225 the SC-derived organoids to human islets was the presence of some SOX9+ cells, whereas in 226 human pancreas sections a clearer distinction between the SOX9- endocrine islets and SOX9+ 
exocrine parenchyma compartment was observed (Fig. 6). For comparison,

228 immunofluorescence (IF) staining of insulin, C-peptide and glucagon of SC30 and NSC20

229 cells in 2D culture is depicted in Supplementary Fig. 10. Next the SC-derived organoids were

230 further characterized. First we were able to measure a sharp increase in insulin and C-peptide

231 content from d22 to d29 organoids (Fig. 7A). This content was comparable with EndoC- $\beta \mathrm{H} 1$

232 cells (101 ng insulin/ $\mu \mathrm{g}$ DNA) and significantly higher comparing 2D with 3D (5.7 vs

$233 \quad 302.27 \mathrm{ng}$ insulin/ $\mu \mathrm{g}$ DNA for SC30, respectively) (Fig. 7B).

234 Then the changes in free cytosolic $\mathrm{Ca}^{2+}$ were measured in real time by Fura-2AM assay. SC-

235 derived organoids derived from SC30 and NSC20 were perifused with modified KR in the

236 absence or presence of $20 \mathrm{mM}$ glucose and $40 \mathrm{mM} \mathrm{KCl}$. The SC30 cell clone showed a

237 detectable increase in free calcium in the cytosol after exposure to glucose and potassium

238 chloride (Fig. 7C), while the NSC20 cell clone only responded to potassium chloride

239 (Supplementary Fig. 11).

240 Finally, the question was addressed whether 3D culture and differentiation could also improve

241 glucose-induced insulin secretion (GSIS) in both cell lines (Fig. 7D/E). SC30-derived

242 organoids showed a significant increase in insulin release when subjected to $20 \mathrm{mM}$ glucose

243 in a static assay. The insulin-releasing properties were also significantly improved compared

244 to the 2D culture. NSC20-derived organoids showed a more robust insulin release in 2D

245 culture though but neither in $2 \mathrm{D}$ or $3 \mathrm{D}$ the cells responded appropriately in response to

246 glucose. EndoC- $\beta$ H1 cells were measured as controls (Fig. 7E). 


\section{Discussion}

249 Here we report the generation and characterization of new hPSC reporter lines with insertion

250 of the GFP2 and $\mathrm{H}-2 \mathrm{~K}^{\mathrm{k}}$ reporter genes following the SOX9 open reading frame and an 251 additional cell line with a knock-in of mCherry into the INS locus. Aided by these cell lines 252 we established a new differentiation protocol geared towards SOX9 MPCs to efficiently drive hPSCs by 3D orbital shaking culture into SC-derived organoids with a beta cell content of $>40 \%$. The SOX9 reporter cell lines showed peak SOX9/GFP2 expression after 10-13 days of differentiation using an experimental 2D differentiation protocol. This protocol is based on previous publications by our group in which we established a robust method for generating NKX6.1-/ PDX1+ pancreatic-duodenal cells [7, 8, 17] as well as adopted stage 3/stage 4 media described by Nostro and colleagues [11].

After purifying the GFP2+/GFP2- fractions, we were able to show that the GFP2+ cell population expressed high levels of $H N F 6, N K X 6-1, P D X 1$ and $S O X 9$, and thus are potentially SOX9 MPCs. Further analysis of MACS-purified SOX9 MPCs at d15 (end of stage 4) revealed mosaic-like expression of NKX6.1 and a few CPA1+ cells. Possibly these cells are representatives of the trunk region, which physiologically represents the niche for further

264 endocrine development. Analysis of the MPC surface markers CD142, CD200 and GP2 265 revealed partial identity with MPCs generated with different protocols $[12,13]$.

266 By pursuing further down the developmental pathway and following the protocol published 267 by Pagliuca and colleagues [14], the cells showed at d18 (end of stage 5) not only a more 268 homogeneous NKX6.1 expression but also scattered NEUROG3+ cells. Then SOX9 MPCs 269 readily developed into insulin/C-peptide-positive and glucagon-positive cells embedded in 270 CK19+ epithelial cells. This fits in with findings from earlier studies in rodents that CK19+ 271 fetal epithelium marks a source for endocrine islets [18]. In line with other studies 272 polyhormonal cells were readily detected in 2D [19]. The SC-derived beta cell fraction 
generated in 2D showed no increased insulin secretion after glucose stimulation. A

274 purification of SOX9 MPCs could not compensate for this deficit in function, although insulin and C-peptide content were increased, which confirms the effectiveness of an enrichment strategy [13].

Before the transition to 3D differentiation we systematically tested various compounds and conditions in stage 3 and 4 to increase the number of SOX9 MPCs. We can confirm that a $24 \mathrm{~h}$ pulse with stage 3 medium, which contains high FGF10 and a SHH inhibitor, is decisive for the differentiation into SOX9 MPCs. Withdrawal of nicotinamide and EGF in stage 4 also greatly reduced the number of SOX9 MPCs [11]. Interestingly, addition of the PKC activator PDBu was of no help at this stage of differentiation [20].

283 Regarding the transcriptional regulation, it has been reported, that SOX9 maintenance is 284 controlled by Wnt/beta-catenin signaling [21], FGF-signaling via FGFR2b [22], Notchsignaling [23] and positive autoregulation [24]. Moreover, SOX9 and Wnt/beta-catenin form a regulatory loop and inhibit each other's transcriptional activity. In chondrocytes SOX9 inhibits canonical Wnt-signaling by direct protein interaction with beta-catenin, yielding in 288 inhibition and degradation of the protein $[25,26]$. Vice versa Wnt/beta-catenin represses 289 SOX9 gene expression in osteoblasts [27]. In our in vitro differentiation approach we can show for both hPSC lines that active canonical Wnt-signaling is an effective inhibitor of SOX9 MPC generation. This underlines the importance of this signaling pathway for differentiation protocols of hPSC into SC-derived beta cells. According to current and previous data, Wnt/beta-catenin not only prevents development of endocrine progenitors [28],

294 but also earlier development of PDX1+ pancreatic-duodenal cells [8] and, as shown here, development into SOX9 MPCs.

296 Surprisingly our data indicate that differentiation into SOX9 MPCs is most effective in 297 presence of EGF and not the commonly used growth factors FGF2/7 or FGF10 [13, 16, 29, 298 30]. FGF7 and FGF10 were less effective with regard to the absolute number of SOX9 MPCs 
or showed lower gene expression of typical MPC marker genes. Previously we had identified

300 FGF2 as a repressor of early development into PDX1 pancreatic-duodenal cells [8]. In this

study SOX9 MPC generation was also slightly less effective when compared to EGF. This

was additionally evident from the reduced expression of SOX9 and NKX6-1 in FGF2-treated

MPCs. In contrast to mouse studies for which an FGF10/FGFR2B/SOX9 feed-forward loop

was described [22], the EGF-signaling pathway seems to play a greater role during differentiation into SOX9 MPCs in the human system.

3D differentiation in shaking orbital cultures or small bioreactors has become the standard for

many somatic cell types [31-33]. Transition from 2D to 3D alone, without changes in

extrinsic or other factors, can lead to a considerable phenotypic improvement [34]. At the

same time, monitoring the in vitro differentiation with molecular biological methods such as

310 RT-qPCR, immunofluorescence or Western blot is time-consuming, cumbersome and

uneconomical. For these reasons, we converted the $2 \mathrm{D}$ differentiation protocol to $3 \mathrm{D}$. In

MPCs into SC-derived beta cells. The 3D reconstructed islet-like organoids comprised SC-

315 derived beta cells with important beta cell features such as expression of typical genes, insulin/C-peptide positive cells, very few polyhormonal cells, calcium influx after glucose exposure, and glucose-stimulated insulin secretion. Our results also show that transition from $2 \mathrm{D}$ to $3 \mathrm{D}$ culture not only results in a quantitative advantage, but also in an qualitatively improvement. The transition from $2 \mathrm{D}$ to $3 \mathrm{D}$ alone increased the insulin content in non-sorted cells by more than 50-fold (SC30). It is also important to note that we observed line-specific effects. While the hESC-based clone differentiated into glucose-responsive cells, this was not achieved for the iPSC-based clone. This result is probably attributed to cell line-specific

323 barriers, which have already been described and represent a major obstacle in the 324 establishment of patient-specific cell replacement therapies [35, 36]. 
325 The currently prevailing differentiation protocols were optimized towards the generation of mainly PDX1+/NKX6.1+ double-positive cells as the seed for SC-derived beta cells $[14,16]$. Our protocol is based on an efficient generation of definitive endoderm using low activin A concentrations (> 90\% endoderm cells), differentiation into PDX1+ pancreatic-duodenal cells by BMP and Wnt-inhition in presence of all-trans retinoic acid $(\sim 80 \%)[7,8]$, and optimized conditions to generate SOX9 MPCs ( 70\%). After using the stage 5-7 media described by Pagliuca and co-workers [14], these cells effectively differentiated into SC-beta cells (> 40\% positive cells). Thus, the new protocol that we present in this report may offer an alternative route to generate SC-derived beta cells.

334 Reporter cell lines are excellent tools to advance research into efficient differentiation methods [37-40]. The SOX9 reporter cell lines reported here are also an excellent model for 336 studying the transition of human bipotent ductal/endocrine precursors into NEUROG3+ endocrine precursor cells. In view of the pleiotropic functions of SOX9 during development 338 and tissue maintenance in diverse organs such as chondrocytes, testes, heart, lung, bile duct, 339 retina and the central nervous system [25, 41, 42], these reporter cell lines are also suited for 340 research on other matters. Additionally, the reporter gene knock-in into the INS-locus enables 341 an exclusive look at insulin-producing cells and can therefore bypass the problem of a 342 heterogenous composition of in vitro differentiated cells caused by not fully effective 343 differentiation protocols. 


\section{Materials \& Methods}

\section{Human cell culture}

347 The human PSC lines Hes-3 ('ESC') and Phoenix ('iPSC', MHHi001-A) [43] were cultured 348 on cell culture plastic coated with hESC-qualified Matrigel (Corning, Amsterdam,

349 Netherlands). mTeSR1 (Stem Cell Technologies, Cologne, Germany) or StemMACS ${ }^{\text {TM }}$ iPS-

350 Brew XF medium (Miltenyi Biotec, Bergisch Gladbach, Germany) was used. Passaging was

351 performed once a week in a ratio of 1:20 up to 1:40 and cluster were seeded onto fresh

352 Matrigel-coated 6-well plates. EndoC- $\beta \mathrm{H} 1$ cells were cultured according to the standard 353 protocol [44].

\section{Generation of hPSC reporter cell lines}

355 To introduce DNA double-strand breaks (DSBs) into the genomic loci of SOX9 and INS the

356 CRISPR/Cas9 system was used. Putative sgRNAs were calculated with CCTop 357 (https://cctop.cos.uni-heidelberg.de/) [45].The sgRNA for the SOX9 locus was cloned into the pLKO5.U6 vector [46] and the sgRNAs, two nickase pairs, for the INS locus were cloned into the pX335-U6-Chimeric_BB-CBh-hSpCas9n vector [47] (Supplementary table 1). Reporter 360 genes were introduced by HDR [48]. A scheme of the repair vectors is presented in Figure 361 1A/4A. Briefly $2 \times 10^{6}$ hPSCs were nucleofected with $2 \mu \mathrm{g}$ repair vector and $2 \mu \mathrm{g}$ 362 Cas9/sgRNA vector using the Neon Nucleofection System. Transfected hPSCs were seeded and selected after $24 \mathrm{~h}$ using either hygromycine $\mathrm{b}$ or blasticidin. Cell clones were picked

364 after 10-14 days, expanded and genotyped by PCR and sequencing upon correct insertion of 365 the transgenes into the desired loci.

\section{D experimental differentiation protocol}

367 For differentiation of hPSCs in 2D, hPSC colonies were dissociated into single cells by

368 Trypsin/EDTA (T/E) (Biochrom, Berlin, Germany) and centrifuged for $3 \mathrm{~min}$ at $300 \mathrm{x} \mathrm{g}$. The 369 pellet was re-suspended in mTeSR1 or iPS-Brew XF containing $5 \mu \mathrm{M}$ Y-27632 (Selleck 
Chemicals, Munich, Germany) and a defined number of cells (100,000 cells/12-well plate cavity, 250,000 cells/6-well plate cavity and $1.3-1.45 \times 10^{6}$ cells per $10 \mathrm{~cm}$ cell culture dish) were seeded on Matrigel-coated cell culture plastics. Cells were allowed to re-attach and differentiation was initiated after $24 \mathrm{~h}$. Differentiation was performed according to an adopted 7-stage protocol (Figure 1B/2A) [7-9, 11, 14]. Media compositions were as followed: stage 1a medium (24 h), RPMI1640, (Biochrom) plus 0.5fold B27 supplement (Thermo Fisher Scientific, Schwerte, Germany), 1\% penicillin/streptomycin (P/S) (penicillin: Santa Cruz Biotechnology, Dallas, USA; streptomycin: Sigma-Aldrich, Munich, Germany), $2 \mathrm{mM}$ glutamine, 1-fold non-essential amino acids (NEAA, Thermo Fisher Scientific, Schwerte,

Germany), $1 \mathrm{mM}$ sodium pyruvate (Capricorn scientific, Ebsdorfergrund, Germany), 0.5-fold

ITS-X (Thermo Fisher Scientific) $0.25 \mathrm{mM}$ vitamin C, $30 \mathrm{ng} / \mathrm{ml}$ activin A (Stem Cell Technologies), and $3 \mu \mathrm{M}$ CHIR99021 (Cayman Chemical, Ann Arbor, USA); stage 1b medium (72 h) was composed as stage 1a medium but lacked CHIR99021. The required activin A concentration was titrated for every individual lot (Supplementary Fig. 1A). Stage 2

384 medium (96 h), advanced RPMI1640 (Thermo Fisher Scientific) plus 0.5 fold B27 385 supplement, $1 \% \mathrm{P} / \mathrm{S}, 2 \mathrm{mM}$ glutamine, 1x NEAA, $0.25 \mathrm{mM}$ vitamin C, $5 \mathrm{ng} / \mathrm{ml}$ FGF7 (Stem Cell Technologies), $2 \mu \mathrm{M}$ IWR-1 (Selleck Chemicals, Munich, Germany), $0.5 \mu \mathrm{M}$ LDN193189 (Sigma-Aldrich) and $1 \mu \mathrm{M}$ all-trans retinoic acid (ATRA, Sigma-Aldrich); stage 3 medium (24 h), DMEM (Biochrom) plus 1\% P/S, $2 \mathrm{mM}$ glutamine, 0.5 fold B27 389 supplement, $50 \mathrm{~g} / \mathrm{ml}$ vitamin C, $50 \mathrm{ng} / \mathrm{ml}$ FGF10 (Stem Cell Technologies), $0.25 \mu \mathrm{M}$ Sant-1 390 (Selleck Chemicals), $2 \mu$ M ATRA, $0.5 \mu$ M LDN193189; stage 4 medium (6 days), DMEM 391 plus $1 \% \mathrm{P} / \mathrm{S}, 2 \mathrm{mM}$ glutamine, 0.5 fold $\mathrm{B} 27$ supplement, $50 \mathrm{~g} / \mathrm{ml}$ vitamin $\mathrm{C}, 10 \mathrm{mM}$ 392 nicotinamide (Sigma-Aldrich), $200 \mathrm{ng} / \mathrm{ml}$ EGF (Stem Cell Technologies), $0.5 \mu \mathrm{M}$ 393 LDN193189; stage 5 medium (3 days), BE5 stock medium plus ITS-X (1:200), $10 \mu \mathrm{g} / \mathrm{ml}$ 394 heparin (Sigma-Aldrich), $20 \mathrm{ng} / \mathrm{ml}$ betacellulin (Stem Cell Technologies), $10 \mu \mathrm{M} \mathrm{ZnSO}_{4}$ 395 (MerckMillipore, Schwalbach, Germany), $0.25 \mu$ M Sant-1, 50 nM ATRA, $1 \mu$ M XXI (Stem 
Cell Technologies) or $1 \mu \mathrm{M}$ LY411575 (Selleck Chemicals), $10 \mu \mathrm{M}$ Alk5iII (Santa Cruz

397 Biotechnology, Dallas, USA) or $10 \mu \mathrm{M}$ RepSox (Selleck Chemicals), $1 \mu \mathrm{M}$ GC1 (Tocris, 398 Bristol, United Kingdom), 3 nM staurosporine (Cayman Chemical), $5 \mu \mathrm{M}$ Y-27632, $100 \mathrm{nM}$ and Sant-1; stage 7 medium (7 days), CMRLM stock medium plus $20 \mathrm{nM}$ insulin (SigmaAldrich), $10 \mu \mathrm{M} \mathrm{ZnSO}$, $10 \mu \mathrm{g} / \mathrm{ml}$ heparin, $15 \mu \mathrm{M}$ ethanolamine (Sigma-Aldrich), $10 \mu \mathrm{M}$ (Sigma-Aldrich), medium trace elements A (1:1000, Corning), medium trace elements B

BE5 stock was composed of MCDB131 (Thermo Fisher Scientific) plus $20 \mathrm{mM}$ D-(+)-

Glucose, $1.754 \mathrm{~g} / \mathrm{NaHCO}_{3}, \quad 2 \%$ FAF-BSA (SERVA, Heidelberg, Germany), $2 \mathrm{mM}$ glutamine and $1 \% \mathrm{P} / \mathrm{S}$. CMRLM stock was composed of $2 \%$ FAF-BSA, $1 \% \mathrm{P} / \mathrm{S}, 2 \mathrm{mM}$ glutamine and $5 \mathrm{mM}$ sodium-pyruvate. FGF2, FGF7, FGF10 (each $100 \mathrm{ng} / \mathrm{ml}$ ) and IWP4 from Tocris (biotechne, Minneapolis, USA). Unless otherwise mentioned, chemicals were

411 obtained from Riedel-de Haen, (Munich, Germany), J.T. Baker (Chihuahua, Mexico) or 412 Sigma-Aldrich.

\section{D production protocol}

414 Differentiation of hPSCs in 3D was initiated by seeding hPSCs on Matrigel-coated cell 415 culture plastics. Media compositions remained the same as described for 2D with slight 416 differences. Stage 3 and stage 4 medium were supplemented with $2 \mu \mathrm{M}$ IWR-1 and $100 \mathrm{ng} / \mathrm{ml}$ 417 EGF was supplemented to stage 4 medium. Differentiation proceeded in $2 \mathrm{D}$ according to the 418 7-stage protocol (Figure 1B/2A) until day 12 of differentiation. Then the cells were washed 419 with PBS, dissociated into single cells by T/E and centrifuged for $4 \mathrm{~min}$ at $300 \mathrm{x}$. The cell 420 pellet was re-suspended in $0.1 \mathrm{mg} / \mathrm{ml}$ DNaseI grade II (Sigma-Aldrich) in PBS $+10 \%$ FCS 421 and incubated at room temperature for 15-20 min. Then the cells were centrifuged for $4 \mathrm{~min}$ at 
300x $\mathrm{g}$ and re-suspended in stage 4 medium supplemented with $5 \mu \mathrm{M}$ Y-27632. 1.5-2.5 x $10^{6}$ cells/ml were seeded on a 6-well suspension culture plate (Greiner bio-one, Kremsmünster, Austria) and cultivated at $100 \mathrm{rpm}$ and $25 \mathrm{~mm}$ hub on an orbital shaker (Infors HT, Celltron, Bottmingen, Switzerland) according to the 7-stage protocol. The medium was changed daily until day 12 of differentiation and thereafter every second day.

\section{Western Blot}

428 Cells at d0, d4, d8, d15, d18 and d29 were taken up in PBS and sonified. A protease inhibitor mixture (Roche Diagnostic, Mannheim, Germany) was then added. The protein content was determined by BCA assay (Thermo Fisher Scientific). $40 \mu \mathrm{g}$ of total protein was loaded and separated by SDS-PAGE and transferred by electro-blotting to a PVDF membrane. Blocking was performed with $5 \%$ nonfat dry milk in PBS plus $0.1 \%$ Tween 20 . The membrane was incubated with anti-CPA1 (1:1000, Origene, cat\# TA500053, clone OTI2A3) overnight at $4{ }^{\circ} \mathrm{C}$ then washed and followed by incubation with the peroxidase-labeled secondary antibody for $1 \mathrm{~h}$. As a loading control actin was used. Protein bands were visualized by chemiluminescence using the detection kit (GE Healthcare Europe, Solingen, Germany) on a 437 chemiluminescence imager (INTAS Science imaging, Göttingen, Germany).

\section{Gene expression analysis}

439 Isolation of total RNA was carried out using the Machery\&Nagel Nucleospin RNA plus Kit

440 (Macherey\&Nagel, Düren, Germany). cDNA was synthesized from 500-2000 ng total RNA using RevertAid ${ }^{\mathrm{TM}}$ H Minus M-MuLV Reverse Transcriptase (Thermo Fisher Scientific) and

442 random hexamer primers. cDNA samples were then diluted to $2.5-5 \mathrm{ng} / \mu \mathrm{l}$ and measured in a 443 qPCR reaction with the GoTaq ${ }^{\circledR}$ qPCR Master Mix (Promega, Walldorf, Germany). All 444 reactions were performed by a 2-step PCR in triplicates followed by melting curve analysis on 445 a ViiA7 real-time PCR cycler (Thermo Fisher Scientific). Primers are specified in 446 Supplementary table 2. Data normalization was performed with qBasePlus (Biogazelle, 447 Zwijnaarde, Belgium) against the geometric mean of the housekeeping genes $G 6 P D, T B P$ and 
TUBA1A. RT-qPCR data are presented as calibrated normalized relative quantities (CNRQ).

449 Analysis of housekeeping gene stability was performed with the geNorm algorithm.

\section{$450 \quad$ Flow cytometry}

451 Cells were washed with PBS and dissociated using T/E. Organoids from 3D culture were 452 collected in a $15 \mathrm{ml}$ conical tube, centrifuged at $50 \mathrm{x} \mathrm{g}$ for $5 \mathrm{~min}$ and subsequently dissociated 453 by incubation with gentle cell dissociation solution (StemCell Technologies) for 15 min and 454 additional $\mathrm{T} / \mathrm{E}$ for $10 \mathrm{~min}$. Single cells were then centrifuged at $300 \mathrm{xg}$ for $3 \mathrm{~min}$ and re455 suspended in PBS $+2 \%$ FCS before flow cytometric measurement. For flow cytometric 456 staining $1 \times 10^{6}$ cells were washed, incubated for $20 \mathrm{~min}$ at $4^{\circ} \mathrm{C}$ with primary conjugated 457 antibodies and washed twice prior to analysis. Flow cytometric measurements were 458 performed on a CyFlow ML flow cytometer (Partec, Münster, Germany). Data analysis was 459 performed using the FlowJo software (Ashland, OR, USA).

460 The following conjugated antibodies were used: anti CXCR4-PE (FC15004, Neuromics, 461 Minneapolis, USA), anti CXCR4-APC (130-098-357, Miltenyi Biotec), anti-H-2K ${ }^{\mathrm{K}}$-APC 462 (130-117-324, Miltenyi Biotec), Anti-CD177-APC (130-101-512, Miltenyi Biotec), Anti463 CD275-APC (130-098-738, Miltenyi Biotec), anti-CD200-APC (130-118-203, Miltenyi 464 Biotec), anti-CD142-PE-Vio616 (130-115-720, Miltenyi Biotec). Anti-GP2 (D277-3, MBL 465 international, Woburn, MA, USA) was stained at 1:500 and then labelled with 1:500 diluted anti-mouse AF647 (Dianova, Hamburg, Germany).

\section{Cell sorting}

468 Fluorescence activated cell sorting (FACS) was performed at the central facility of the 469 Hannover Medical School. For MACS $1 \times 10^{7}$ dissociated cells were taken up in PBE buffer 470 (PBS, $\mathrm{pH} 7.2,0.5 \% \mathrm{BSA}$, and 2 mM EDTA) and were then conjugated with anti $\mathrm{H} 2-\mathrm{K}^{\mathrm{K}}$ 471 magnetic microbeads (Miltenyi-Biotec) for $15 \mathrm{~min}$ on ice. Cell sorting was then performed on 472 an autoMACS Pro (Miltenyi-Biotec). 


\section{Immunofluorescence}

475 For immunofluorescence staining, hPSCs were seeded onto Matrigel-coated glass cover slides 476 (SPL Life Sciences, Pocheon, South Korea) with $5 \mu$ M Y-27632. After 24 h the cells were 477 fixated with $4 \%$ (w/v) paraformaldehyde (PFA), buffered in PBS, pH 7.4. The same fixation 478 was used for organoids at day 15 and day 29 after differentiation which were embedded in 479 paraffin and sectioned. After pretreatment and blocking steps the same primary antibodies 480 were used for cells and organoids and incubated for 1-3 h at room temperature or overnight at $4^{\circ} \mathrm{C}$ (Supplementary Table 3). The cells as well as organoids were stained with conjugated either with AlexaFluor or Cy fluorophores secondary antibodies (Dianova) and counterstained with mounting medium containing DAPI. For comparison immunostaining of human islets

484 from four non-diabetic donors were performed (for details see new (Supplementary Table 4).

485 Stained cells or stained organoids were examined using an inverse Olympus IX81 microscope (Olympus, Hamburg, Germany) or an upright Olympus microscope BX61 and representative

487 pictures were taken of each analyzed sample as previously described [49].

\section{Insulin and C-peptide content and secretion}

489 Cells grown in 2D or 3D culture were washed with bicarbonate-buffered Krebs-Ringer (KR) 490 solution and hungered for $2 \mathrm{~h}$ in $\mathrm{KR}$ without glucose, supplemented with $0.1 \%$ albumin. 491 Thereafter the cells were stimulated either with 2 or $20 \mathrm{mM}$ glucose or $2 \mathrm{mM}$ glucose and $30 \mathrm{mM} \mathrm{KCl}$ for $1 \mathrm{~h}$. To measure insulin and C-peptide secretion, the medium was removed and centrifuged for $5 \mathrm{~min}$ at $700 \mathrm{xg}$. For this measurement, the cells were taken up in PBS,

494 sonicated and centrifuged for $5 \mathrm{~min}$ at $700 \mathrm{xg}$. The resulting supernatant was used to 495 determine hormone secretion. Secreted insulin in the supernatant and insulin content of the incubated cells were determined by radioimmunoassay using human insulin as standard and

497 the resulting values were normalized to DNA content [44]. Human C-peptide content and C498 peptide secretion was measured by a sandwich ELISA assay (DRG Diagnostics, Marburg, 499 Germany). 


\section{Calcium imaging}

501 Cytosolic free-Ca ${ }^{2+}$ was determined with Fura-2/AM. Day 28 clusters were dissociated, 502 grown on Matrigel-coated glass coverslips overnight and loaded with $3 \mu \mathrm{M}$ Fura-2/AM by 503 incubation in modified Krebs-Ringer (KR) solution (25 mM HEPES, $3 \mathrm{mM}$ glucose, and $5041.5 \% \mathrm{BSA}$ ) for $30 \mathrm{~min}$ at $37^{\circ} \mathrm{C}$. Perifusion was performed with a modified $\mathrm{KR}$ solution 505 containing $0 \mathrm{mM}$ or $20 \mathrm{mM}$ glucose and $0 \mathrm{mM}$ glucose plus $40 \mathrm{mM} \mathrm{KCl}$ at a flow rate of $5061 \mathrm{ml} / \mathrm{min}$ using a peristaltic pump (Ismatec, Zürich, Switzerland). Images were taken every $5072 \mathrm{sec}$ using the inverted IX81 microscope equipped with an UPlanSApo $40 \times 0.95$ numerical 508 aperture objective (Olympus) and an incubation chamber to maintain $60 \%$ humidity, $37^{\circ} \mathrm{C}$, 509 and $5 \% \quad \mathrm{CO}_{2}$, with excitation/emission filter settings of $340 \pm 26 \mathrm{~nm} \mathrm{\&} 387 \pm 11 \mathrm{~nm}$, 510 respectively.

\section{$511 \quad$ Statistics}

512 Unless stated otherwise values represent mean \pm SEM and the number of independent 513 experiments $(\mathrm{n}=$ independent biological replicates $)$ is stated in each figure legend. Statistical 514 analyses were performed using the GraphPad Prism analysis software (Graphpad, San Diego, 515 CA, USA) using unpaired, two-tailed Student's t-test or ANOVA plus Dunnett's or Tukey's 516 post-hoc tests for multiple comparisons. P-values for Student's t-test are depicted in each 517 figure. A summary of all GraphPad Prism statistical test results in particular the ANOVA plus 518 post-hoc tests are available online. 


\section{Acknowledgements}

521 This work has been supported by the Deutsche Forschungsgemeinschaft (DFG, German

522 Research Foundation, NA 1285/2-1). The MHHi001-A cell line was kindly provided by Dr.

523 A. Haase from the LEBAO (Leibniz Research Laboratories for Biotechnology and Artificial

524 Organs), Hannover Medical School. We gratefully acknowledge the technical assistance of

525 Rebecca Chucholl and Monika Funck. We would also like to acknowledge the assistance of

526 the Cell Sorting Core Facility of the Hannover Medical School supported by the Braukmann-

527 Wittenberg-Herz-Stiftung and the DFG.

528 


\section{References}

530 1. Seymour P A (2014) Sox9: a master regulator of the pancreatic program. Rev Diabet $531 \quad$ Stud 11: 51-83

532 2. Piper K, Ball S G, Keeling J W, Mansoor S, Wilson D I, Hanley N A (2002) Novel SOX9 expression during human pancreas development correlates to abnormalities in

3. Furuyama K, Kawaguchi Y, Akiyama H, Horiguchi M, Kodama S, Kuhara T, Hosokawa S, Elbahrawy A, Soeda T, Koizumi M et al (2011) Continuous cell supply from a Sox9-expressing progenitor zone in adult liver, exocrine pancreas and intestine.

4. Kopp J L, Dubois C L, Schaffer A E, Hao E, Shih H P, Seymour P A, Ma J, Sander M (2011) Sox9+ ductal cells are multipotent progenitors throughout development but do not produce new endocrine cells in the normal or injured adult pancreas. Development

5. Jennings R E, Berry A A, Strutt J P, Gerrard D T, Hanley N A (2015) Human pancreas development. Development 142: 3126-3137

6. Zhou Q, Law A C, Rajagopal J, Anderson W J, Gray P A, Melton D A (2007) A

7. Davenport C, Diekmann U, Budde I, Detering N, Naujok O (2016) Anterior-Posterior Depends on the Differential Signaling of Retinoic Acid, Wnt-, and BMP-Signaling.

8. Dettmer R, Cirksena K, Münchhoff J, Kresse J, Diekmann U, Niwolik I, Buettner F F Differentiation of Human Embryonic Stem Cells. Cells 9: 1927

9. Diekmann U, Lenzen S, Naujok O (2015) A reliable and efficient protocol for human pluripotent stem cell differentiation into the definitive endoderm based on dispersed single cells. Stem Cells Dev 24: 190-204

10. Mahaddalkar P U, Scheibner K, Pfluger S, Ansarullah, Sterr M, Beckenbauer J, Irmler 
11. Nostro M C, Sarangi F, Yang C, Holland A, Elefanty A G, Stanley E G, Greiner D L, Keller G (2015) Efficient generation of NKX6-1+ pancreatic progenitors from multiple human pluripotent stem cell lines. Stem Cell Reports 4: 591-604

12. Kelly O G, Chan M Y, Martinson L A, Kadoya K, Ostertag T M, Ross K G, markers for the isolation of pancreatic cell types derived from human embryonic stem cells. Nat Biotechnol 29: 750-756

13. Ameri J, Borup R, Prawiro C, Ramond C, Schachter K A, Scharfmann R, Semb H (2017) Efficient Generation of Glucose-Responsive Beta Cells from Isolated GP2(+) Human Pancreatic Progenitors. Cell Rep 19: 36-49

14. Pagliuca F W, Millman J R, Gurtler M, Segel M, Van Dervort A, Ryu J H, Peterson Q P, Greiner D, Melton D A (2014) Generation of functional human pancreatic beta cells in vitro. Cell 159: 428-439

15. Belo J, Krishnamurthy M, Oakie A, Wang R (2013) The Role of SOX9 Transcription

16. Rezania A, Bruin J E, Arora P, Rubin A, Batushansky I, Asadi A, O'Dwyer S, Quiskamp N, Mojibian M, Albrecht T et al (2014) Reversal of diabetes with insulinproducing cells derived in vitro from human pluripotent stem cells. Nat Biotechnol 32:

17. Sahabian A, Sgodda M, Naujok O, Dettmer R, Dahlmann J, Manstein F, Cantz T, Zweigerdt R, Martin U, Olmer R (2019) Chemically-Defined, Xeno-Free, Scalable Production of hPSC-Derived Definitive Endoderm Aggregates with Multi-Lineage

18. Bouwens L (1998) Cytokeratins and cell differentiation in the pancreas. J Pathol 184: 234-239

19. Bruin J E, Erener S, Vela J, Hu X, Johnson J D, Kurata H T, Lynn F C, Piret J M, Asadi A, Rezania A et al (2014) Characterization of polyhormonal insulin-producing 
pancreatic progenitors into functional islets capable of treating pre-existing diabetes in mice. Diabetes 61: 2016-2029

21. Kormish J D, Sinner D, Zorn A M (2010) Interactions between SOX factors and Wnt/beta-catenin signaling in development and disease. Dev Dyn 239: 56-68

22. Seymour P A, Shih H P, Patel N A, Freude K K, Xie R, Lim C J, Sander M (2012) A Sox9/Fgf feed-forward loop maintains pancreatic organ identity. Development 139: 3363-3372

23. Shih H P, Kopp J L, Sandhu M, Dubois C L, Seymour P A, Grapin-Botton A, Sander M (2012) A Notch-dependent molecular circuitry initiates pancreatic endocrine and ductal cell differentiation. Development 139: 2488-2499

601

24. Mead T J, Wang Q, Bhattaram P, Dy P, Afelik S, Jensen J, Lefebvre V (2013) A far-

25. Akiyama H, Lyons J P, Mori-Akiyama Y, Yang X, Zhang R, Zhang Z, Deng J M, Taketo M M, Nakamura T, Behringer R R et al (2004) Interactions between Sox9 and beta-catenin control chondrocyte differentiation. Genes Dev 18: 1072-1087

26. Topol L, Chen W, Song H, Day T F, Yang Y (2009) Sox9 inhibits Wnt signaling by promoting beta-catenin phosphorylation in the nucleus. J Biol Chem 284: 3323-3333

28. Sharon N, Vanderhooft J, Straubhaar J, Mueller J, Chawla R, Zhou Q, Engquist E N, and Endocrine Compartments during Pancreas Development. Cell Rep 27: 2281-

29. Ameri J, Stahlberg A, Pedersen J, Johansson J K, Johannesson M M, Artner I, Semb H (2010) FGF2 specifies hESC-derived definitive endoderm into foregut/midgut cell 
31. Ackermann M, Kempf H, Hetzel M, Hesse C, Hashtchin A R, Brinkert K, Schott J W, Haake K, Kühnel M P, Glage S et al (2018) Bioreactor-based mass production of human iPSC-derived macrophages enables immunotherapies against bacterial airway infections. Nat Commun 9: 5088

32. Halloin C, Schwanke K, Löbel W, Franke A, Szepes M, Biswanath S, Wunderlich S, Merkert S, Weber N, Osten F et al (2019) Continuous WNT Control Enables Advanced hPSC Cardiac Processing and Prognostic Surface Marker Identification in Chemically Defined Suspension Culture. Stem Cell Reports 13: 775

33. Nair G G, Tzanakakis E S, Hebrok M (2020) Emerging routes to the generation of functional $\beta$-cells for diabetes mellitus cell therapy. Nat Rev Endocrinol 16: 506-518

34. Furuyama K, Chera S, van Gurp L, Oropeza D, Ghila L, Damond N, Vethe H, Paulo J A, Joosten A M, Berney T et al (2019) Diabetes relief in mice by glucose-sensing insulin-secreting human alpha-cells. Nature 567: 43-+

35. Ortmann D, Vallier L (2017) Variability of human pluripotent stem cell lines. Curr Opin Genet Dev 46: 179-185

36. Keller A, Dziedzicka D, Zambelli F, Markouli C, Sermon K, Spits C, Geens M (2018) Genetic and epigenetic factors which modulate differentiation propensity in human pluripotent stem cells. Hum Reprod Update 24: 162-175

37. Micallef S J, Li X, Schiesser J V, Hirst C E, Yu Q C, Lim S M, Nostro M C, Elliott D A, Sarangi F, Harrison L C et al (2012) INS(GFP/w) human embryonic stem cells facilitate isolation of in vitro derived insulin-producing cells. Diabetologia 55: 694706

38. Micallef S J, Janes M E, Knezevic K, Davis R P, Elefanty A G, Stanley E G (2005) Retinoic acid induces Pdx1-positive endoderm in differentiating mouse embryonic stem cells. Diabetes 54: 301-305

39. Gupta S K, Wesolowska-Andersen A, Ringgaard A K, Jaiswal H, Song L, Hastoy B, Ingvorsen C, Taheri-Ghahfarokhi A, Magnusson B, Maresca M et al (2018) NKX6.1 induced pluripotent stem cell reporter lines for isolation and analysis of functionally relevant neuronal and pancreas populations. Stem Cell Res 29: 220-231 
650 40. Blöchinger A K, Siehler J, Wißmiller K, Shahryari A, Burtscher I, Lickert H (2020) Generation of an INSULIN-H2B-Cherry reporter human iPSC line. Stem Cell Res 45: 101797

41. Blache P, van de Wetering M, Duluc I, Domon C, Berta P, Freund J N, Clevers H, Jay $\mathrm{P}$ (2004) SOX9 is an intestine crypt transcription factor, is regulated by the Wnt pathway, and represses the CDX2 and MUC2 genes. J Cell Biol 166: 37-47

42. Kawaguchi Y (2013) Sox9 and programming of liver and pancreatic progenitors. $J$ Clin Invest 123: 1881-1886

43. Haase A, Göhring G, Martin U (2017) Generation of non-transgenic iPS cells from human cord blood CD34(+) cells under animal component-free conditions. Stem Cell

44. Gurgul-Convey E, Kaminski M T, Lenzen S (2015) Physiological characterization of the human EndoC- $\beta$ H1 $\beta$-cell line. Biochem Biophys Res Commun 464: 13-19

45. Stemmer M, Thumberger T, del Sol Keyer M, Wittbrodt J, Mateo J L (2015) CCTop: 664 An Intuitive, Flexible and Reliable CRISPR/Cas9 Target Prediction Tool. PLoS One

46. Heckl D, Kowalczyk M S, Yudovich D, Belizaire R, Puram R V, McConkey M E, Thielke A, Aster J C, Regev A, Ebert B L (2014) Generation of mouse models of

47. Cong L, Ran F A, Cox D, Lin S, Barretto R, Habib N, Hsu P D, Wu X, Jiang W, Marraffini L A et al (2013) Multiplex genome engineering using CRISPR/Cas systems. Science 339: 819-823

48. Dettmer R, Naujok O (2020) Design and Derivation of Multi-Reporter Pluripotent Stem Cell Lines via CRISPR/Cas9n-Mediated Homology-Directed Repair. Curr Protoc Stem Cell Biol 54: e116

49. Jörns A, Wedekind D, Jähne J, Lenzen S (2020) Pancreas Pathology of Latent 

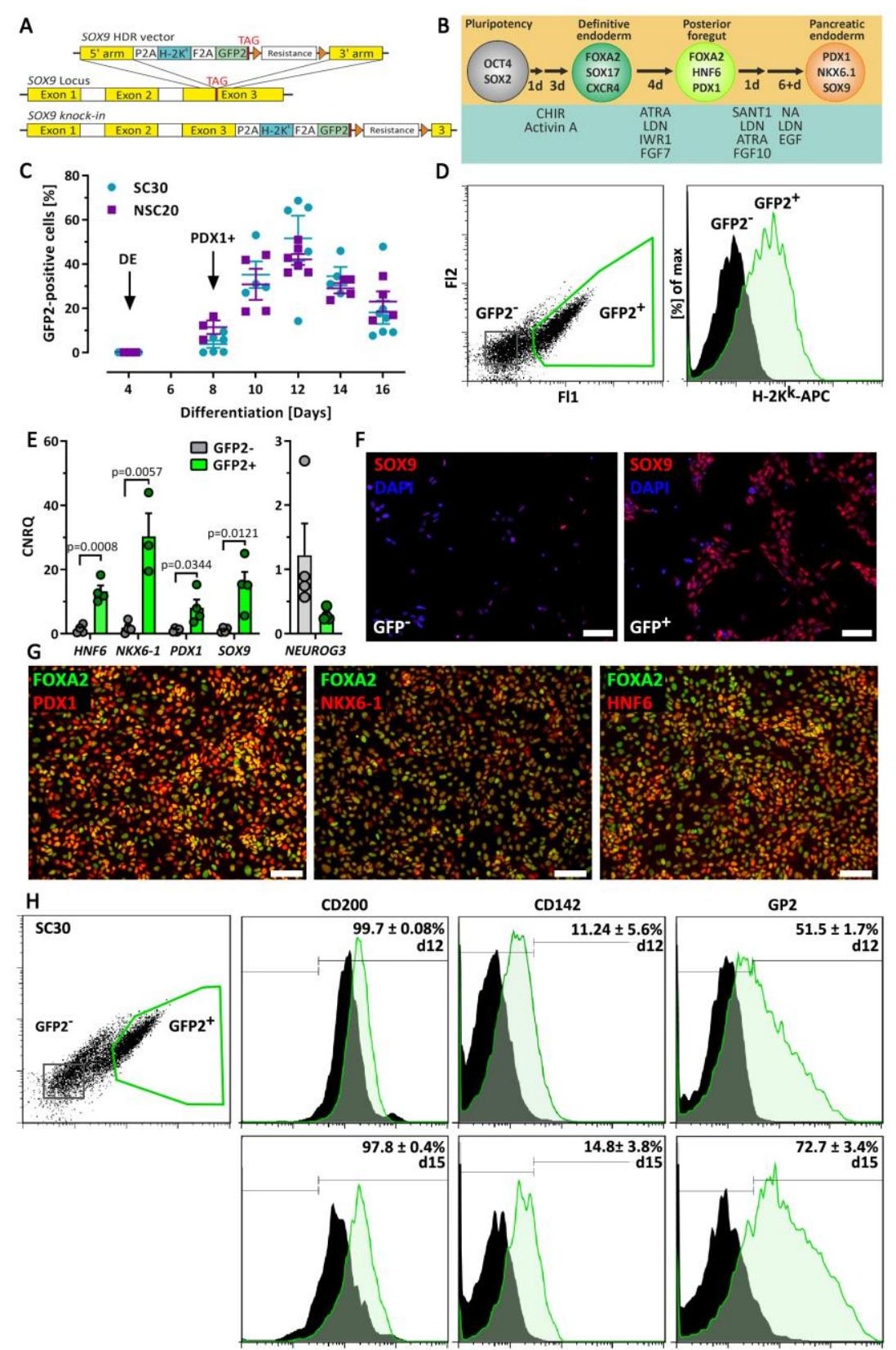

Figure 1. (A) Schematic presentation of the SOX9 HDR vector and the human SOX9 locus before and after homologous recombination. (B) Schematic presentation of the 4-stage experimental 2D differentiation protocol for the generation of SOX9+ progenitors. (C) GFP2 expression during differentiation of the SC30 and NSC20 cells. Data are means \pm SEM, $n=4-$ 8. Arrows mark developmental stages. (D) Flow cytometry dot plot and histogram of SC30 GFP2 expression and gated $\mathrm{H} 2-\mathrm{K}^{\mathrm{k}}$ staining at d12. (E) RT-qPCR analysis of sorted SC30 derived GFP2+ and GFP2- cells (d11-d12). Depicted is the relative gene expression of HNF6, NKX6-1, PDX1, and SOX9. Data are means \pm SEM, n= 3-4. Two-tailed Student's t-test. $(\mathbf{F})$ Immunofluorescence staining of SOX9 (red) in SC30 derived $\mathrm{GFP}^{+}$and $\mathrm{GFP}^{-}$cells (d12). Nuclei were counterstained with DAPI. (G) Immunofluorescence staining of PDX1, HNF-6 and NKX6-1 (red) and FOXA2 (Green) of sorted SC30 derived GFP2 ${ }^{+}$cells (d12). (F/G) Scale bar $=100 \mu \mathrm{m}$. (H) Flow cytometry dot plot and histogram of SC30 GFP2 and CD200, CD142 and GP2 expression at d12 and d15 (end of stage 4). Bifurcated gates were set according to unstained controls, values are means \pm SEM, $n=3-4$. 
A

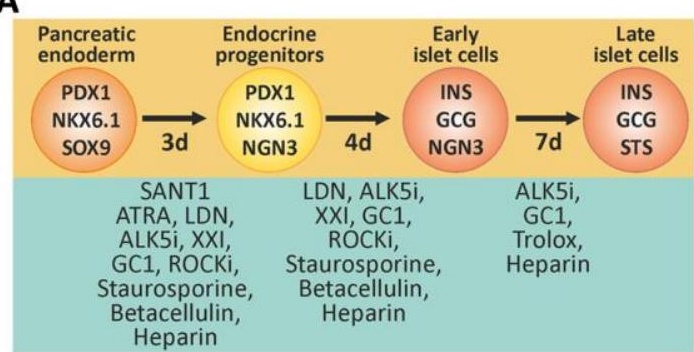

B

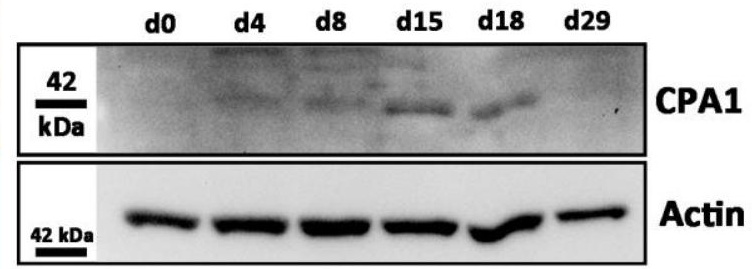

C
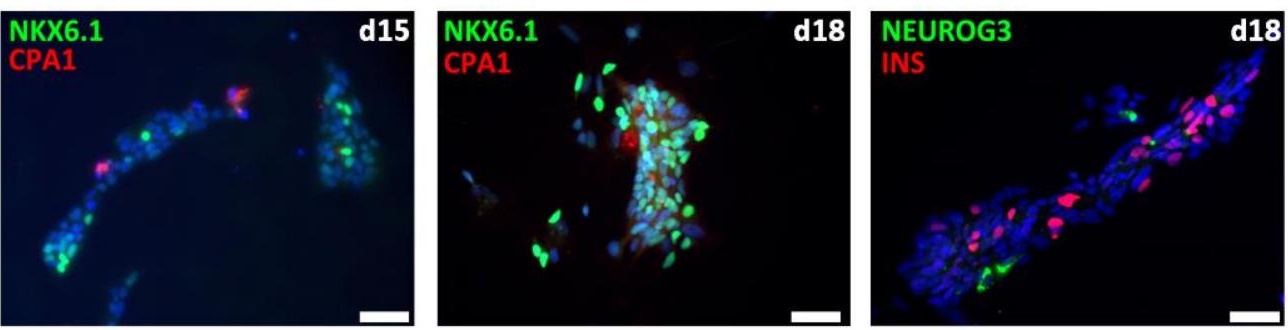

D

d18

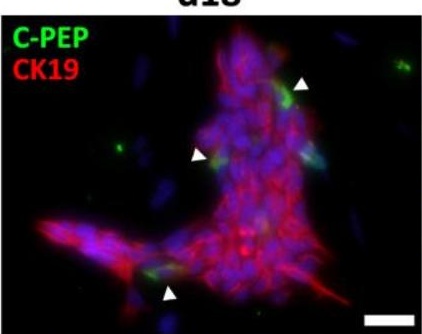

d22

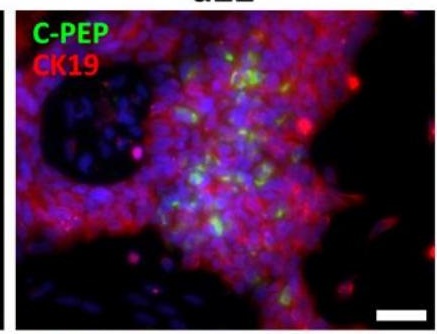

d29
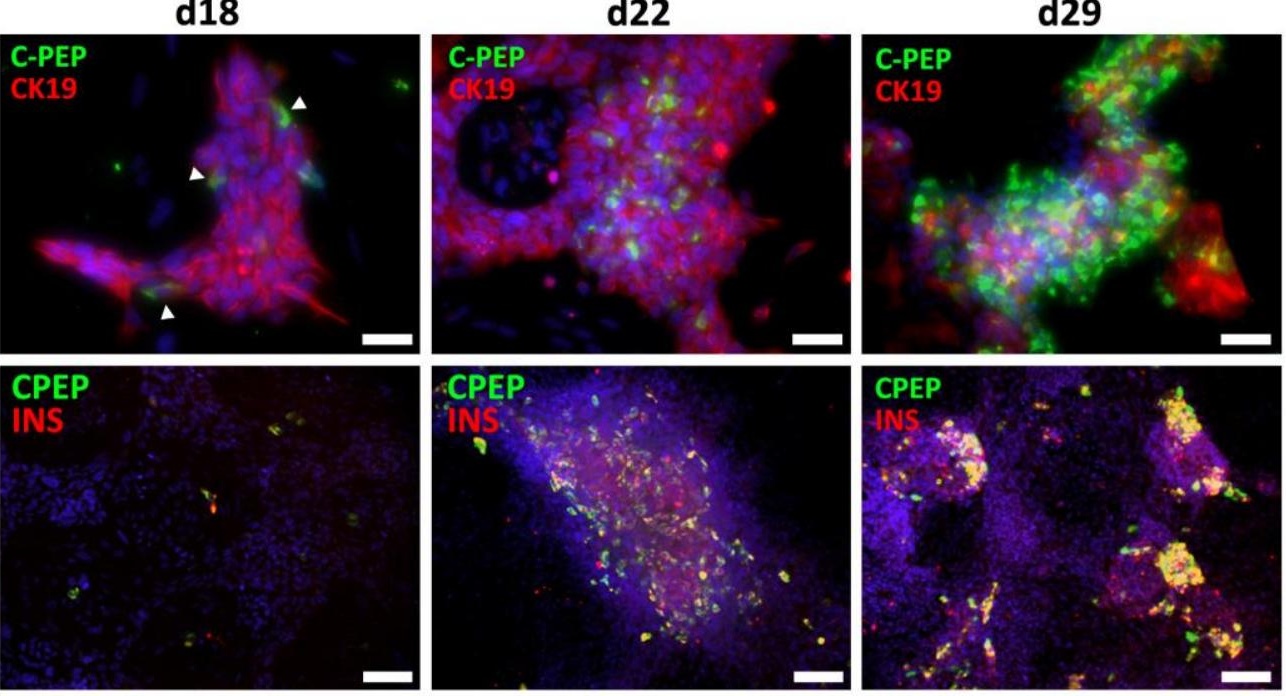

$\mathbf{E}$
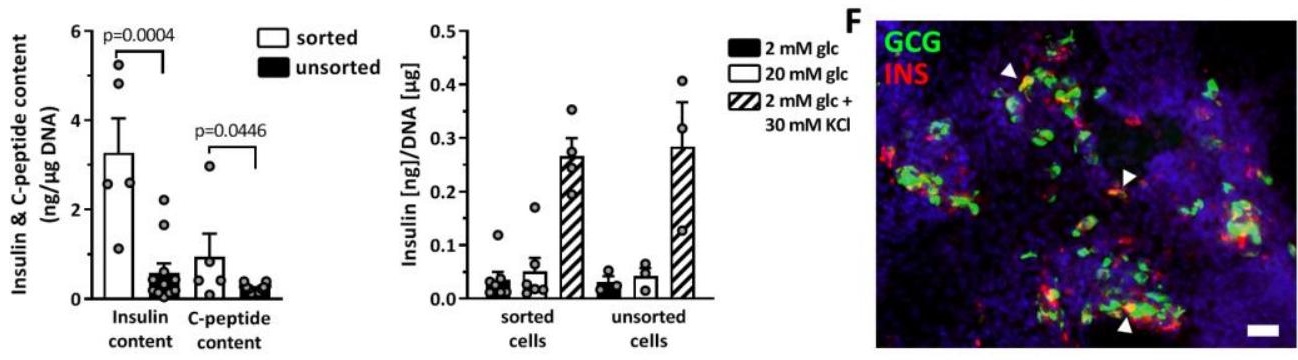

Figure 2. (A) Scheme of the 3-stage protocol for differentiation of SOX9+ MPCs into stem cell-derived beta cells. MACS was performed at d12 using the SC30 cell clone. (B) Analysis of CPA1 protein expression during differentiation (d0-d29) by Western Blot. (C) Immunofluorescence staining of NKX6.1/CPA1 and NEUROG3/insulin after stage 4 (d15) or 5 (d18), respectively. Scale bar $=50 \mu \mathrm{m}$. (D) Immunofluorescence staining of CK19/Cpeptide and C-peptide at d18, d22 or d29 of differentiation. Scale bar $=50 \mu \mathrm{m}$ (CK19/Cpeptide) or $100 \mu \mathrm{m}$. Arrowheads indicate early insulin-positive cells. (E) Measurement of insulin and C-peptide secretion and content in d29 sorted SC30 cells vs unsorted cells. Data are means \pm SEM, $n=5-12$ (content) and $n=3-7$ (secretion). Two-tailed Student's t-test, $* * * \mathrm{p}<0.001, * \mathrm{p}<0.05$. (F) Immunofluorescence staining of glucagon and insulin in $\mathrm{d} 29$ cells. Arrowheads mark polyhormonal cells. Scale bar $=50 \mu \mathrm{m}$. 
A

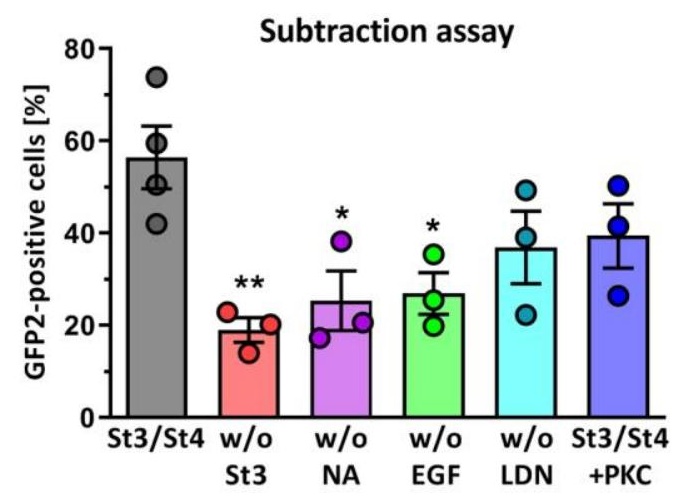

B

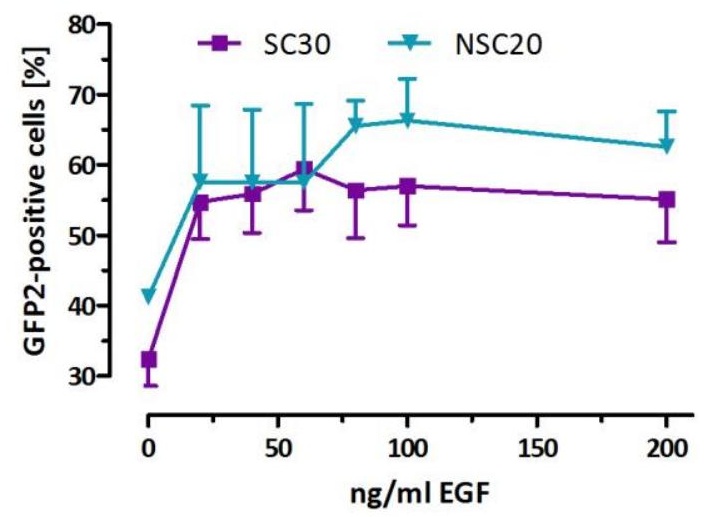

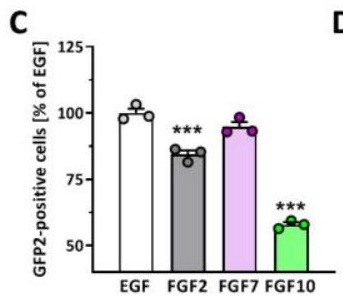

${ }^{2.0} 1 \quad P D X 1$
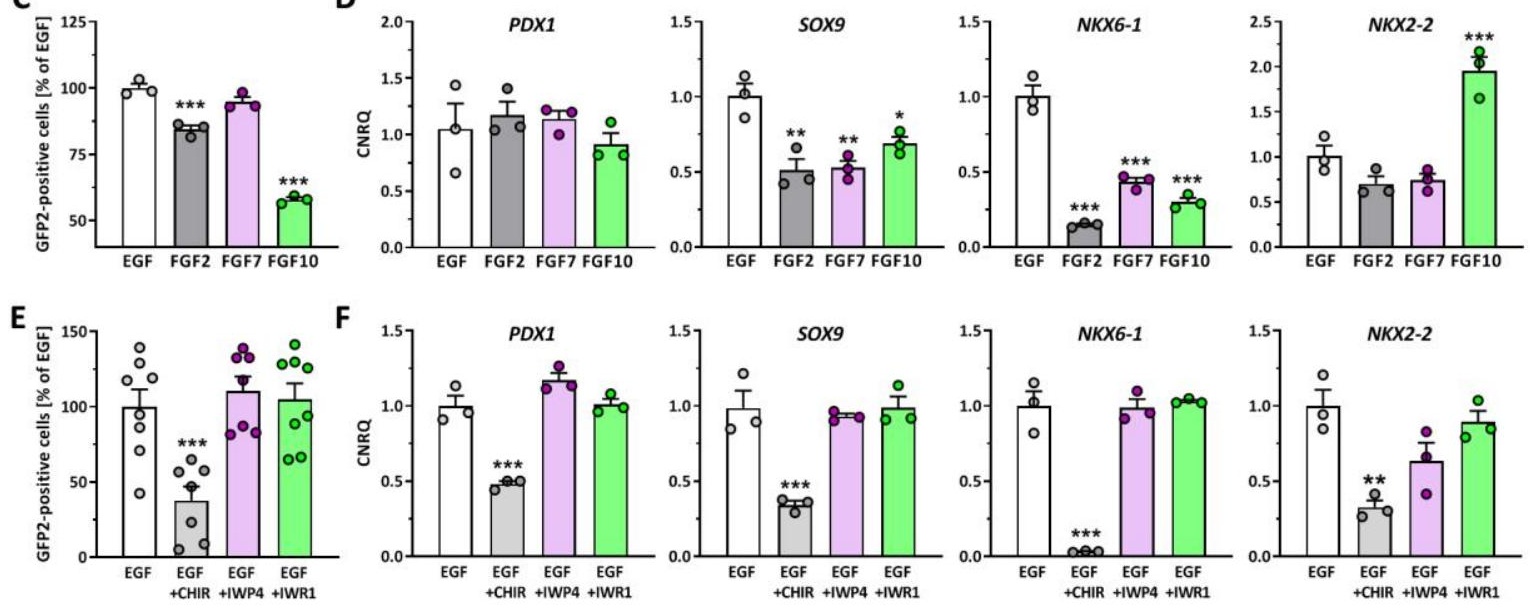

Figure 3. (A) Measurement of GFP2+ cells at d12 after subtraction of either stage 3, nicotinamide (NA), EGF, or LDN193189 (LDN). For comparison stage 4 plus protein kinase $\mathrm{C}$ activation by $100 \mathrm{nM}$ PDBu. Data are means \pm SEM, $\mathrm{n}=3$. (B) GFP2-expression in dependence of the EGF concentration at d12. Data are means \pm SEM, $n=3$. (C/D) Effect of different growth factors each used at $100 \mathrm{ng} / \mathrm{ml}$ on GFP2 expression (C) at d12 and pancreatic marker gene expression (D). Depicted is the relative gene expression of PDX1, SOX9, NKX61 , and NKX2-2. Data are means \pm SEM. $\mathrm{n}=7-8$ (GFP2 flow cytometry), $\mathrm{n}=3$ (RT-qPCR). (E/F) Effect of canonical Wnt-signaling on GFP2 expression (E) at d12 and pancreatic marker gene expression $(\mathbf{F})$. The pathway was activated by CHIR $(3 \mu \mathrm{M})$ or inhibited by IWP4 $(1 \mu \mathrm{M})$ or IWR-1 $(2 \mu \mathrm{M})$. Depicted is the relative gene expression of PDX1, SOX9, NKX6-1, and NKX2-2. Data are means \pm SEM. $\mathrm{n}=3$ (GFP2, RT-qPCR). ANOVA plus Dunnett's post-test, $* * * \mathrm{p}<0.001, * * \mathrm{p}<0.01, * \mathrm{p}<0.05$. 
A

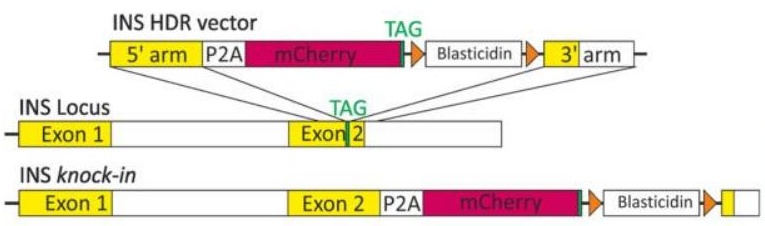

$\mathrm{C}$

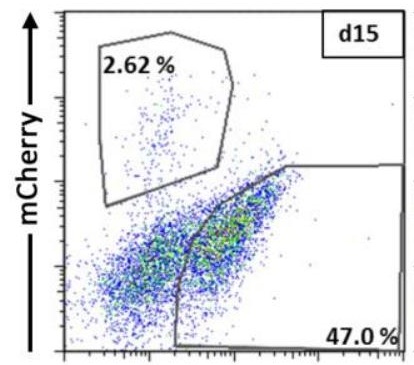

$47.0 \%$

D
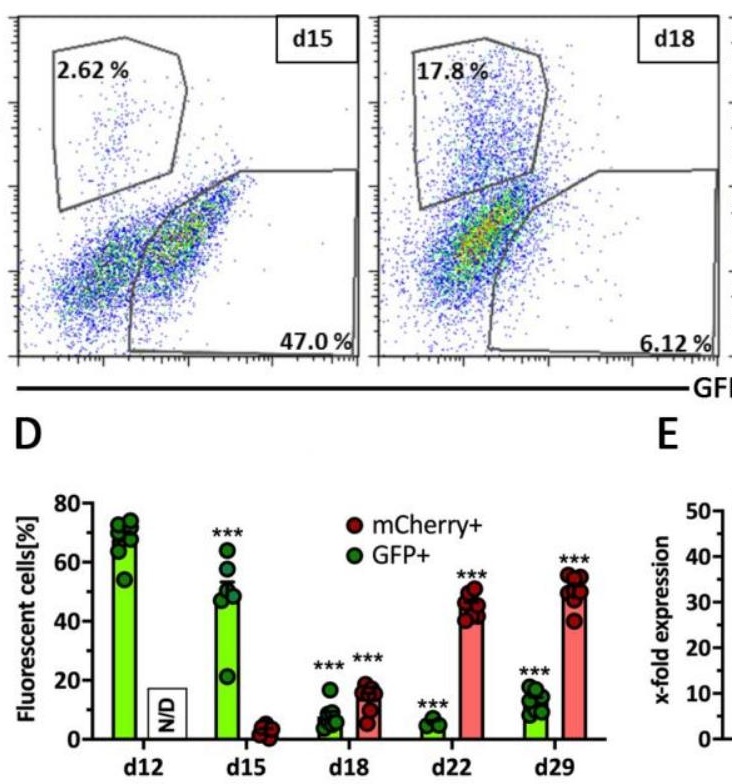

B

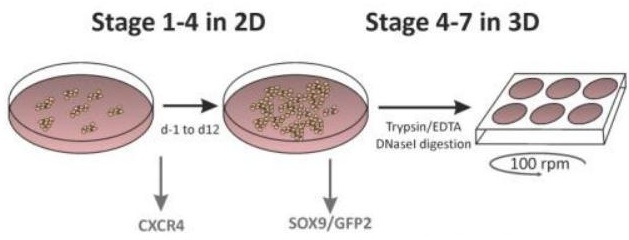

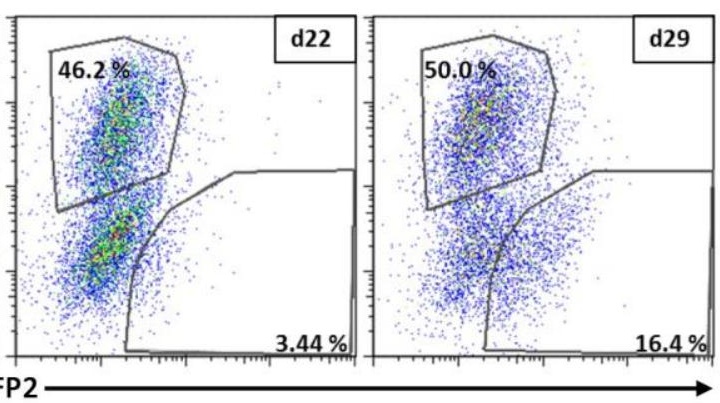

$\mathrm{E}$

Figure 4. (A) Schematic presentation of the INS HDR vector and the human INS locus before and after homologous recombination. (B) Schematic presentation of the 3D production protocol for the differentiation of SC30/NSC20 and SC30 ICNC4 cell clones into stem cellderived islets and phase contrast images of clusters generated by $3 \mathrm{D}$ orbital shaking culture. Monitoring of differentiation with CXCR4 and GFP2 measurement on $\mathrm{d} 4$ and d12. (C) Representative flow cytometry dot plots of mCherry vs GFP2 protein expression during 3D differentiation. The numbers in the gates indicate the percentage of SOX9- or INS-expressing cells at different stages of differentiation. (D) Kinetics of GFP2 and mCherry protein expression in SC30 ICNC4 cells during 3D differentiation. Values are means \pm SEM. $n=3-7$. ANOVA plus Tukey's post-test, $* * * \mathrm{p}<0.001, * * \mathrm{p}<0.01, * \mathrm{p}<0.05$, compared to d12/d15 of differentiation. (E) RT-qPCR analysis of the beta cell marker genes INS, NKX6-1, glucokinase $(G C K)$, GLUT2 and KIR6.2 in sorted mCherry+ vs mCherry- cells at d29 of differentiation generated with the SC30 ICNC4 cell clone. Values are means \pm SEM. $n=5$, 
A
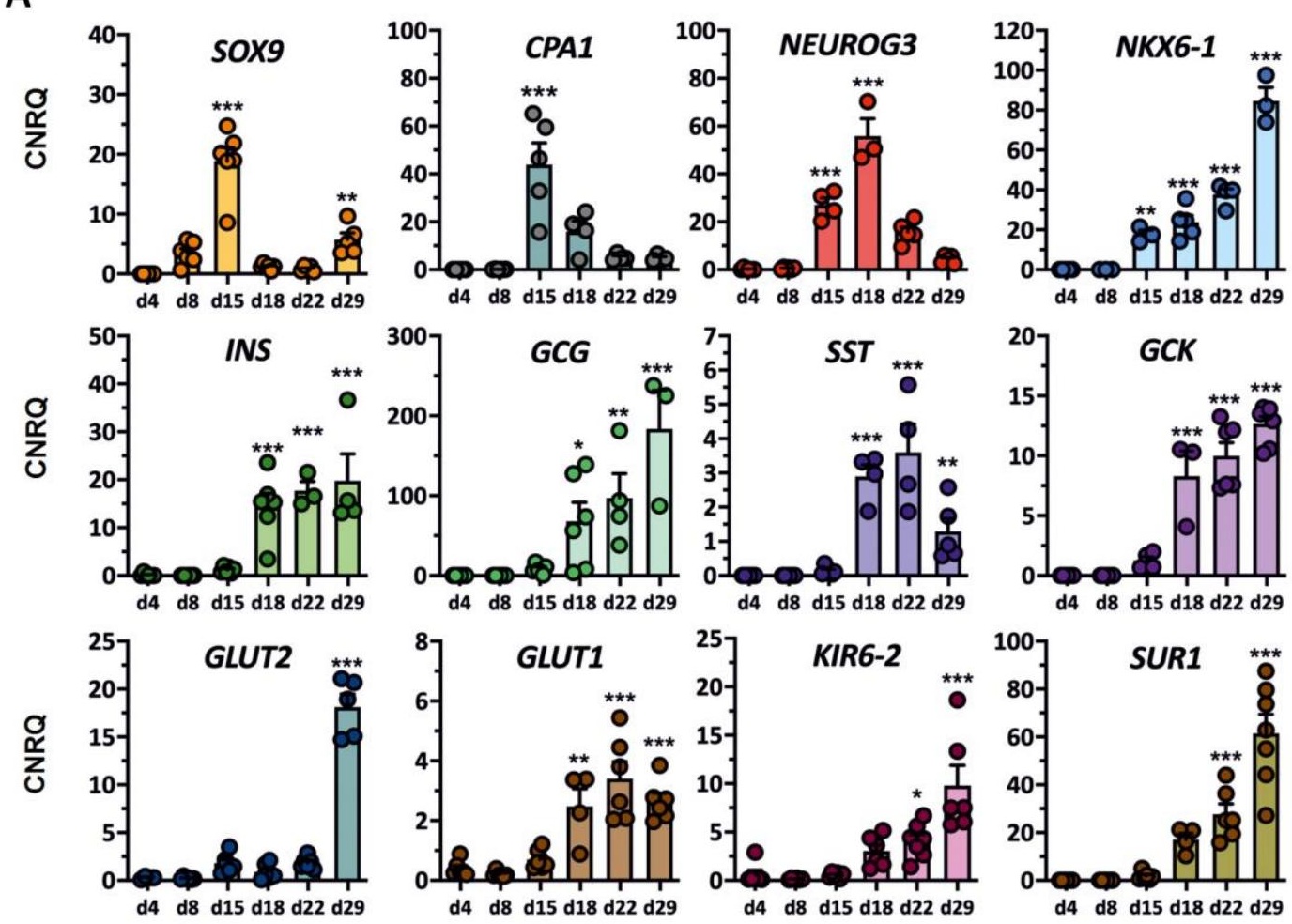

B
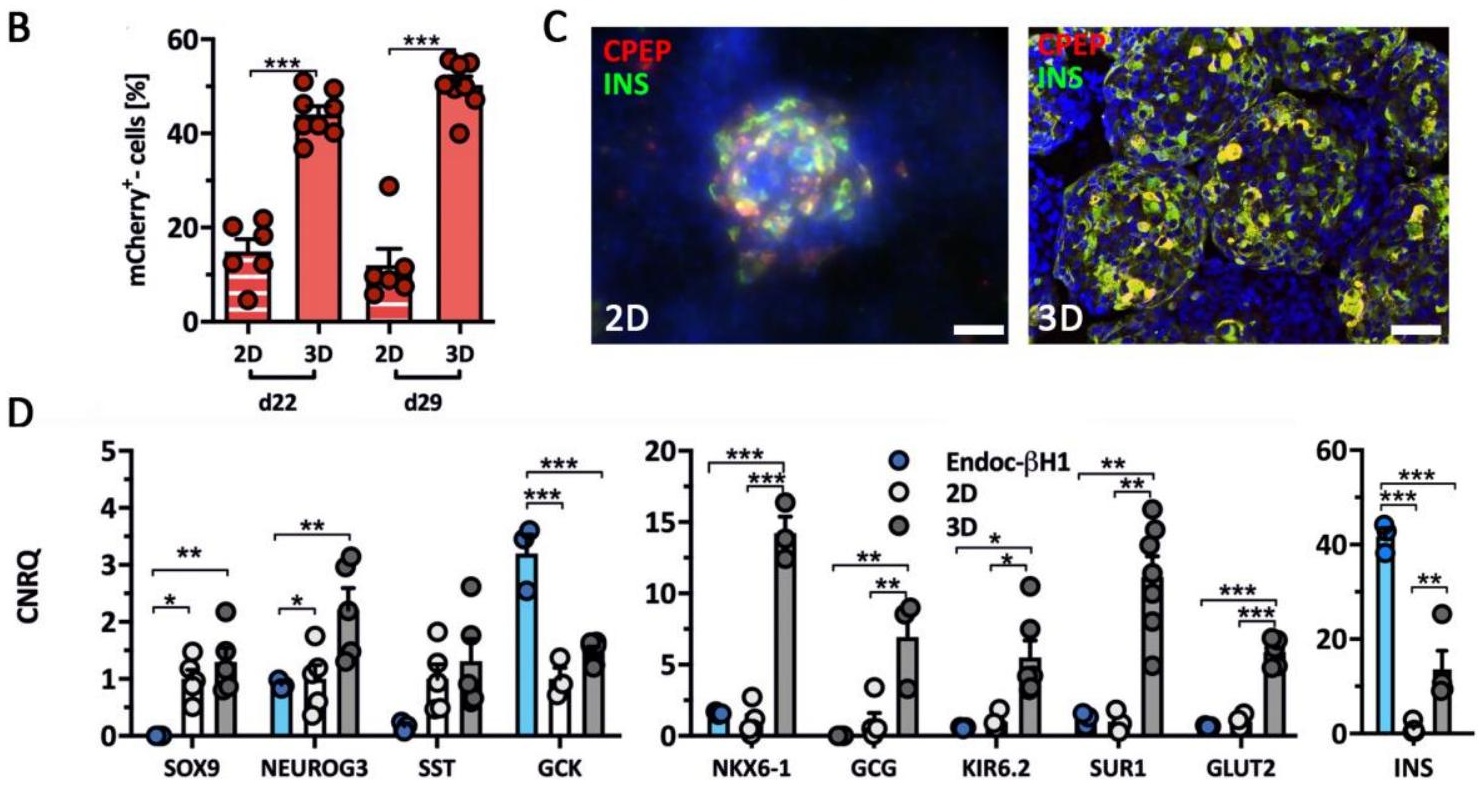

Figure 5. (A) Expression kinetics of pancreatic and endocrine genes during differentiation from d4 to d29 measured by RT-qPCR in SC30 ICNC4 cells. Values are means \pm SEM. $n=3-$ 6. ANOVA plus Tukey's post-test, *** $\mathrm{p}<0.001$, ** $\mathrm{p}<0.01, * \mathrm{p}<0.05$, compared to $\mathrm{d} 4$ of differentiation. (B) Effect of 2D vs 3D differentiation on mCherry expression at d22 and d29 in SC30 ICNC4 cells. Values are means \pm SEM. $n=4-6$. ANOVA plus Tukey's post-test, $* * * \mathrm{p}<0.001, * * \mathrm{p}<0.01, * \mathrm{p}<0.05$. (C) Double-immunofluorescence staining of insulin (green) and C-peptide (red) in SC30-derived cells at d29 in 2D- or 3D-derived cells. Scale bar $=50 \mu \mathrm{m}$. (D) Effect of $2 \mathrm{D}$ vs $3 \mathrm{D}$ differentiation on pancreatic and endocrine marker gene expression measured by RT-qPCR comparing SC30 ICNC4 to EndoC- $\beta$ H1 cells. Values are means \pm SEM. $\mathrm{n}=3-6$. ANOVA plus Tukey's post-test, $* * * \mathrm{p}<0.001, * * \mathrm{p}<0.01, * \mathrm{p}<0.05$. Relative expression values for 2D differentiation were set to 1 . 
bioRxiv preprint doi: https://doi.org/10.1101/2021.02.02.429390; this version posted February 3, 2021. The copyright holder for this preprint (which was not certified by peer review) is the author/funder, who has granted bioRxiv a license to display the preprint in perpetuity. It is made available under aCC-BY 4.0 International license.

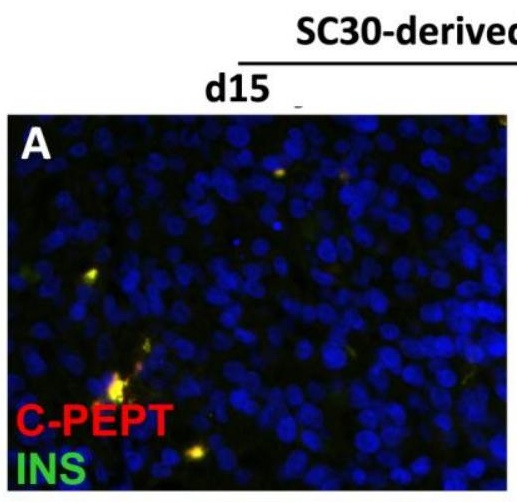

\section{d29}
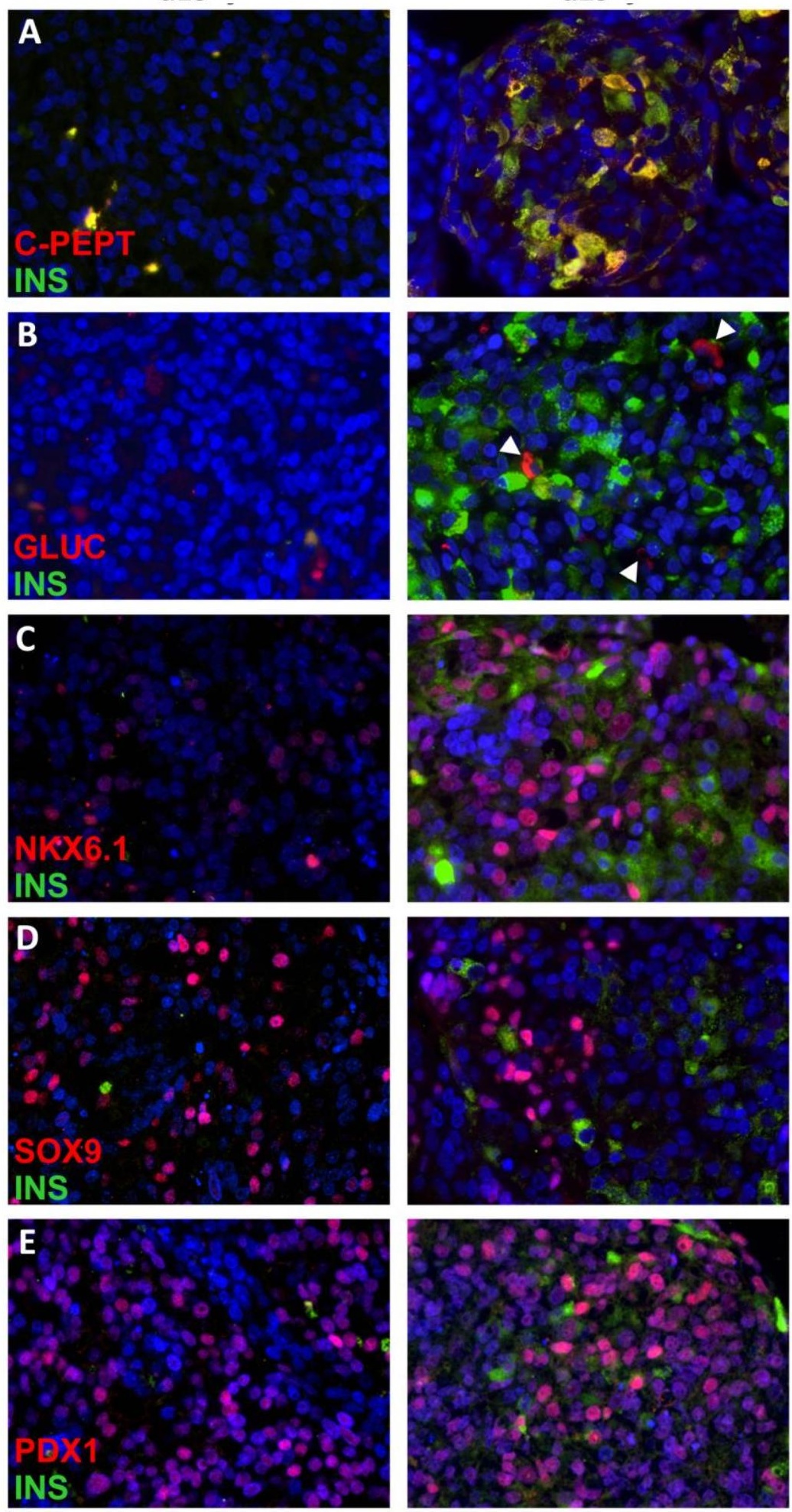
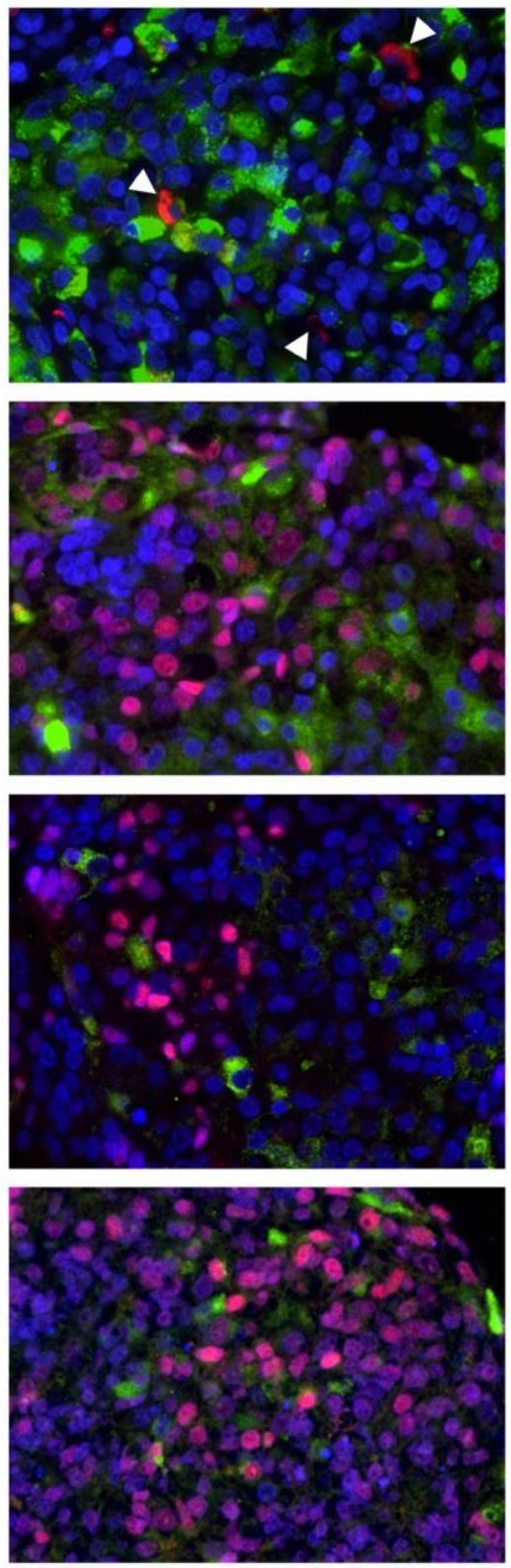

Human non-diabetic pancreas
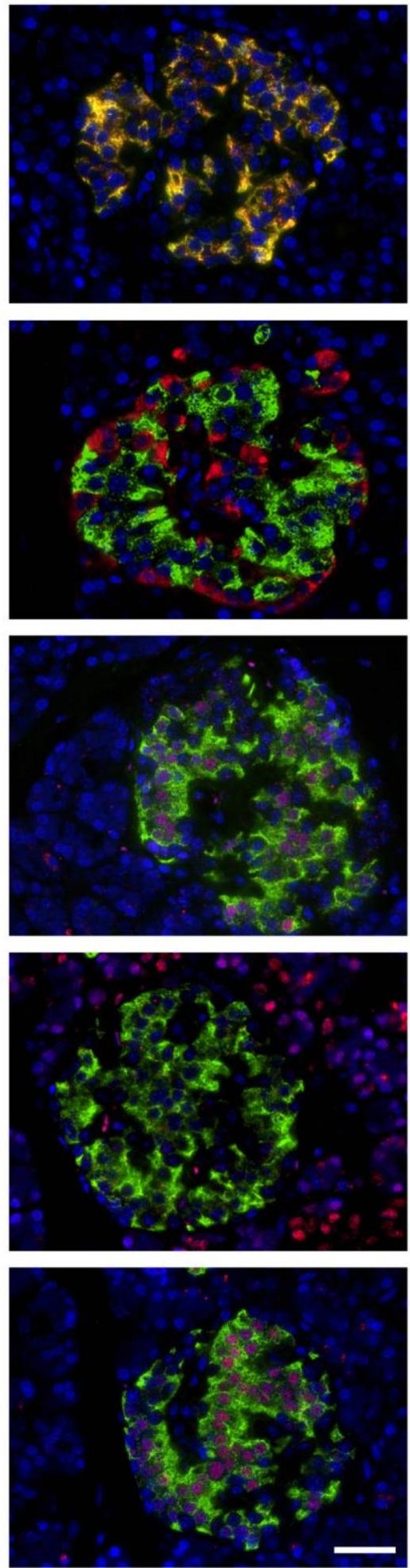

Figure 6. Immunhistochemical analysis of SC-derived pancreatic organoids. d15 spheroids and $\mathrm{d} 29$ stem cell-derived organoids derived in 3D from the SC30 clone were fixed, sectioned and double-stained for (A) C-peptide (red) and insulin (green) or insulin (green) and glucagon, NKX6.1, SOX9 or PDX1 (B-E, all in red). A human non-diabetic pancreas was 
A

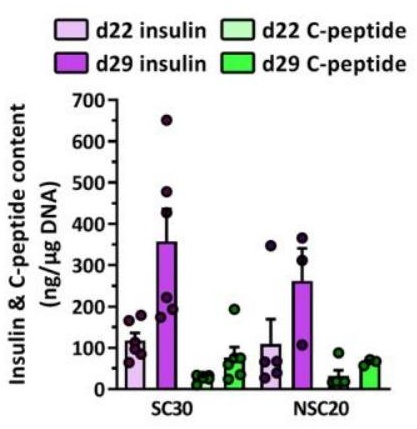

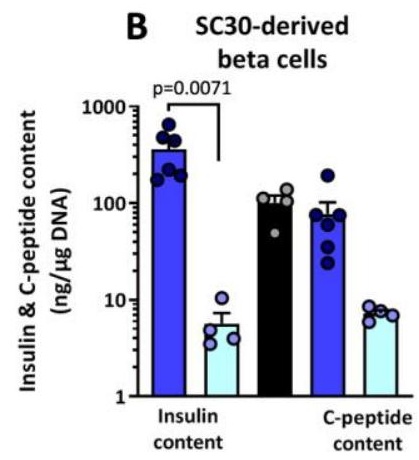

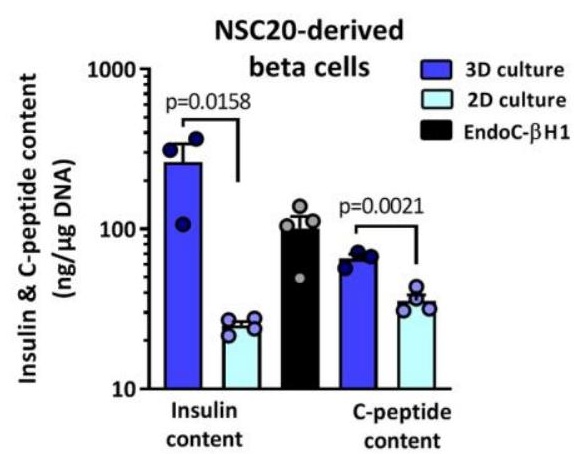

C
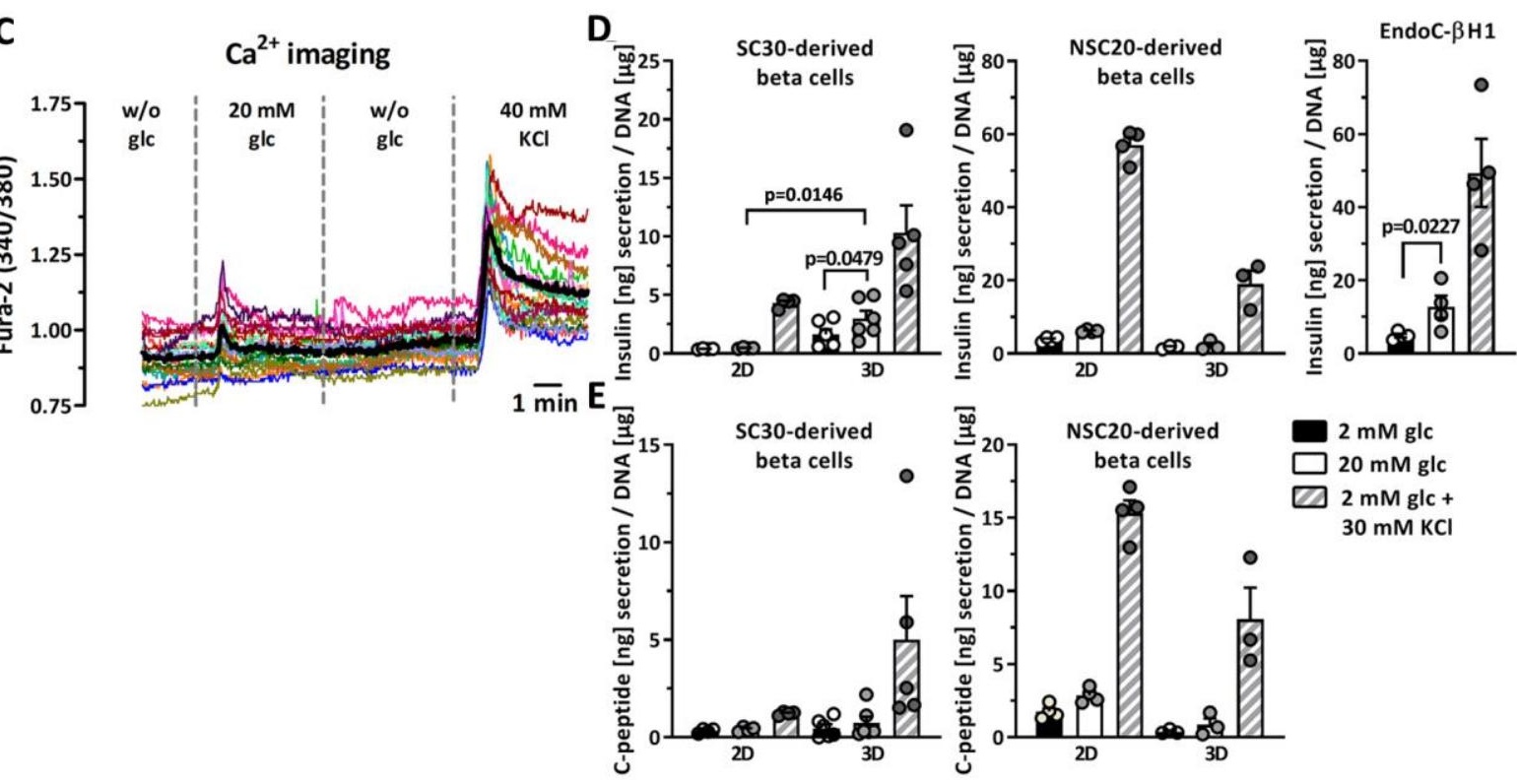

Figure 7. Insulin and C-peptide content

(A) Insulin and C-peptide content of NSC20- and SC30-derived organoids at d22 and d29 of differentiation in 3D. Values are means \pm SEM, $n=3-6$. (B) Insulin and C-peptide content of NSC20- and SC30-derived organoids at d29 differentiated in 2D or 3D in comparison to EndoC- $\beta \mathrm{H} 1$ cells. (C) Real time detection of cytosolic free- $\mathrm{Ca}^{2+}$ in SC30-derived organoids by recording of the Fura-2/AM emission ratio at 340 and $380 \mathrm{~nm}$. The cells were perifused with basal KR w/o glucose, $20 \mathrm{mM}$ glucose in KR, basal KR w/o glucose and finally KR plus $40 \mathrm{mM} \mathrm{KCl}$. Mean value of 19 recorded cells are shown in bold black. (D/E) Measurement of insulin and C-peptide secretion in NSC20- and SC30-derived organoids at d29 after 2D and $3 \mathrm{D}$ differentiation in comparison to EndoC- $\beta \mathrm{H} 1$ cells. Data are means $\pm \mathrm{SEM}, \mathrm{n}=3-6$. Twotailed Student's t-test, ** $\mathrm{p}<0.01, * \mathrm{p}<0.05$. 


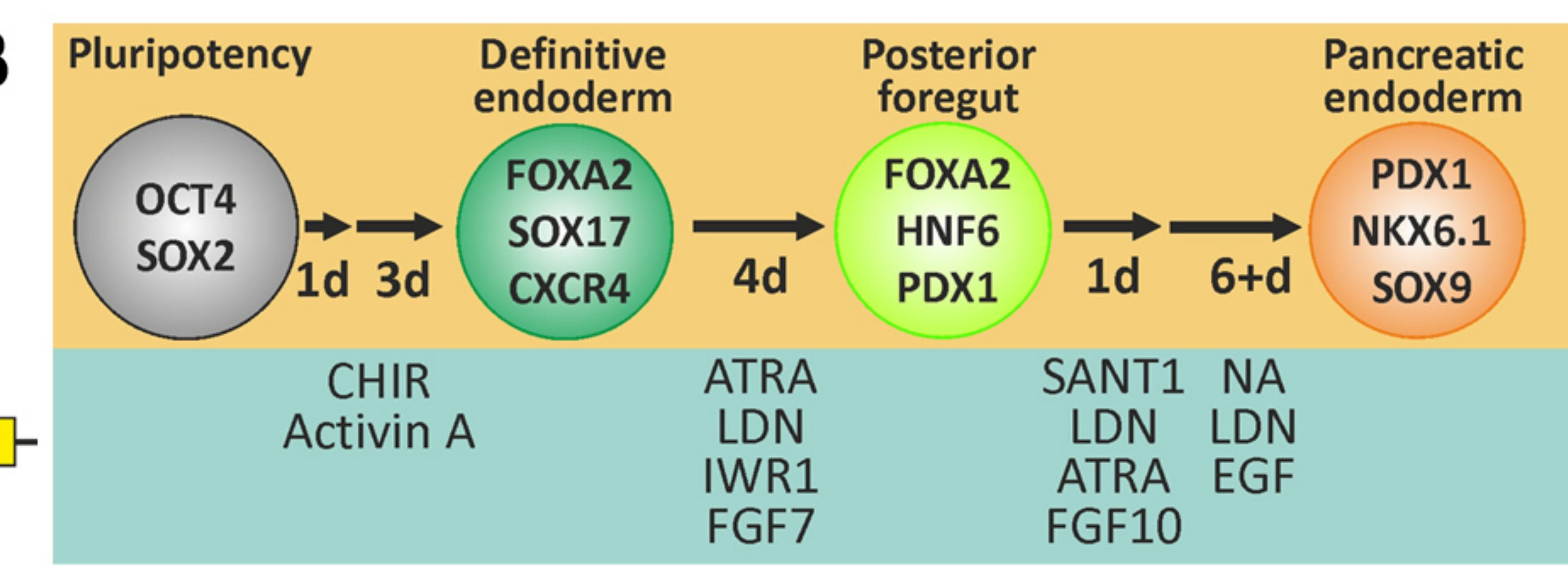

C

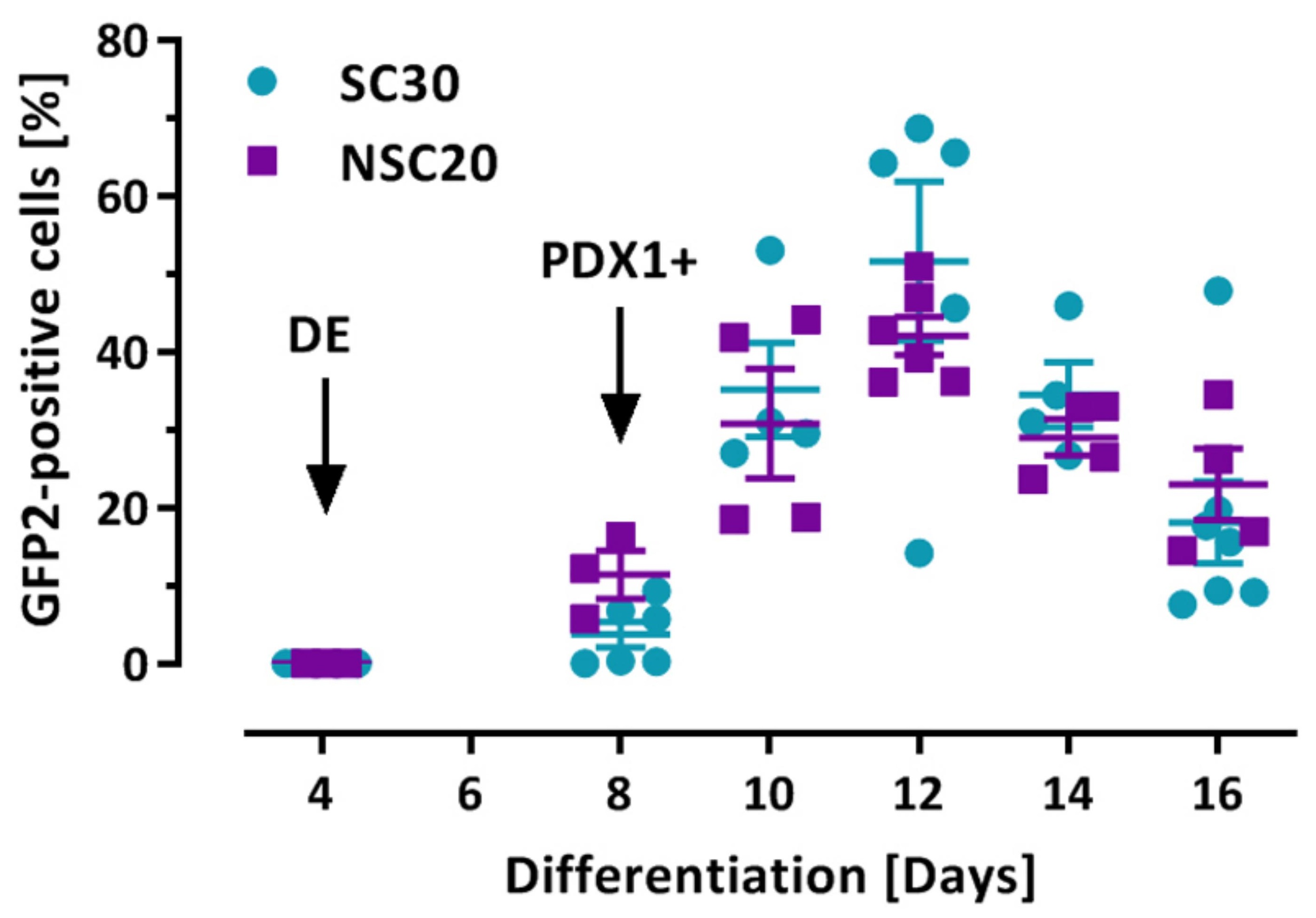

D

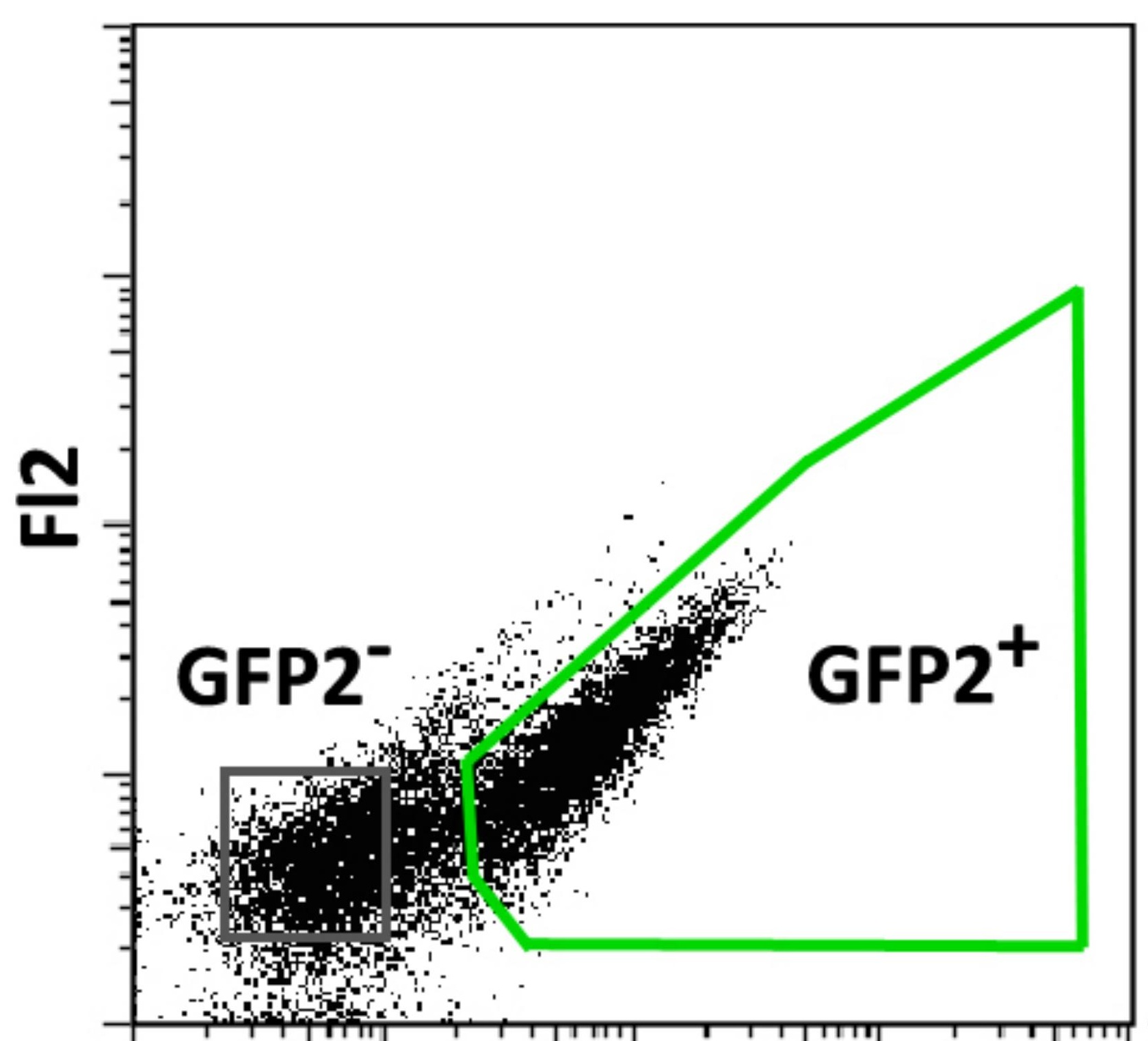

Fl1

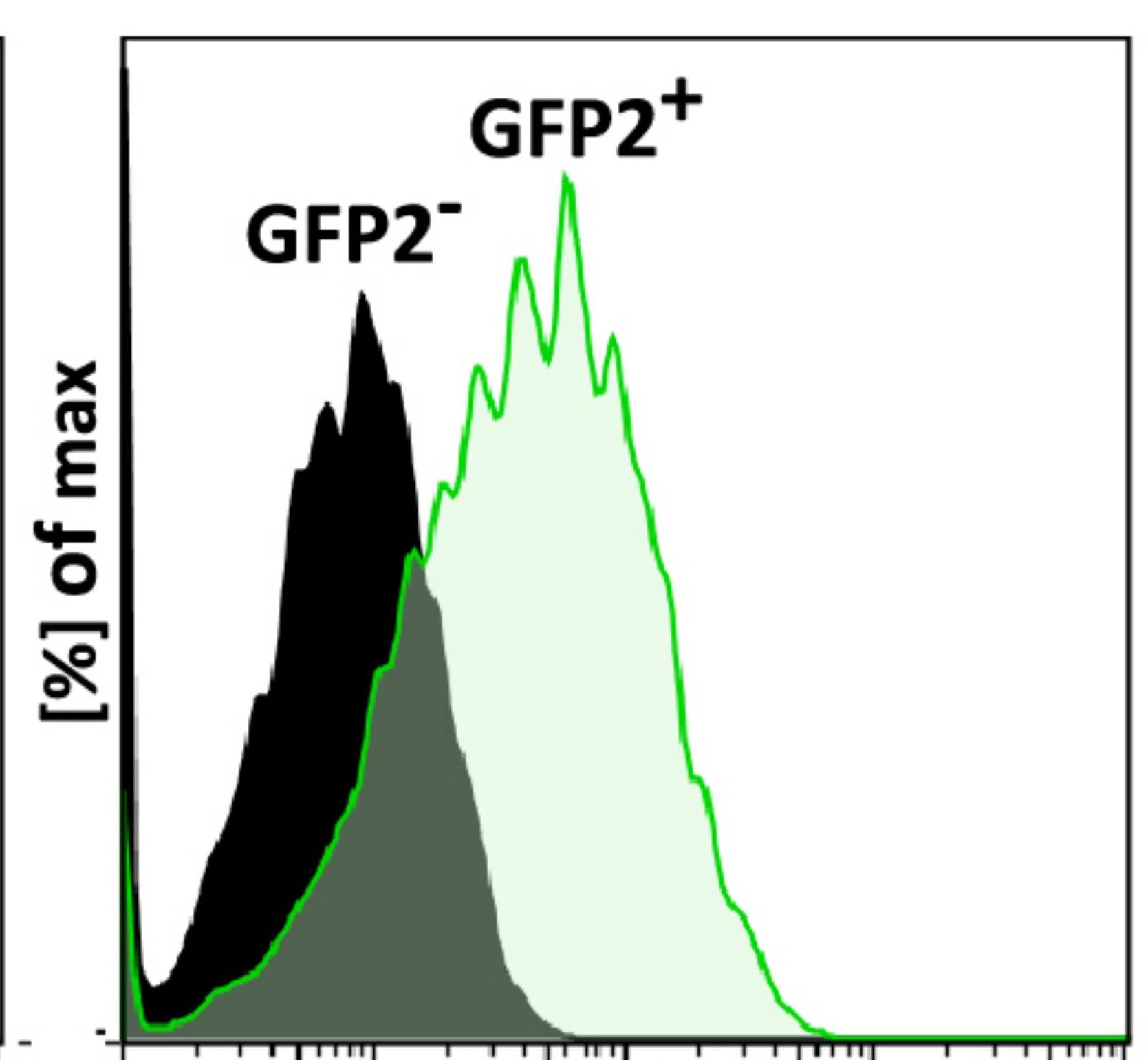

H-2Kk-APC

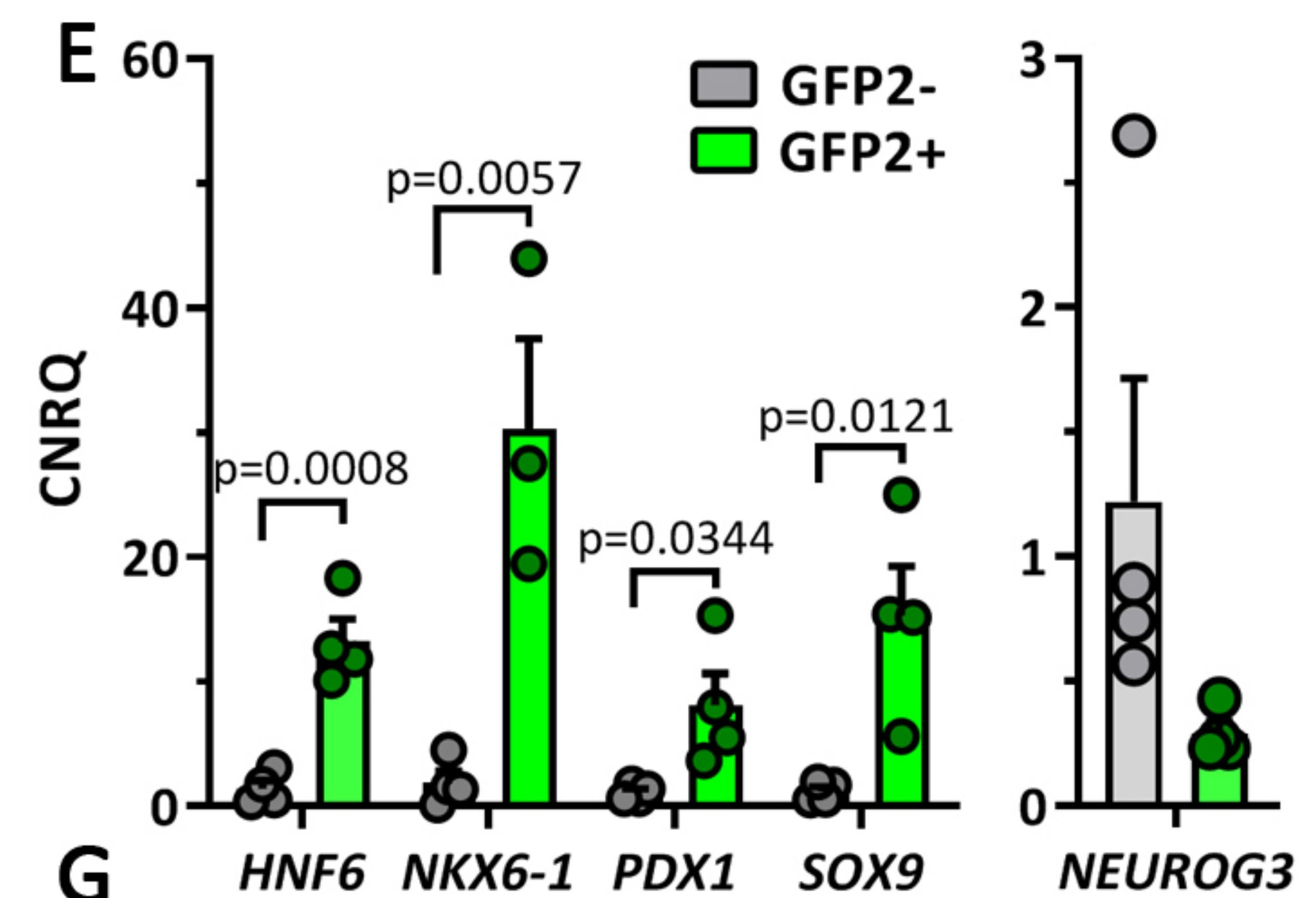

Foxo

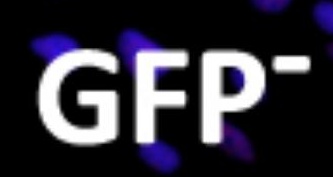

GFP ${ }^{+}$

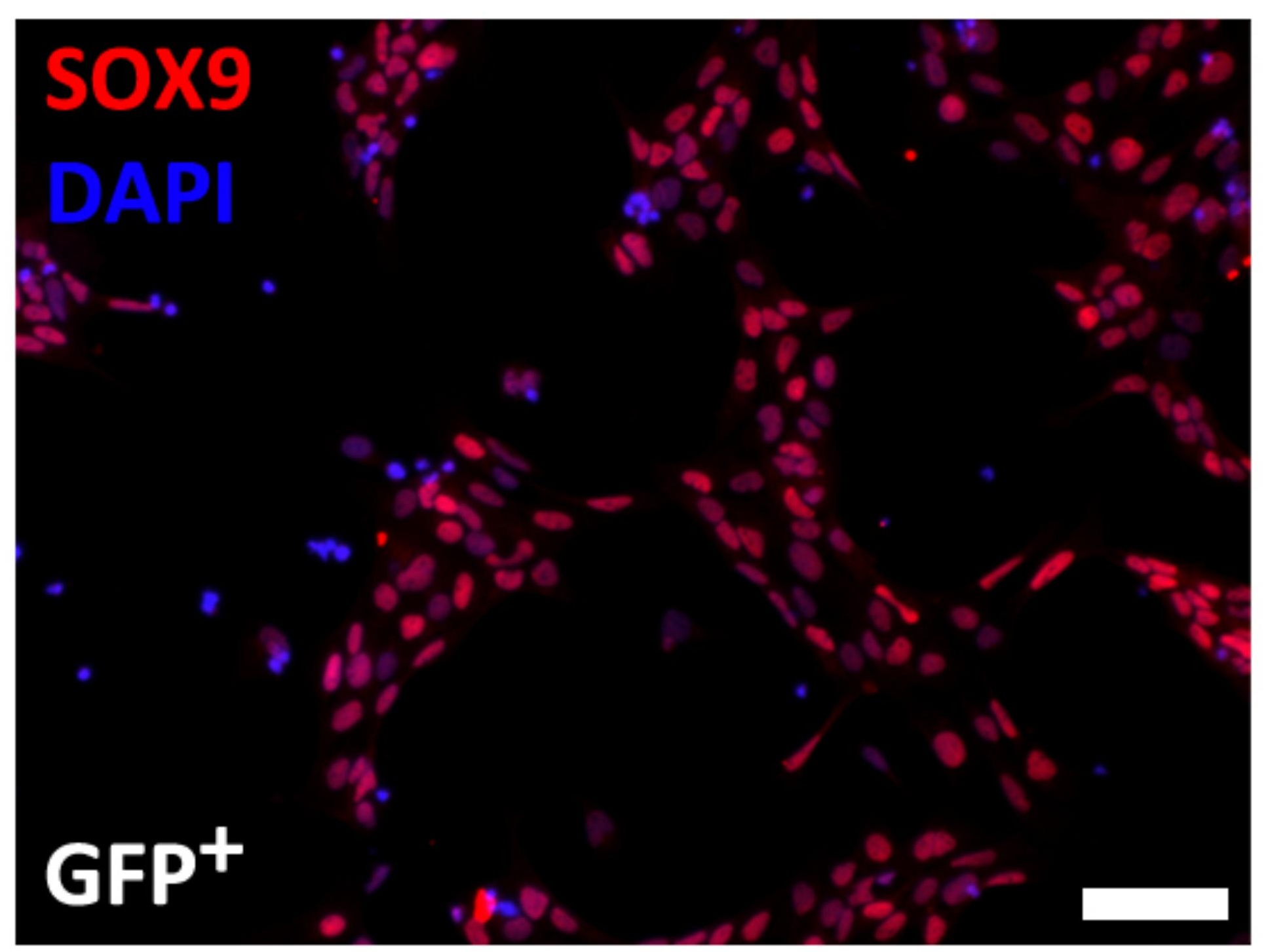

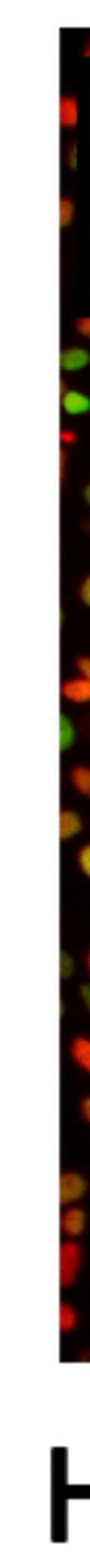
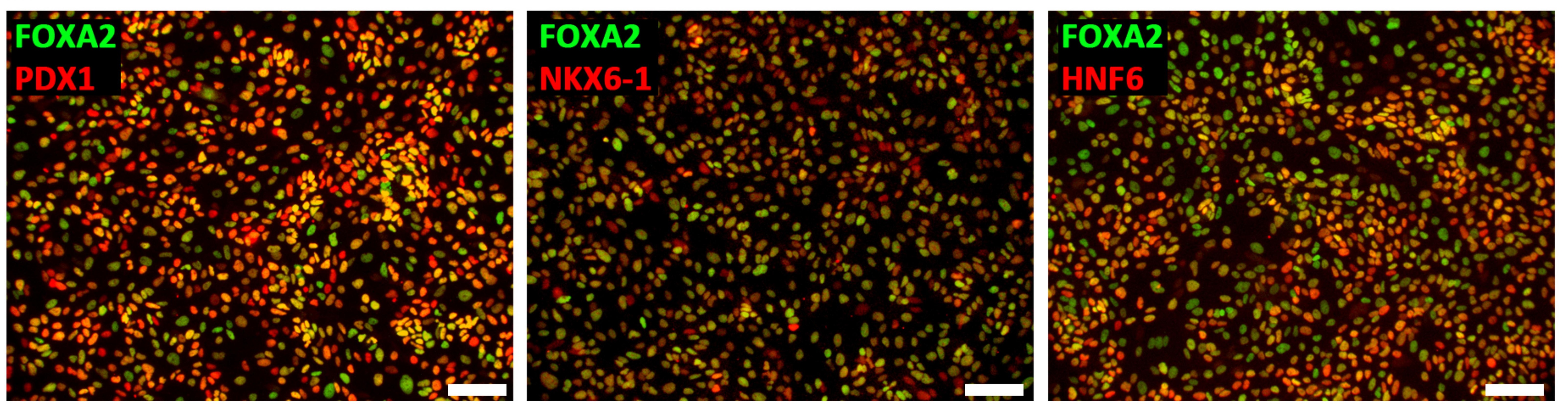

CD200

CD142
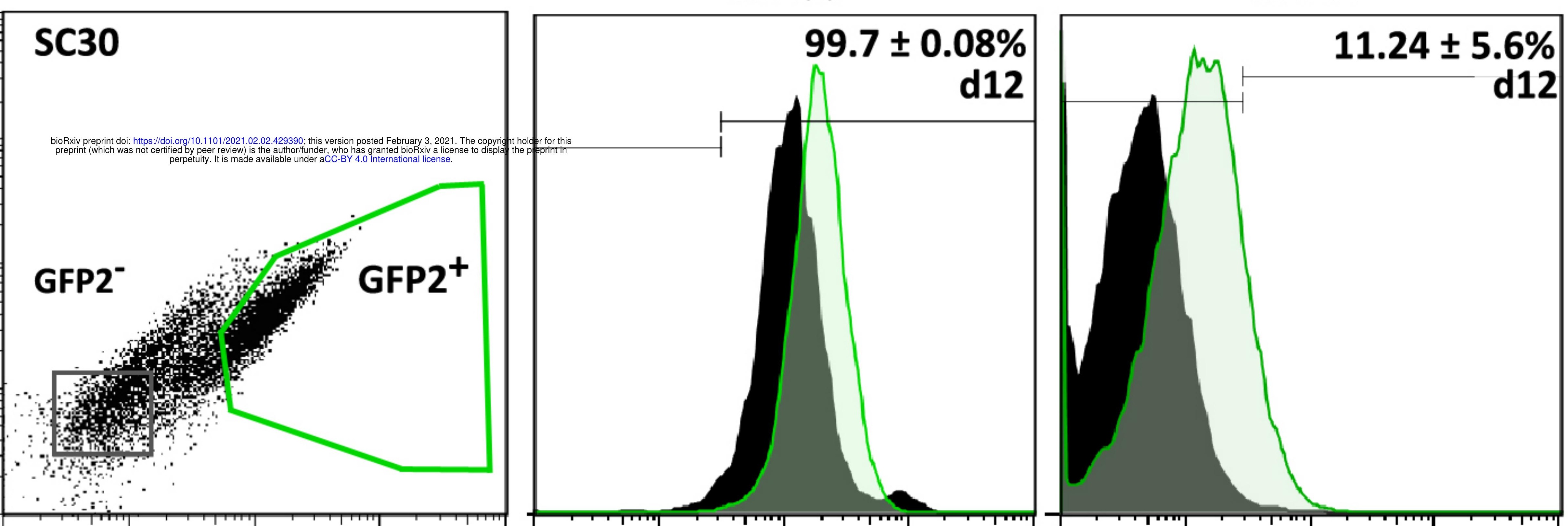

GP2
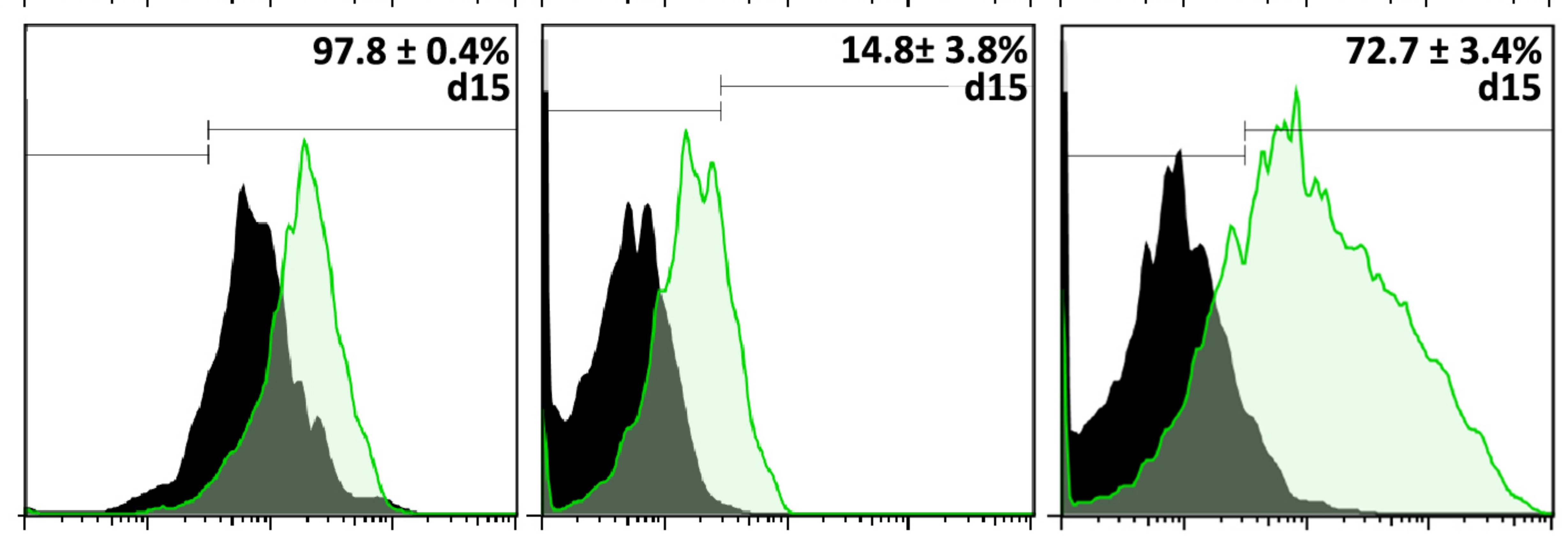


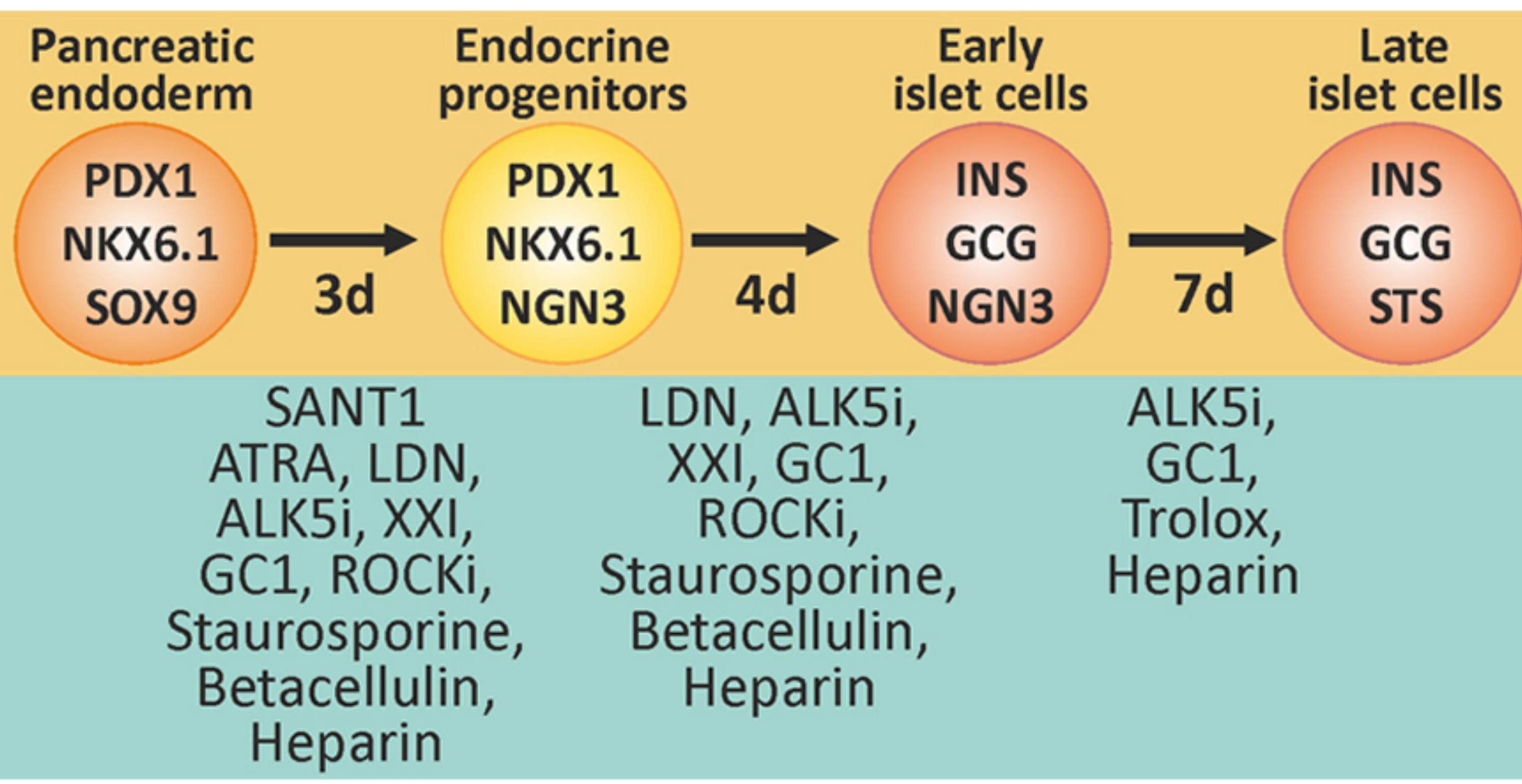

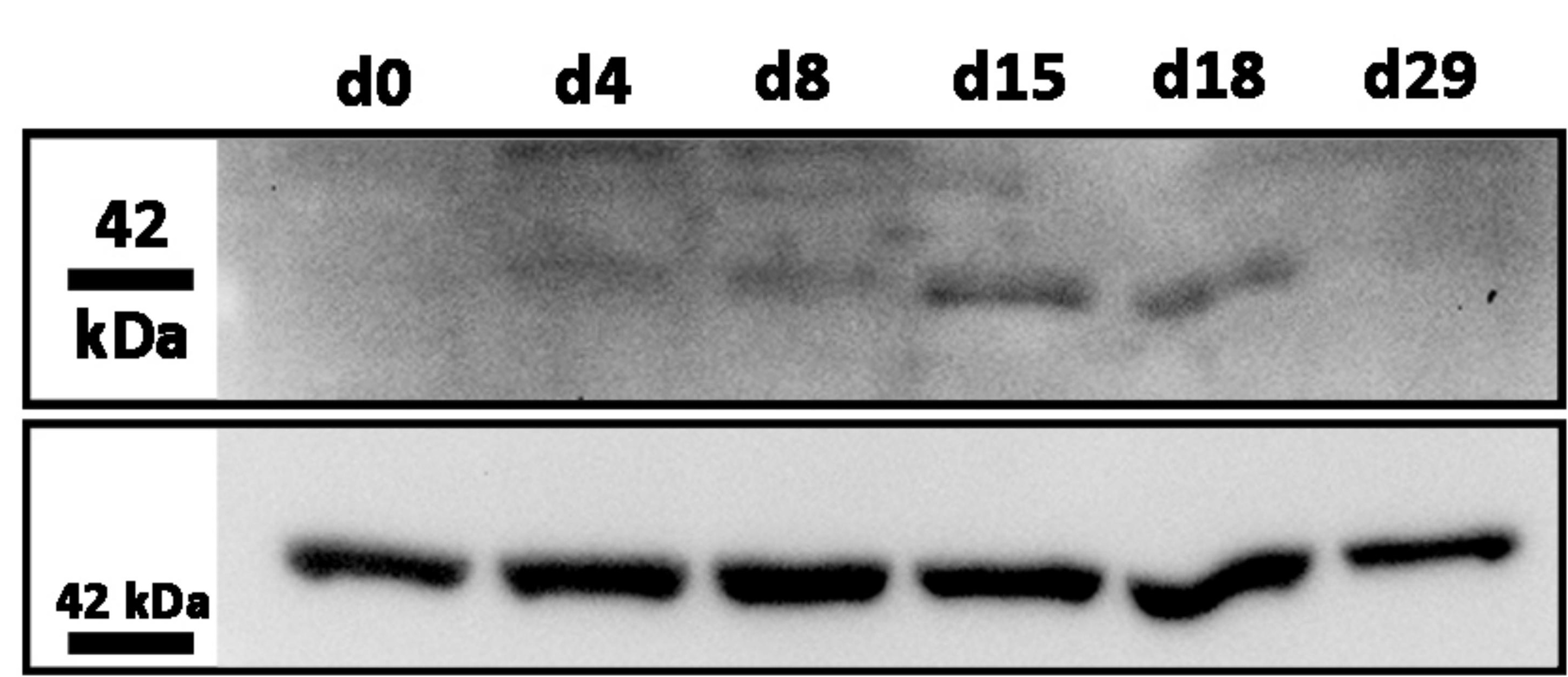

CPA1
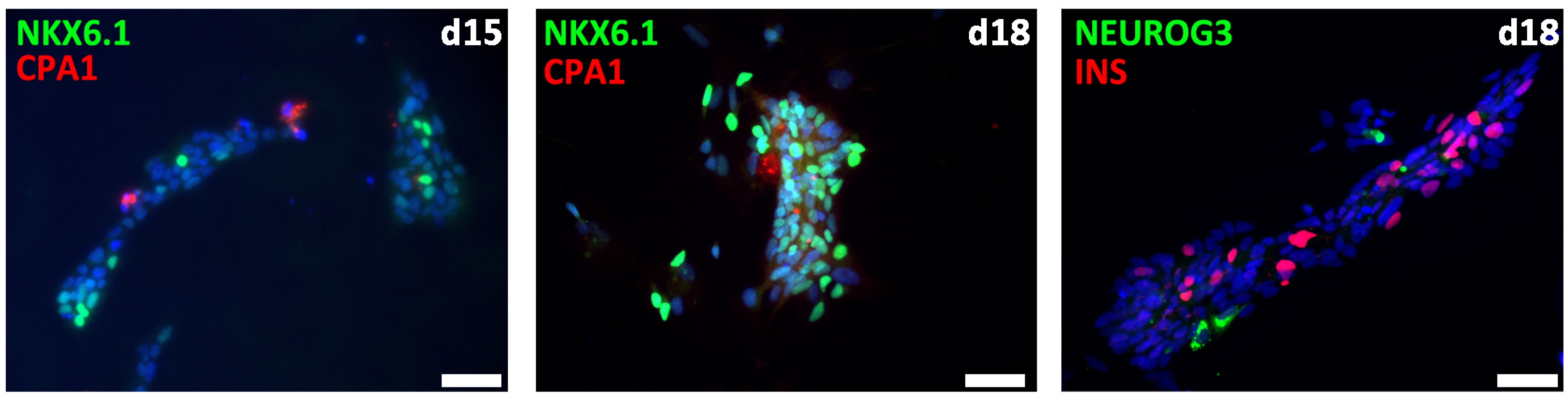

\section{d18}
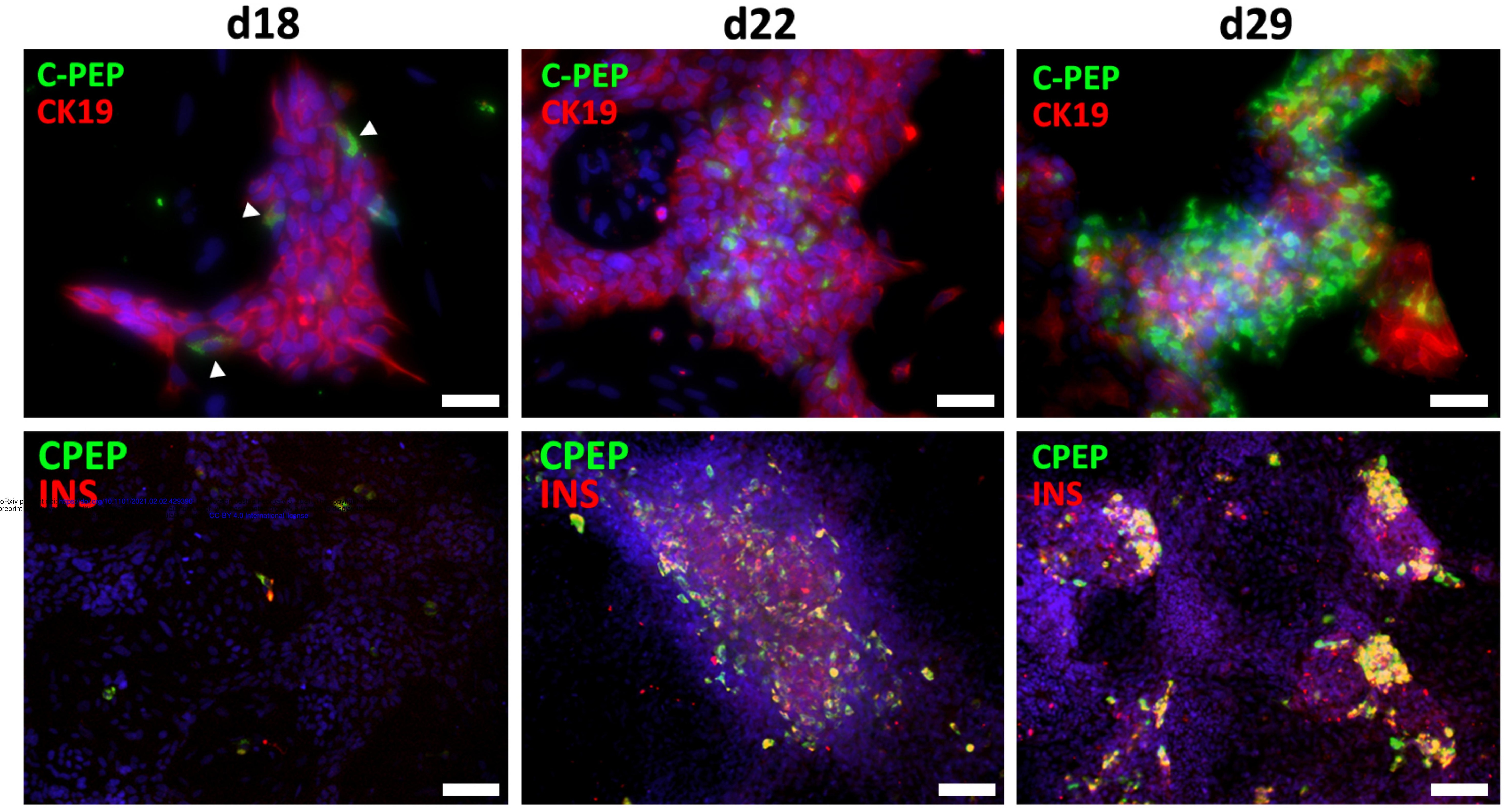

E
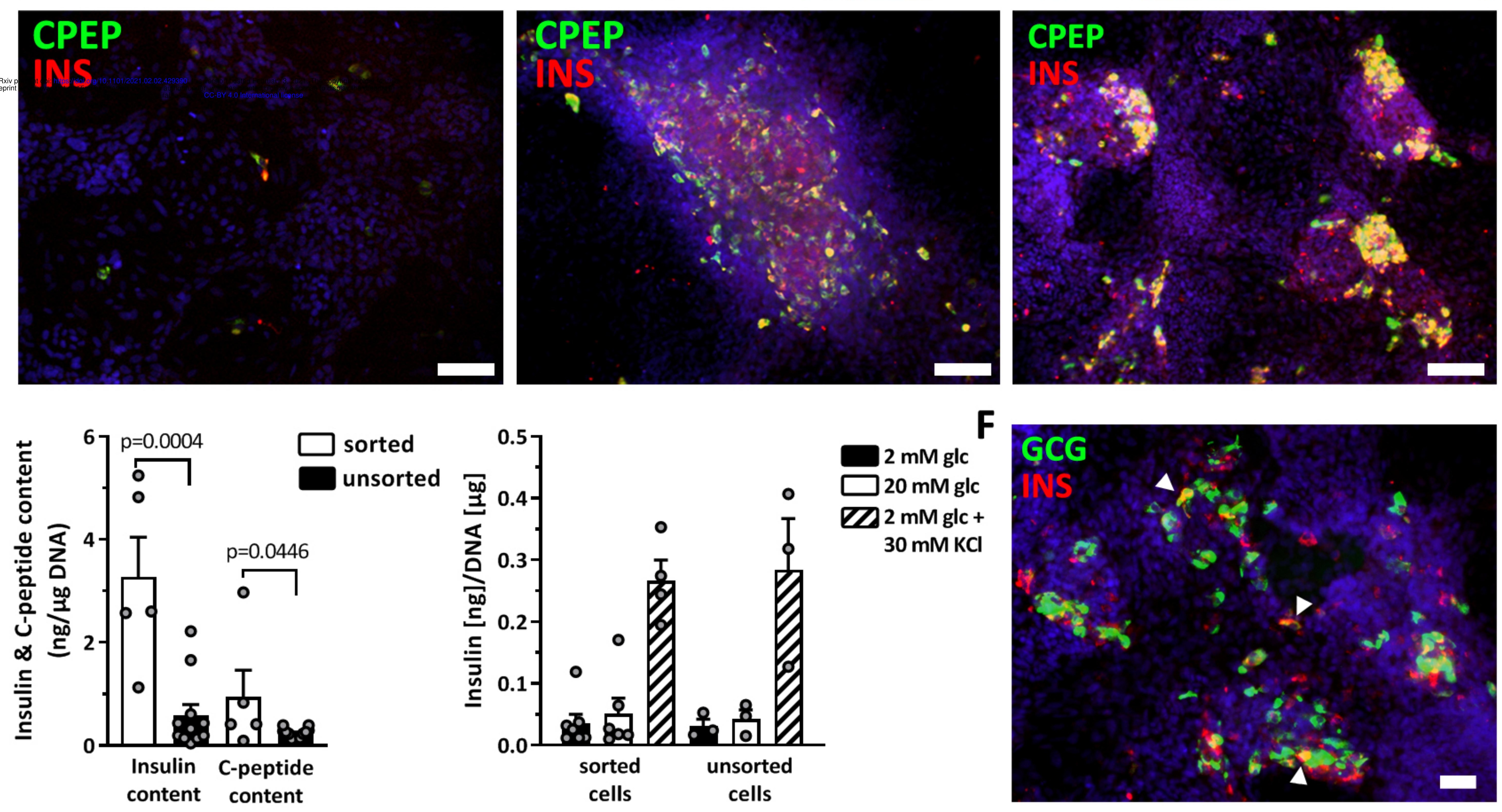

F

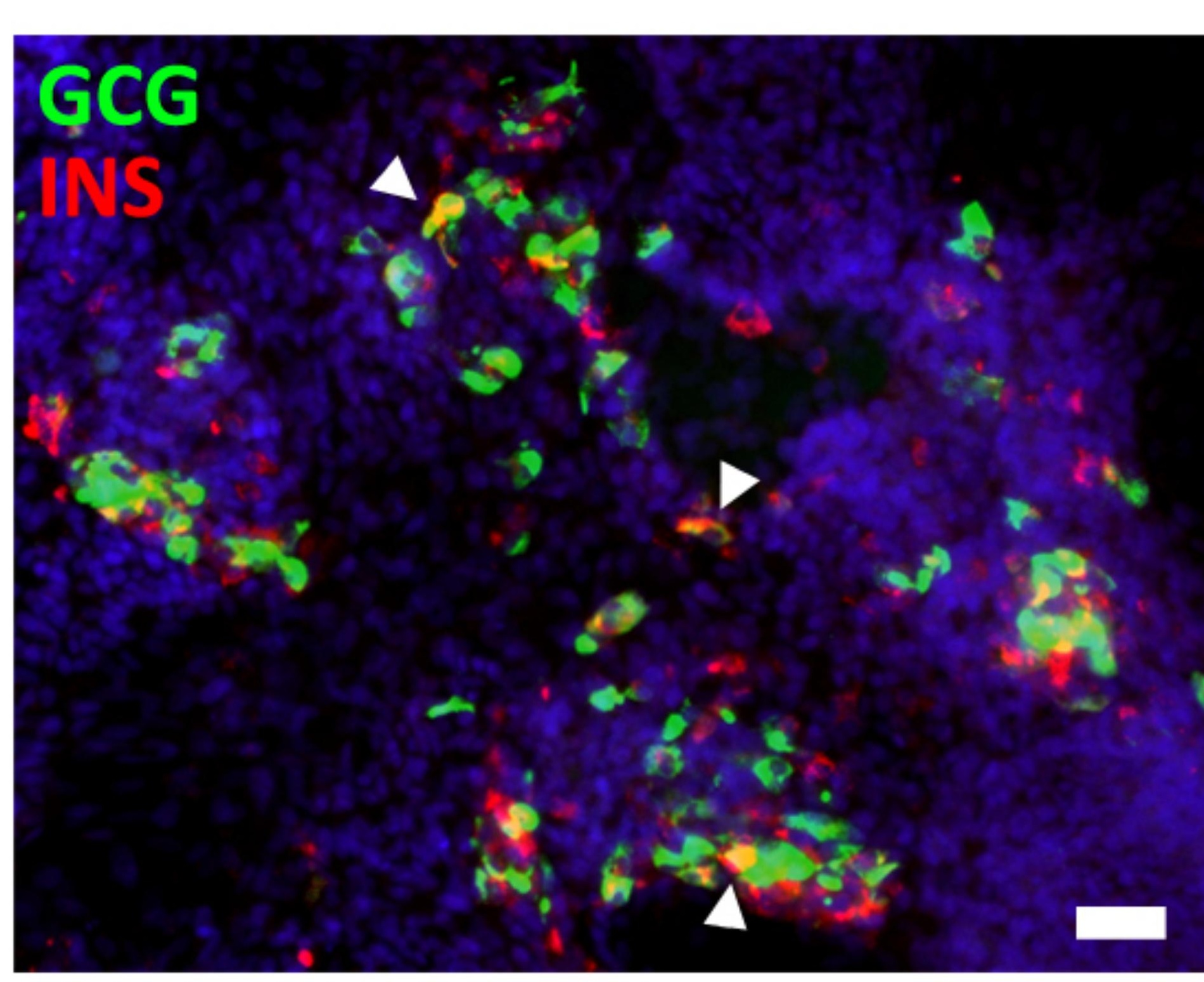



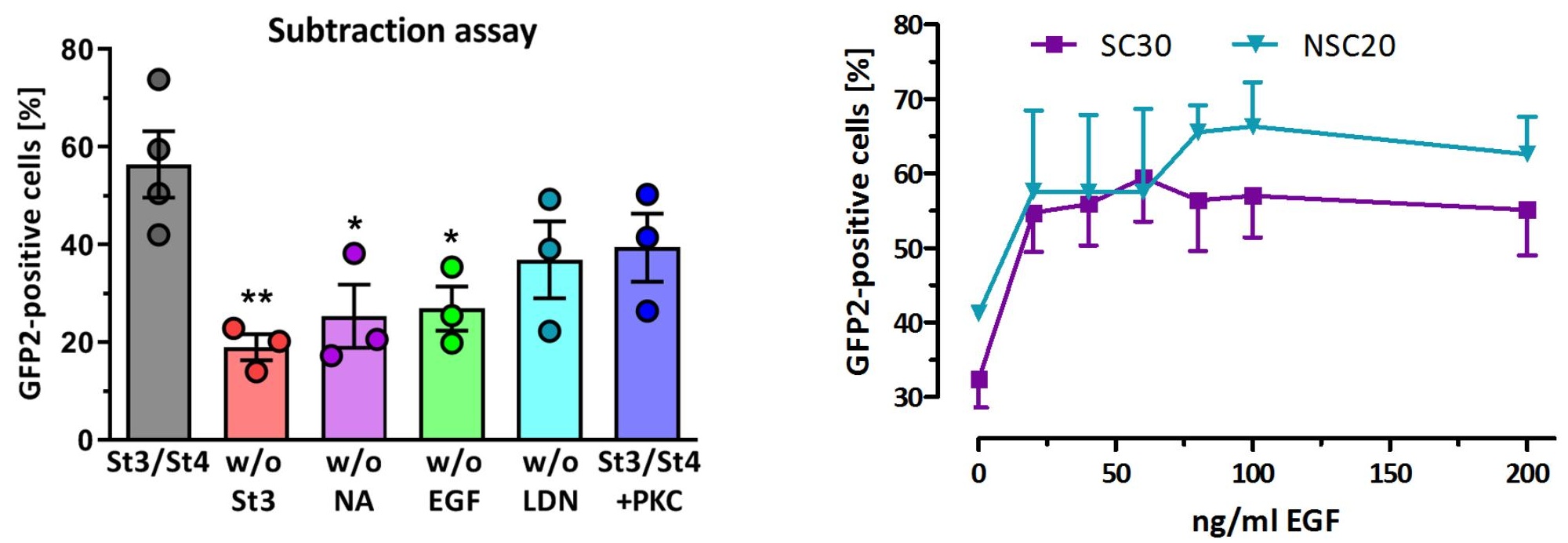

C
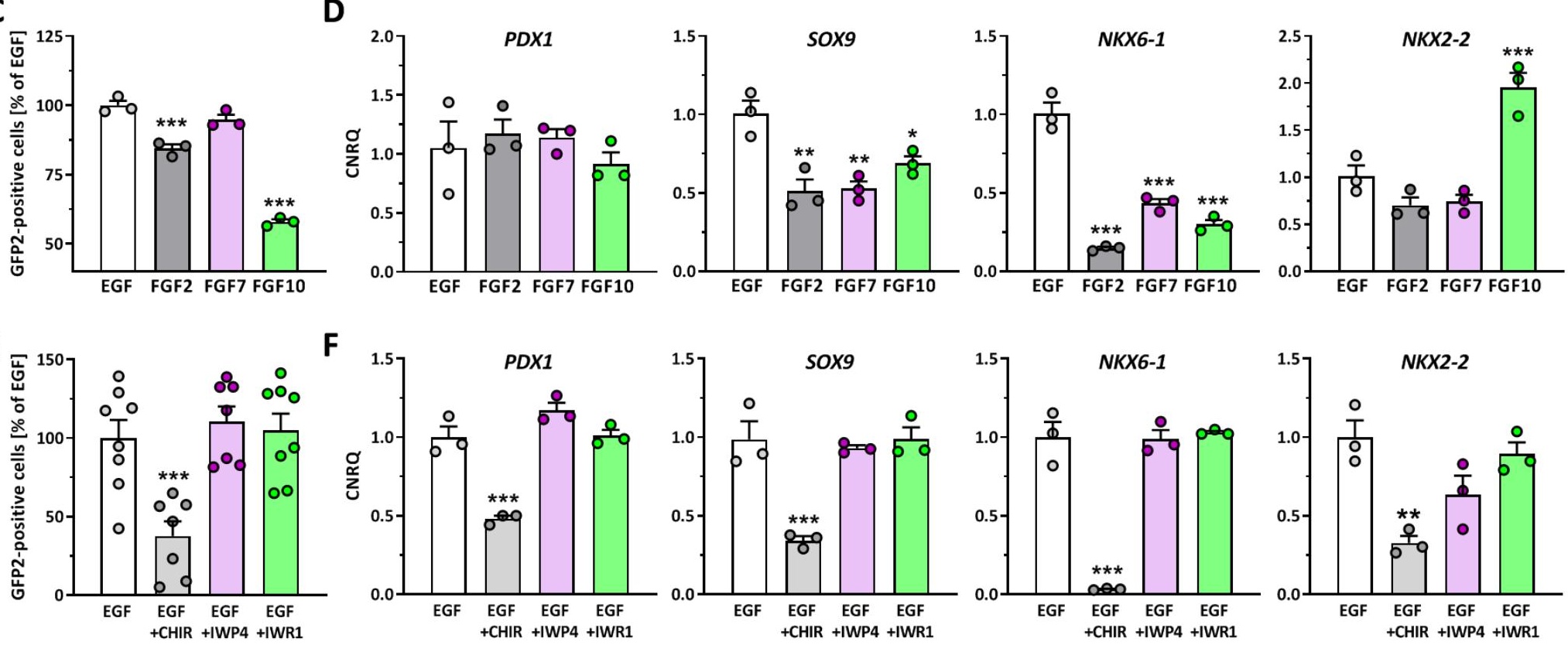
B

Stage 1-4 in 2D

Stage 4-7 in 3D

\begin{tabular}{l|l|l|l|}
\multicolumn{1}{l}{ INS HDR vector } \\
\hline INS Locus
\end{tabular}

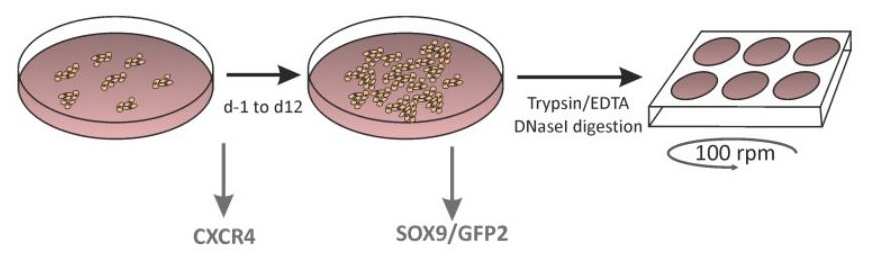

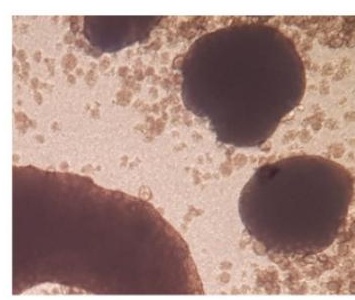

70 rpm

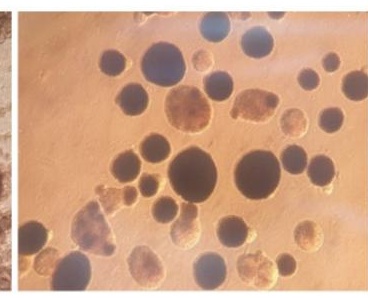

100 rpm

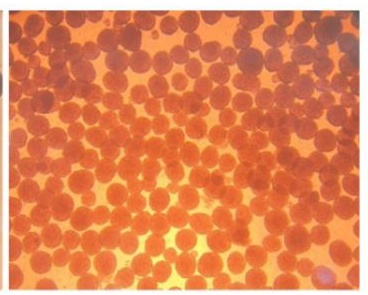

100 rpm + DNasel

C
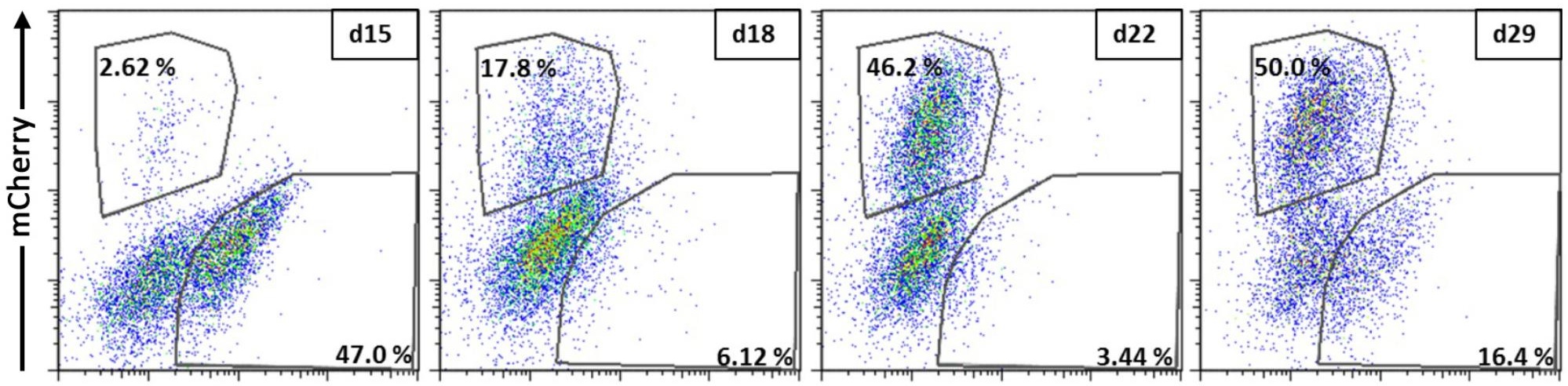

D

E
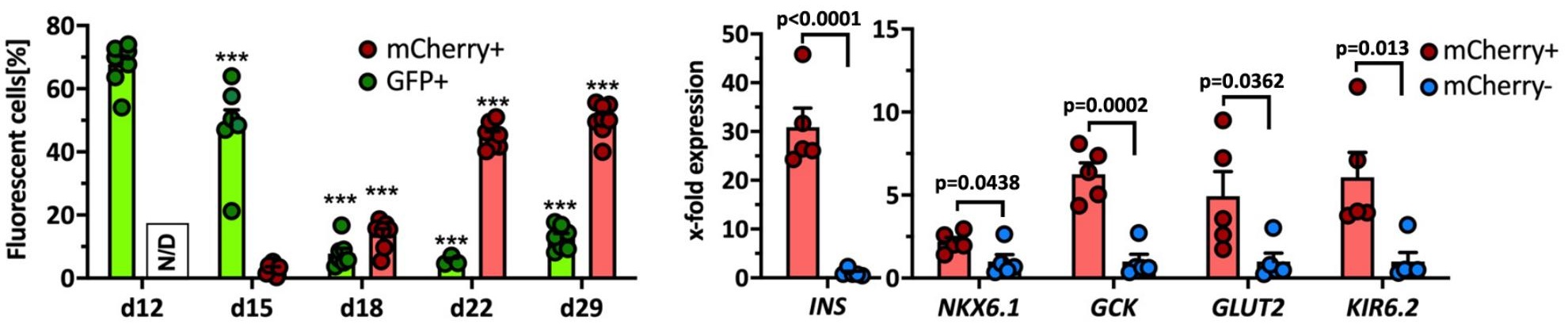
A
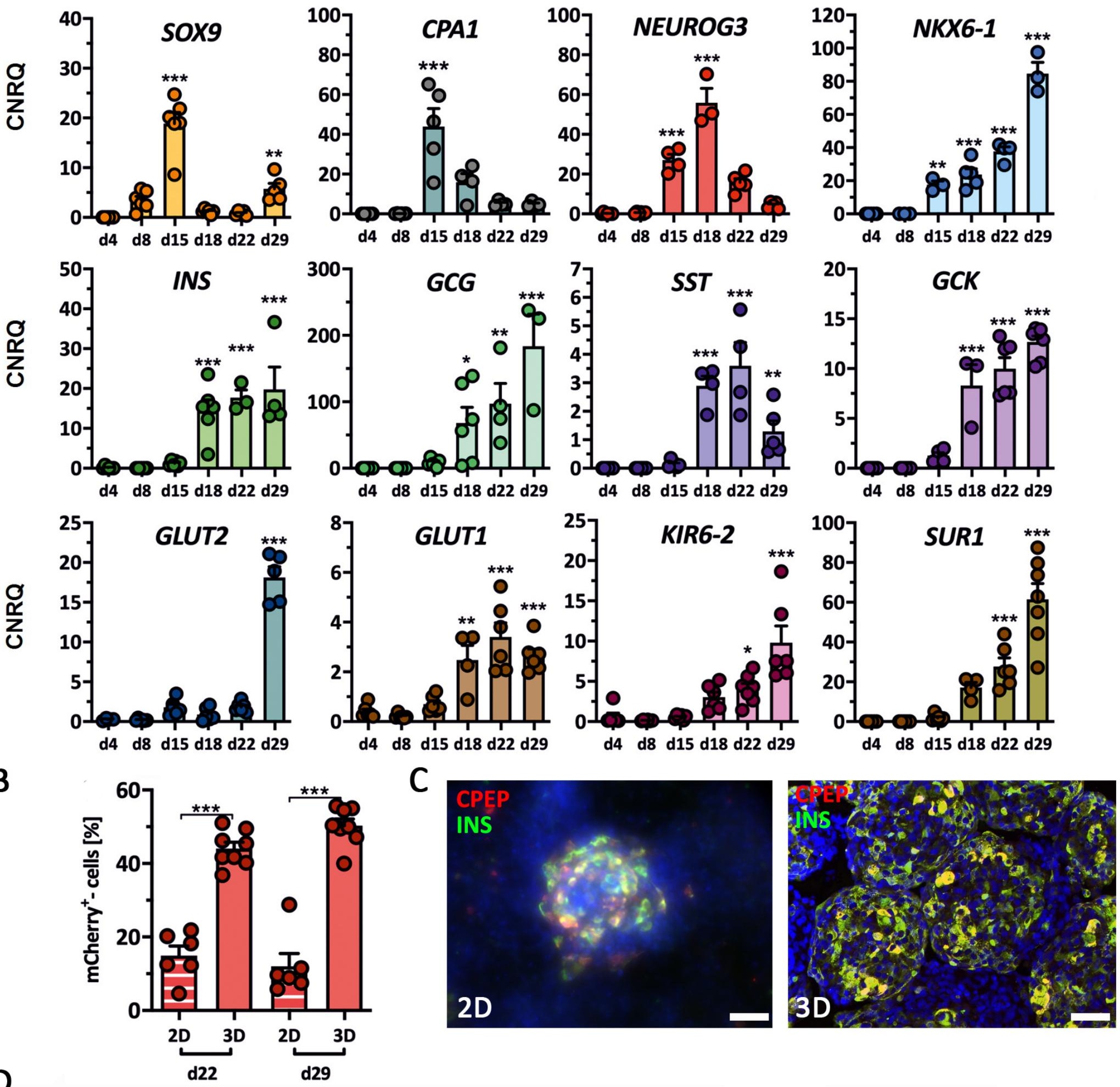

D
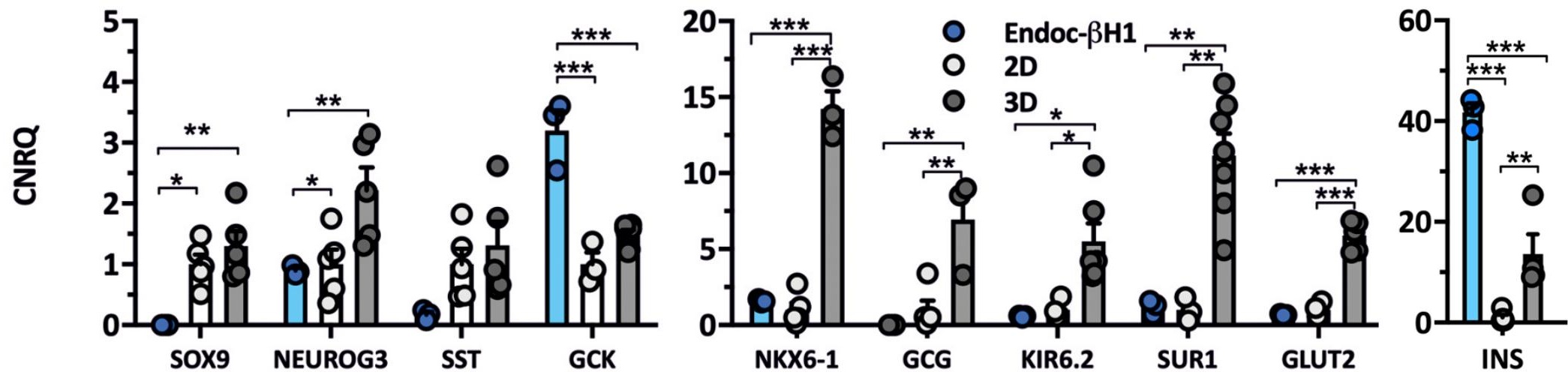
SC30-derived organoids

d15

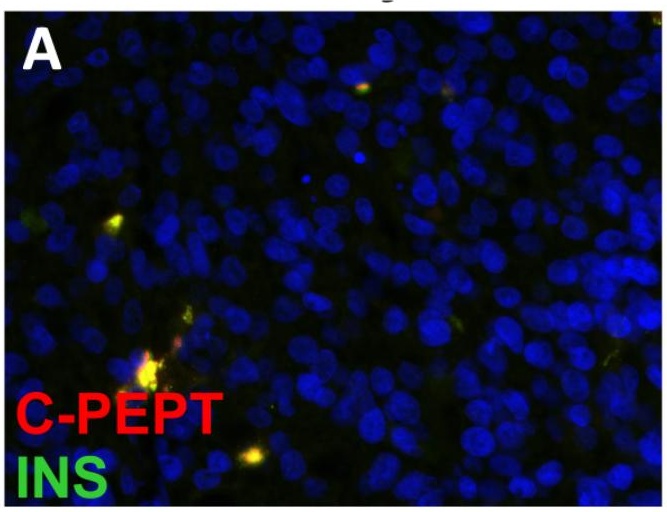

B

GLUC

INS

C

NKX6.1

INS

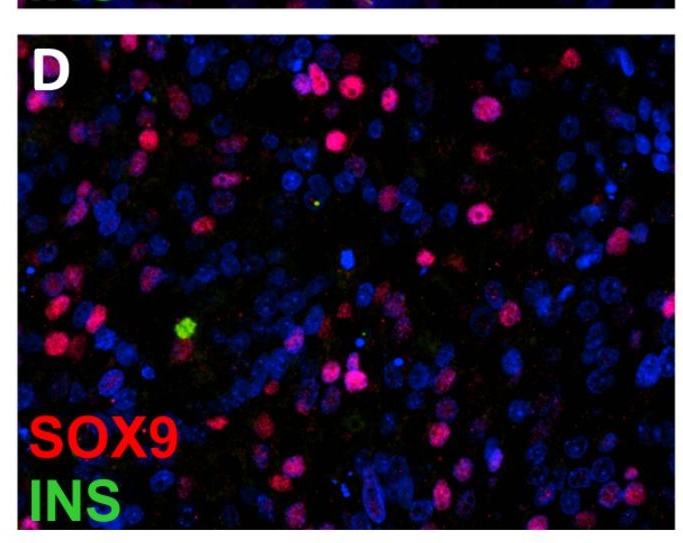

E

PBX1

INS d29
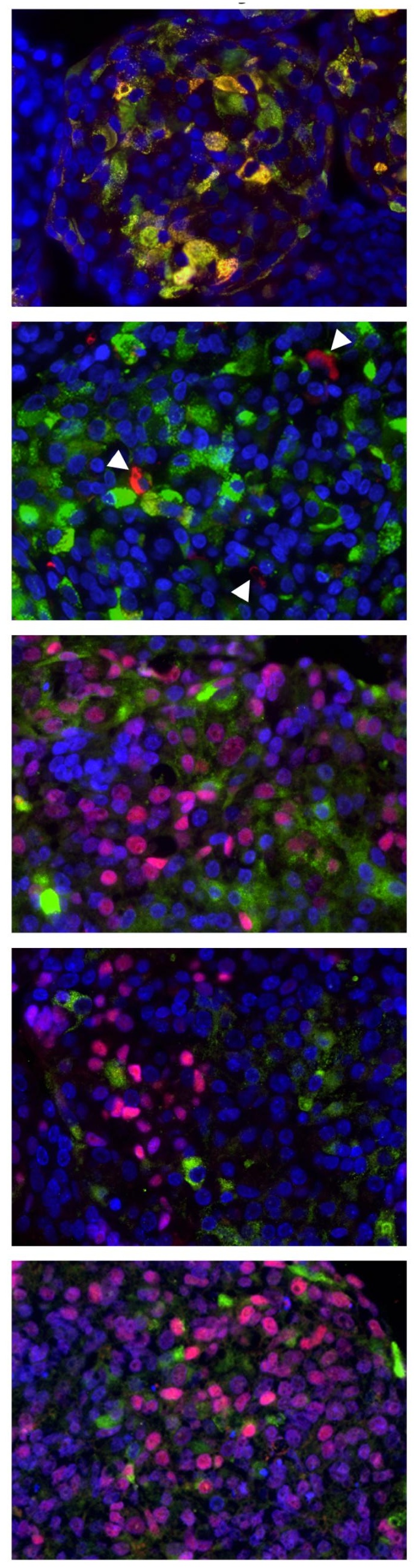

Human non-diabetic pancreas
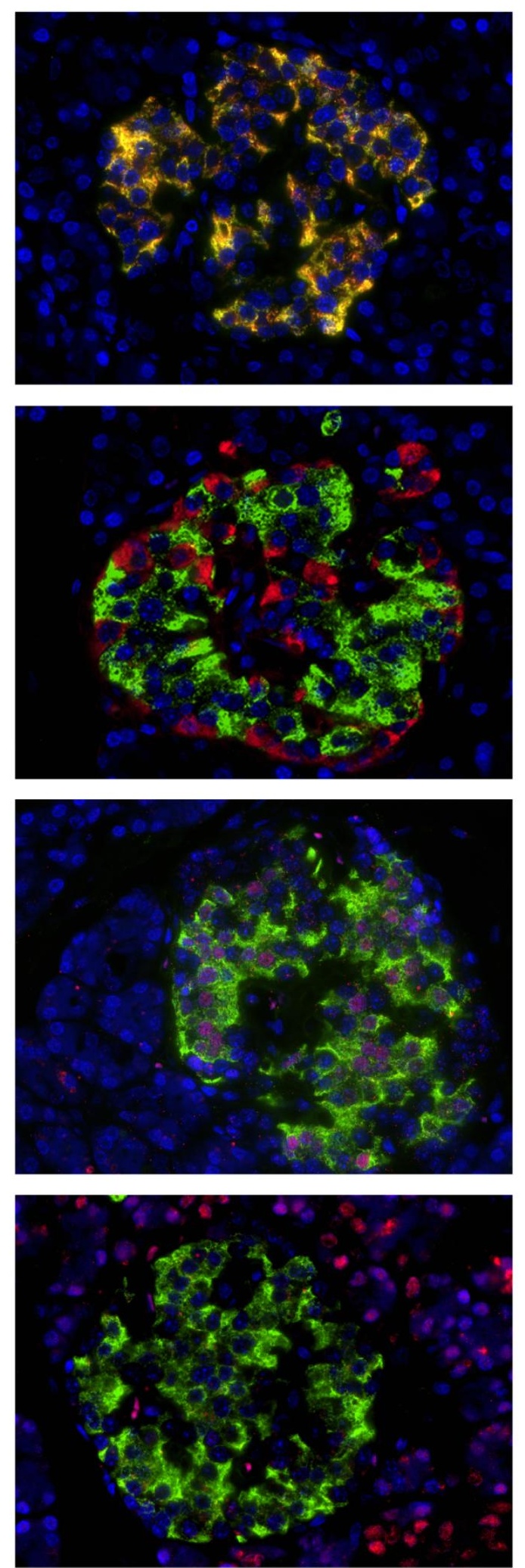
GFP2/H-2KK- negative cell fraction after sort

FACS

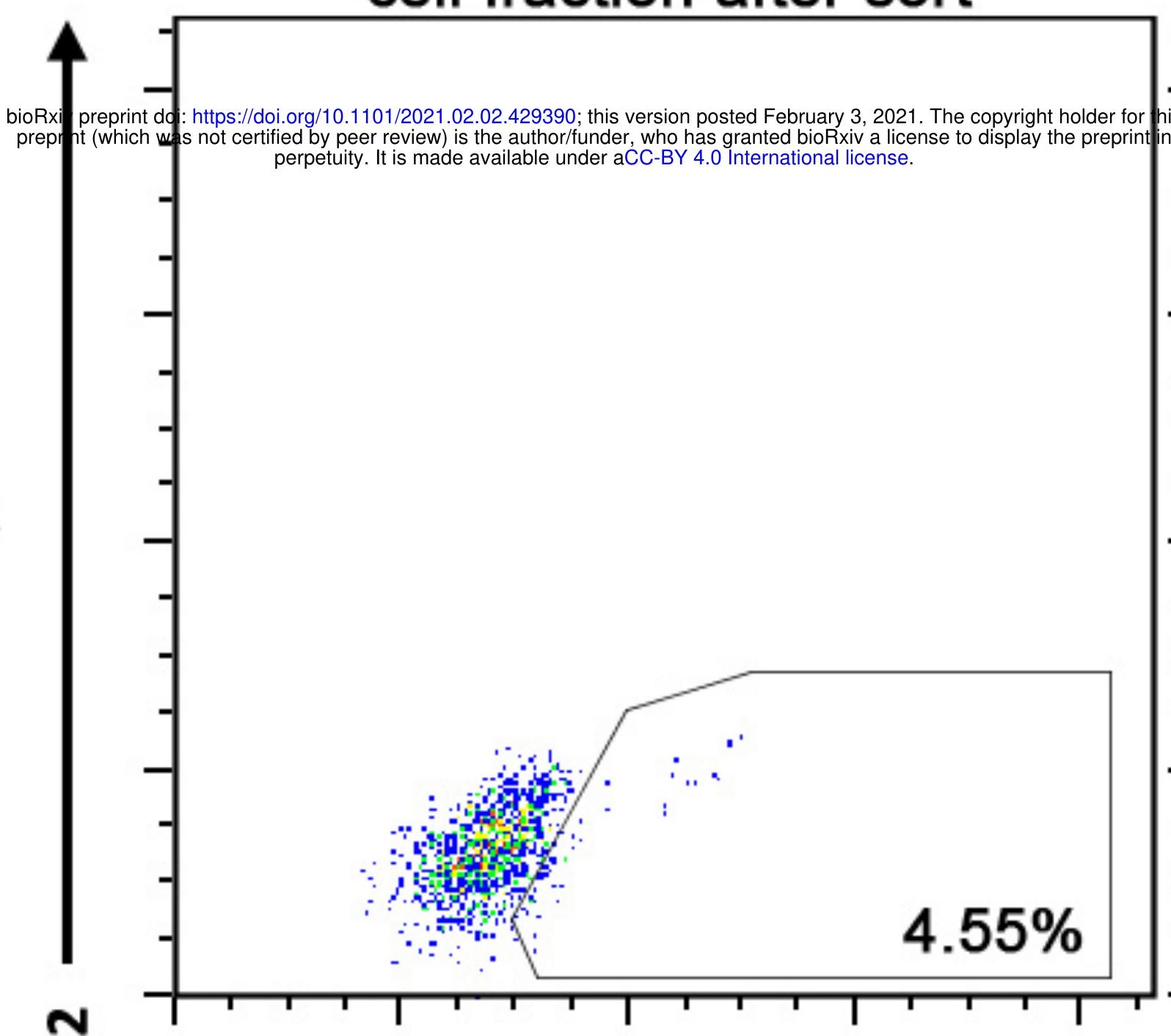

-

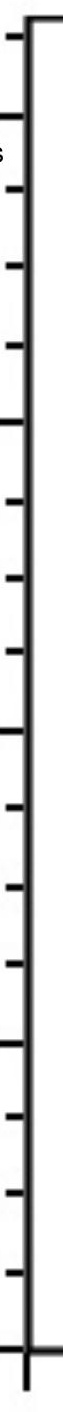

GFP2/H-2KK-positive cell fraction after sort

MACS
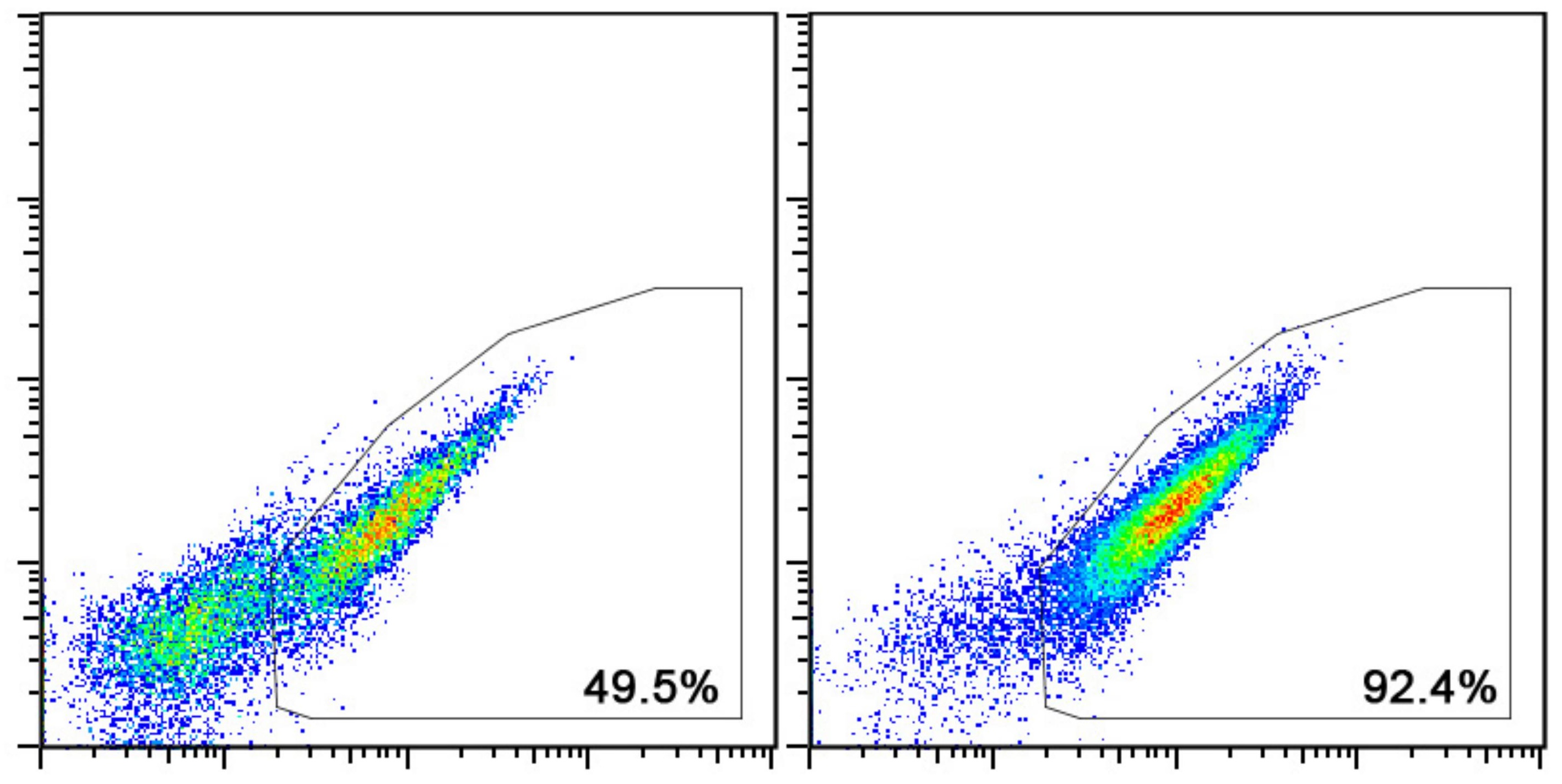

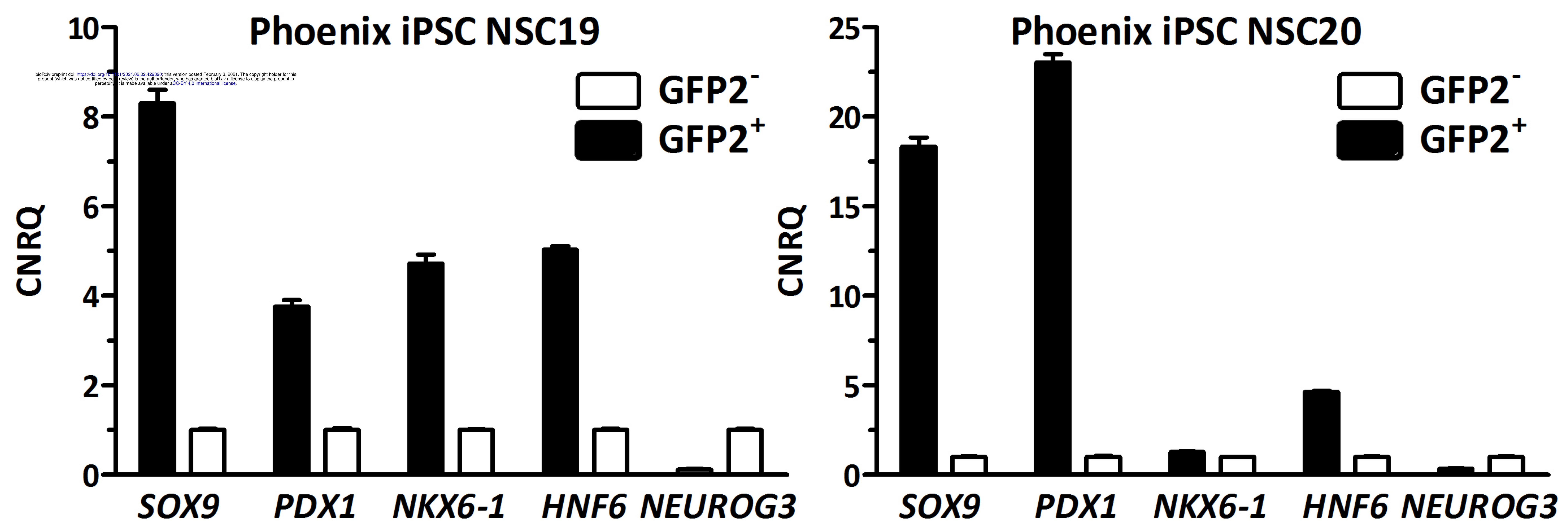

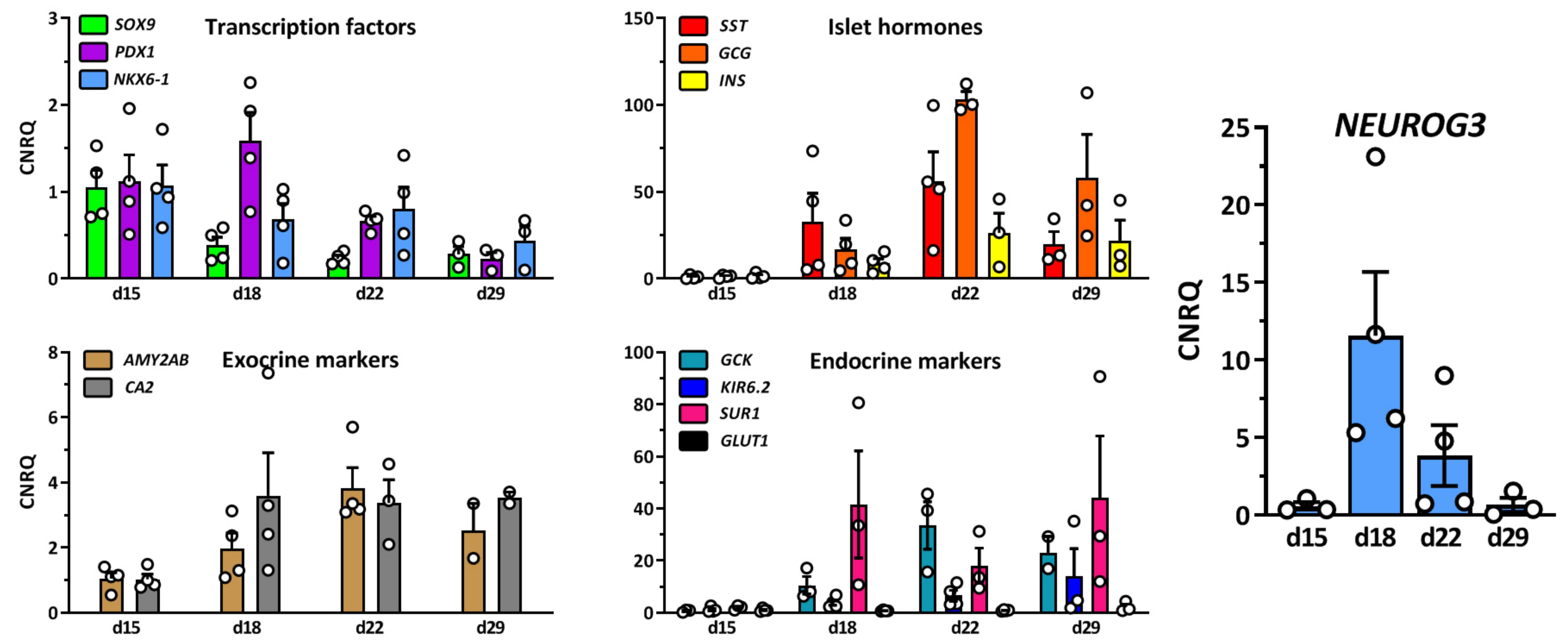

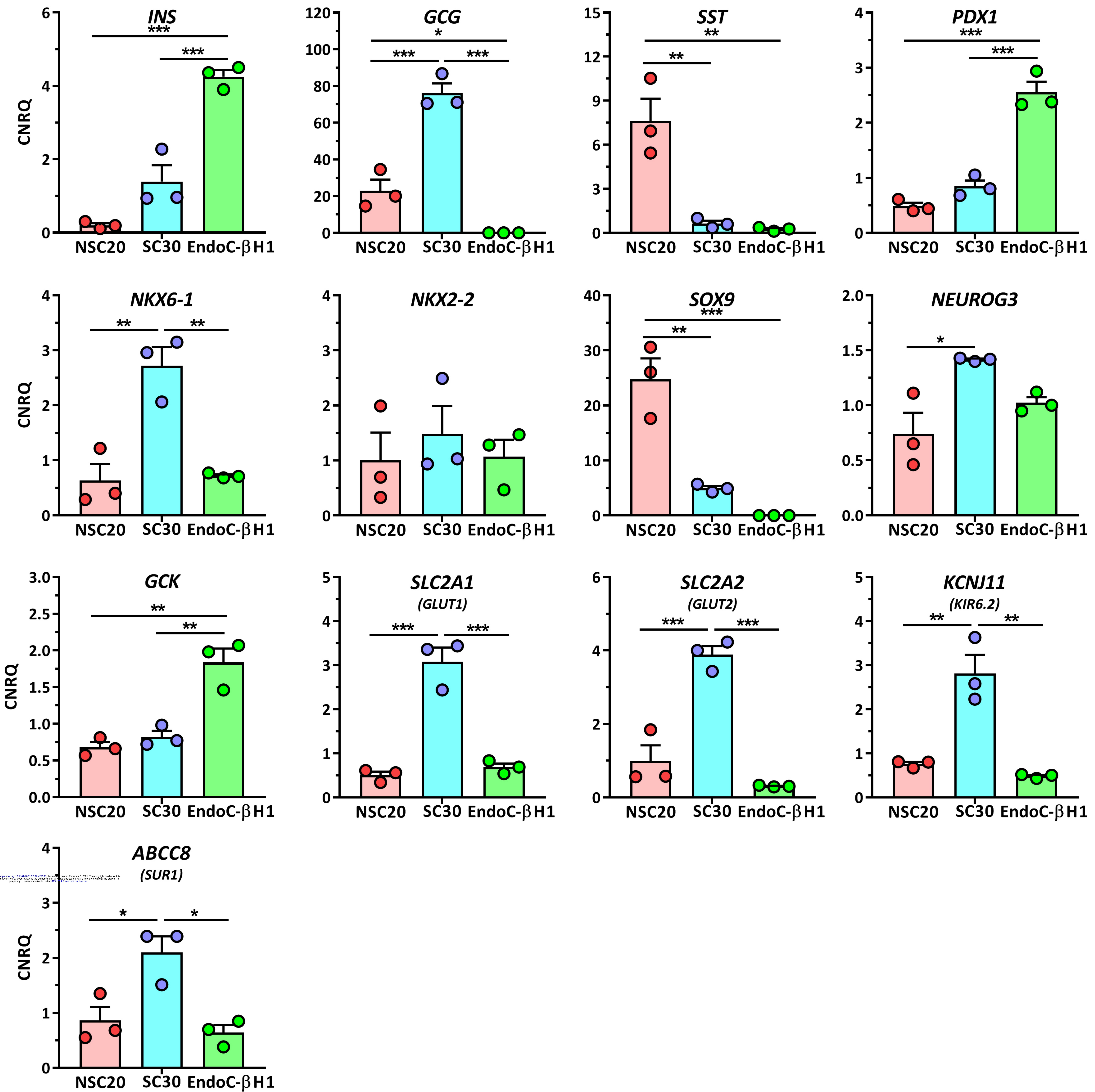
SC30-derived organoids d15 d29
Human non-diabetic pancreas

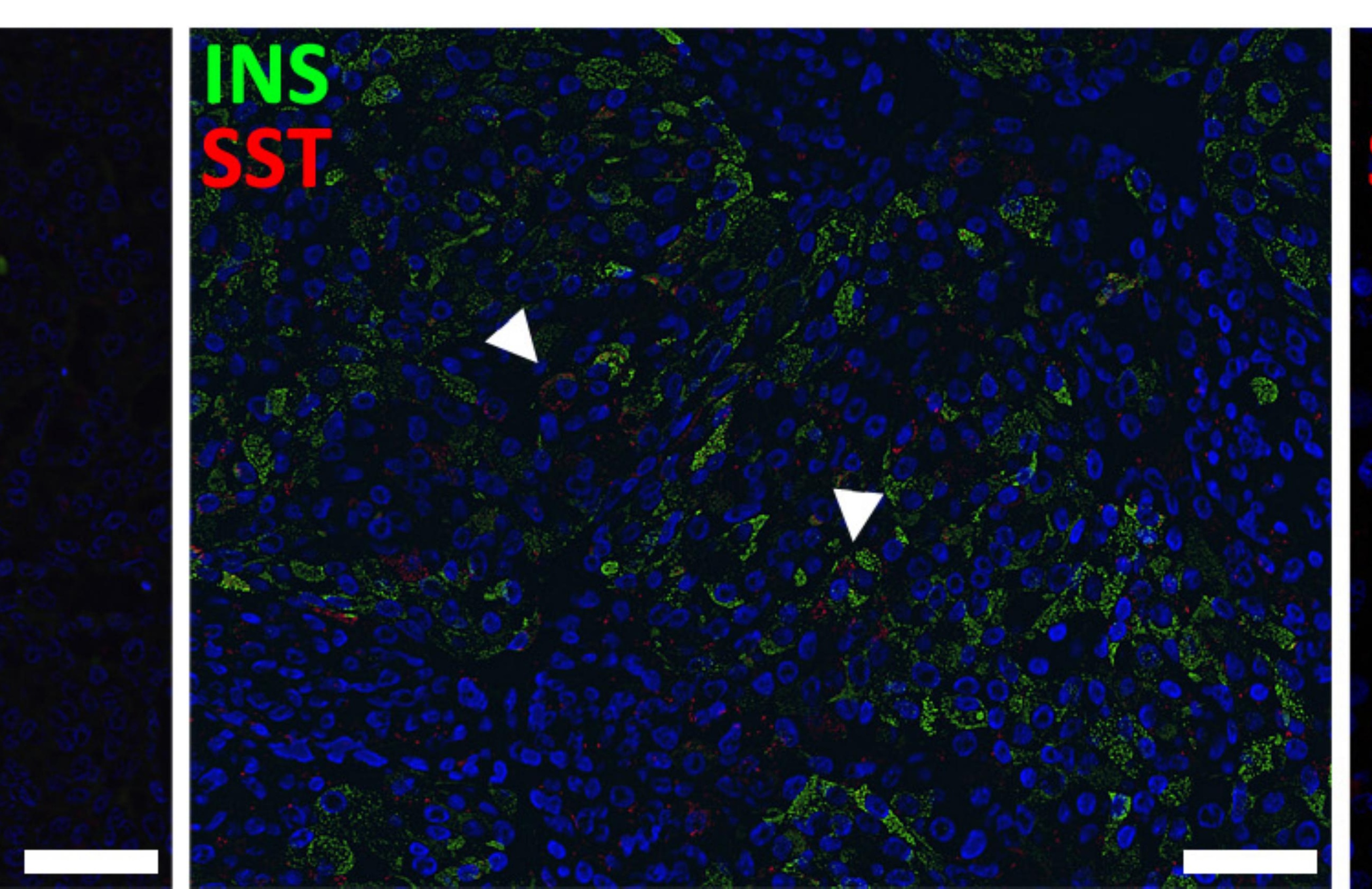

\section{INS}

SST 

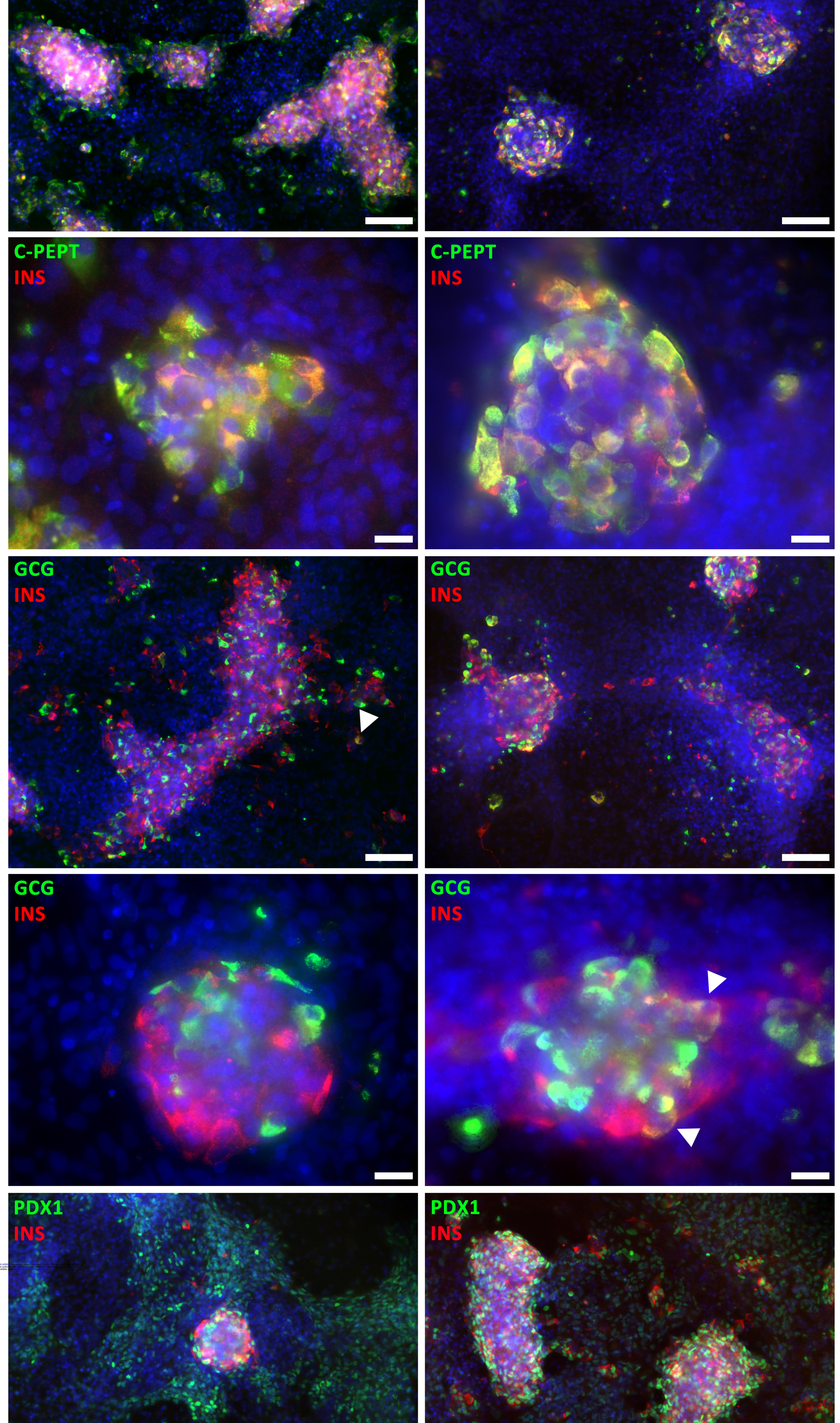

PDX1

INS

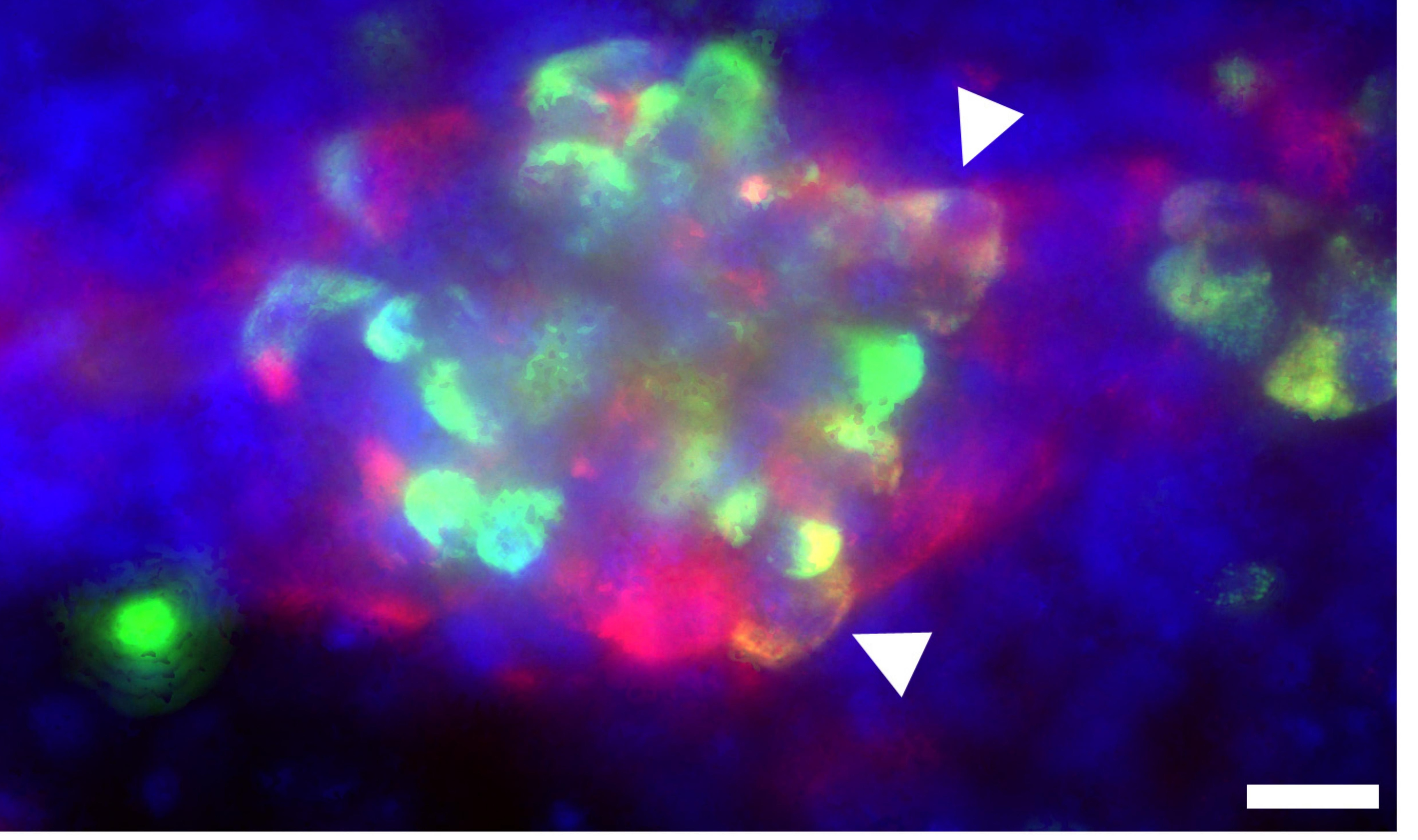




\section{Supplementary data}

A
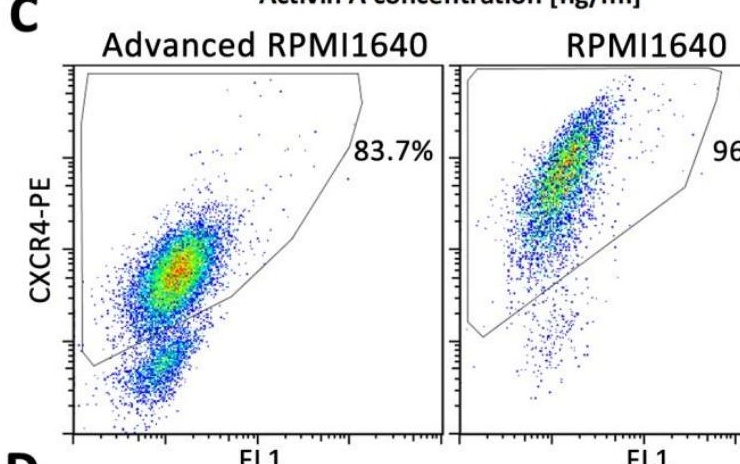

D

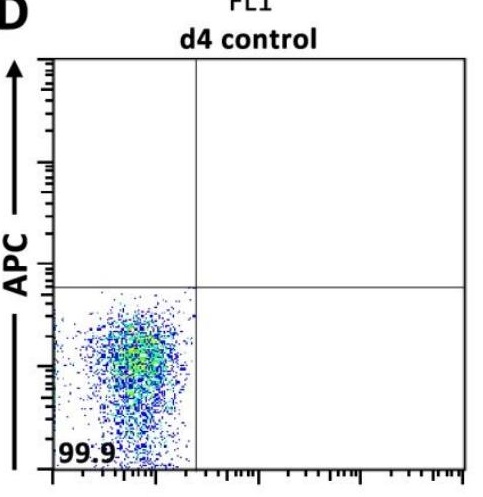

Titration of activin A

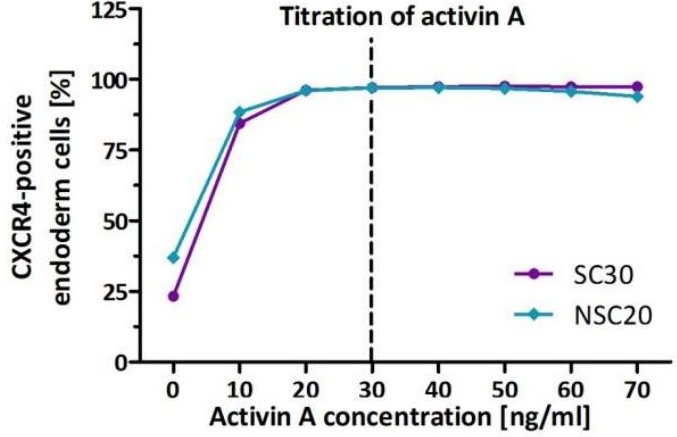

RPMI1640

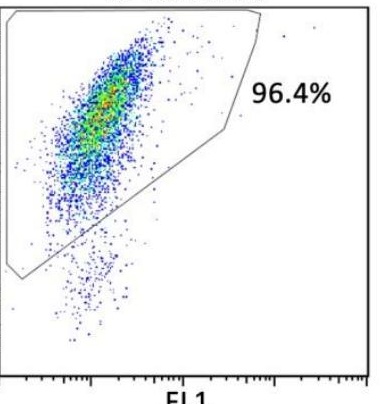

d4 CD177APC

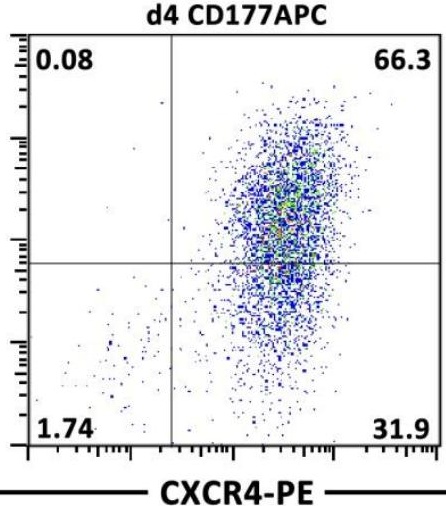

B

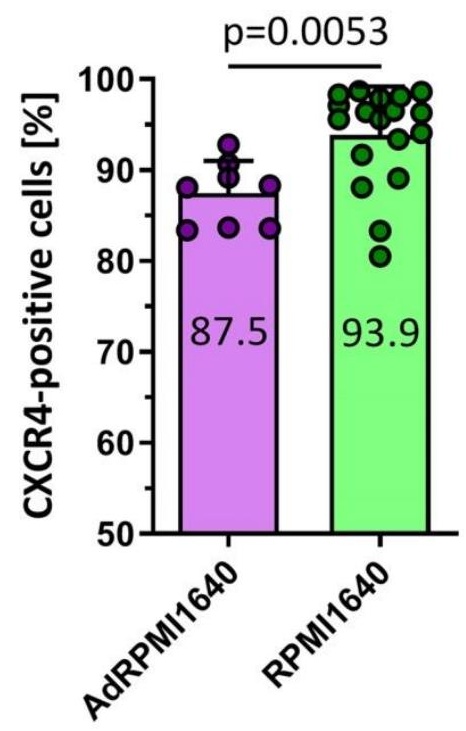

Supplementary figure 1. Endoderm and pancreatic-duodenal differentiation efficiency. (A) Titration of the optimal activin A concentration for differentiation of hPSC into CXCR4positive endoderm cells. (B) Flow cytometric quantification of CXCR4 at d4 of endoderm differentiation. Data are means \pm SEM, $\mathrm{n}=8-18$, two-tailed Student's t-test, $* * \mathrm{p}<0.01$. Differentiation protocol based on [9]. (C) Representative flow cytometry dot plots of CXCR4 staining in two endoderm differentiation media. (D) Double flow cytometric staining of CD177-APC/CXCR4-PE and CD275-APC/CXCR4-PE at d4 of endoderm differentiation. (E) PDX1/FOXA2 double-positive pancreatic duodenal cells at d8 of differentiation. Differentiation protocol based on [7] and [8]. 
P1. Pagliuca et al. (Cell, 2014) d4

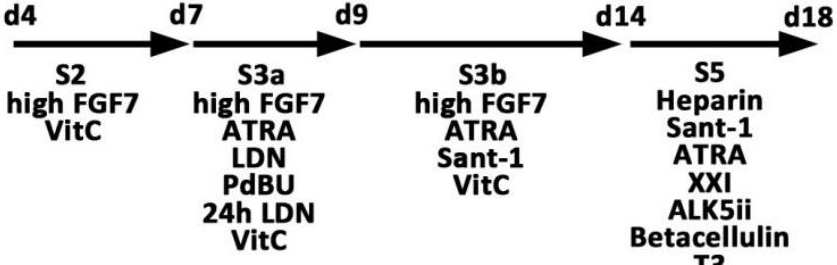

P2. S3B+S5
Pagliuca et al. \&
Davenport et al. Davenport et al.
(Stem Cells 2016)

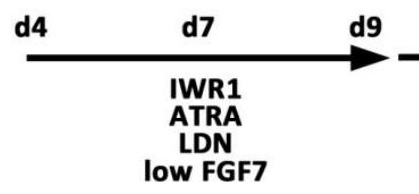

d4

P3. Davenport et al.
\& St4 Nostro et al. (Stem Cell Rep 2015)
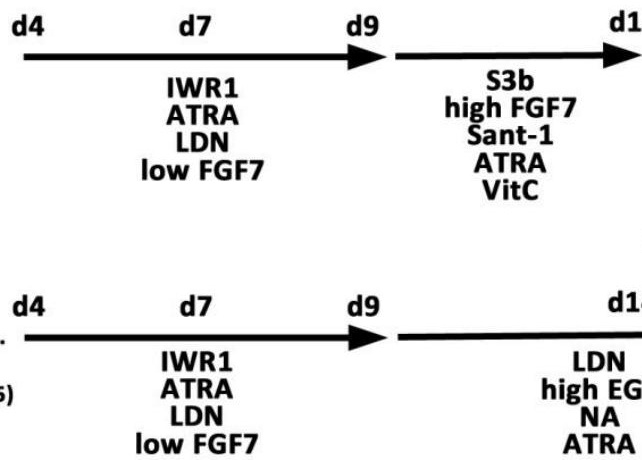

T3

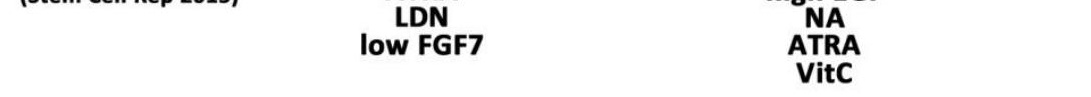

P4. Adopted Pagliuca et al.

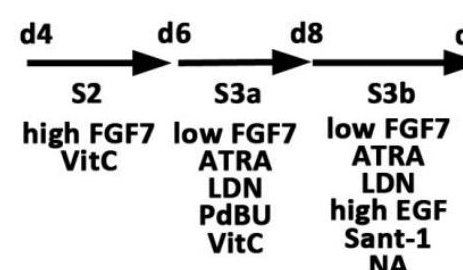
d11

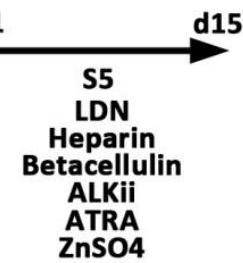

P5. Nostro et al.

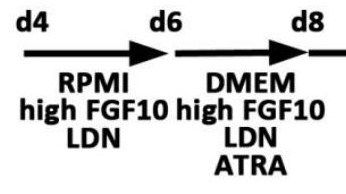
d4
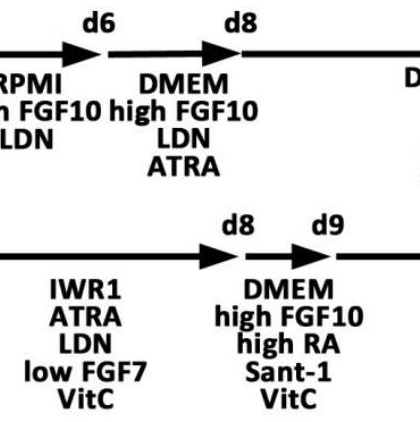
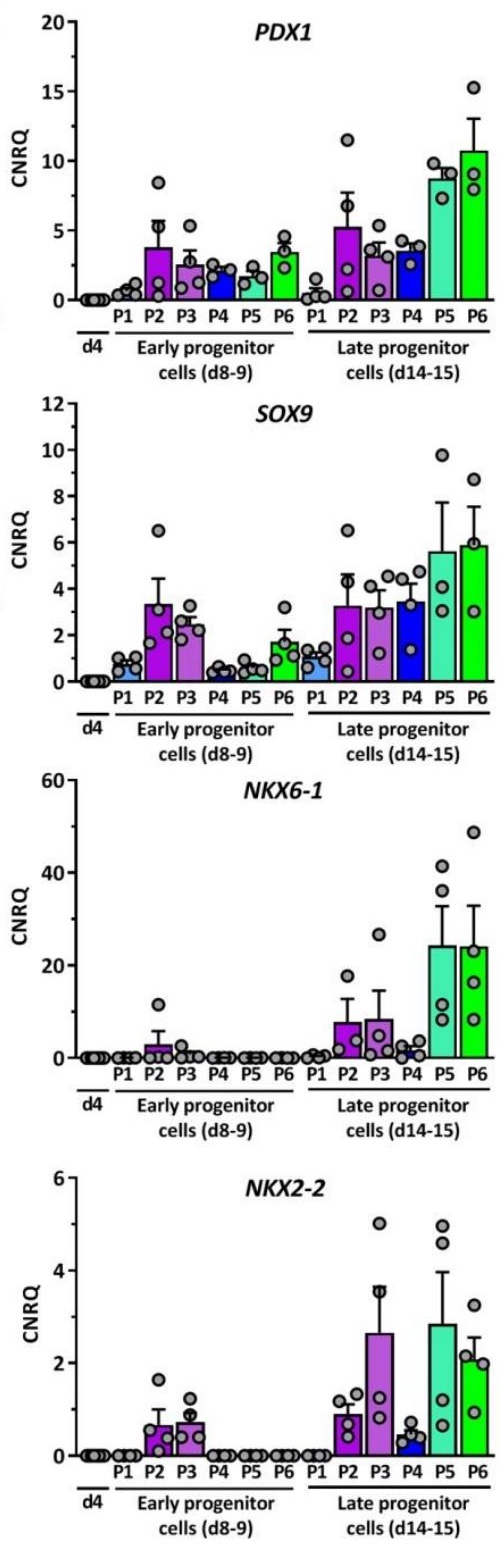

Supplementary figure 2. Comparison of six adopted differentiation protocols for the generation of MPCs from hPSC.

Depicted is the relative gene expression of PDX1, SOX9, NKX6-1, and NKX2-2. Data are means \pm SEM. $n=3-4$. The differentiation protocols were adopted from [7], [8], [11] and [14]. 


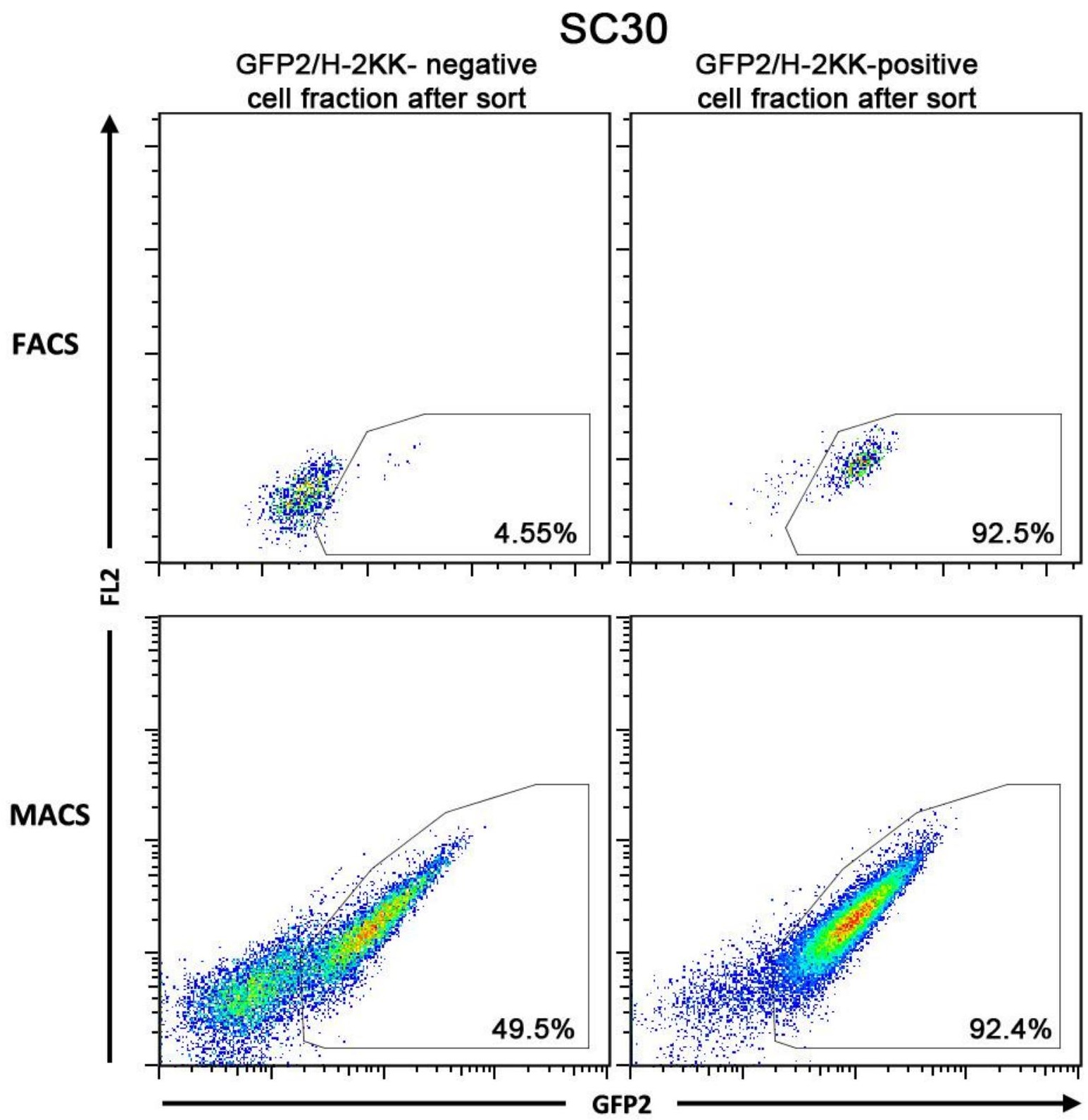

Supplementary figure 3. Representative dot plot presentation of cell sorting experiments using the SC30 cell clone. GFP2 ${ }^{+}$pancreatic progenitors can be sorted by FACS (upper images) or MACS (upper images) with comparable efficiencies. 


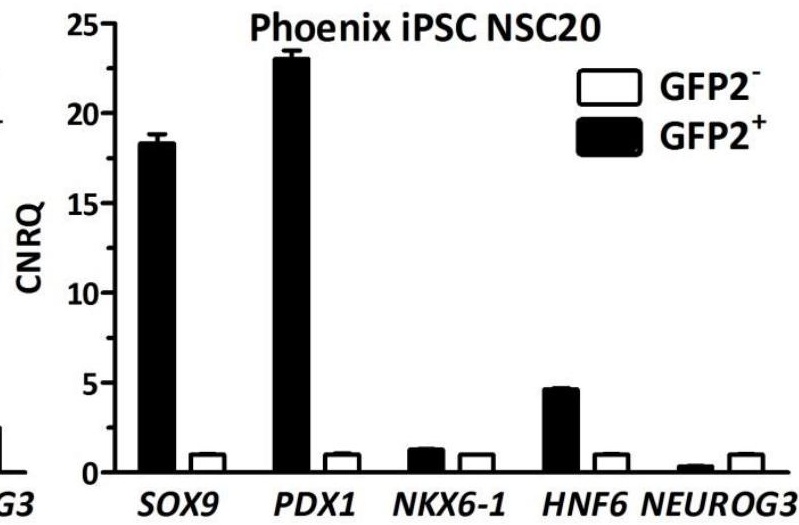

Supplementary figure 4. RT-qPCR analysis of sorted NSC19 and NSC20 derived GFP2+ and GFP2- cells at d12 of differentiation. Depicted is the relative gene expression of $S O X 9$, PDX1, NKX6-1, HNF6, and NEUROG3. Data are means \pm SD from a single sorting experiment measured in triplicate.
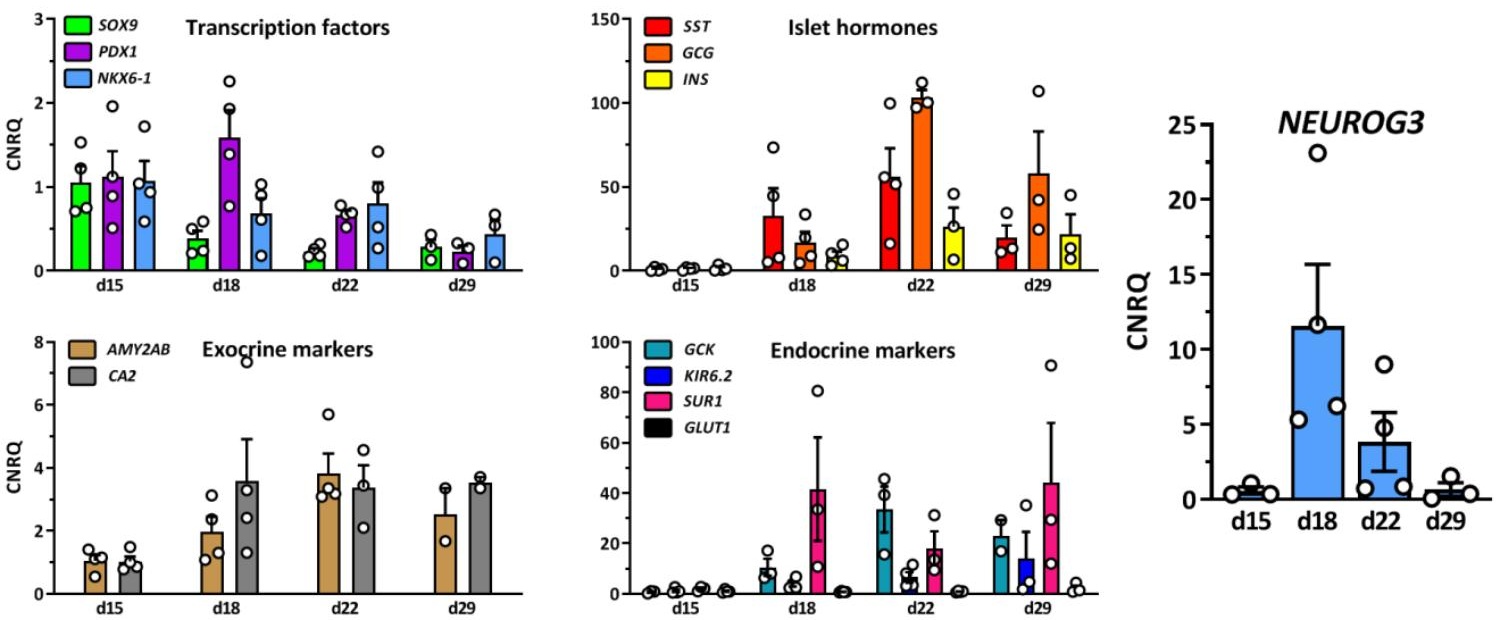

Supplementary figure 5. RT-qPCR analysis of sorted GFP2 ${ }^{+}$cells after MACS at day 12 of differentiation using the SC30 cell clone. Further differentiation was conducted according to the 2D experimental protocol. Depicted is the relative gene expression of the transcription factors, $S O X 9, P D X 1, N K X 6-1$ and NEUROG3, the islet hormones somatostatin (SST), glucagon $(G C G)$ and insulin (INS), the exocrine marker genes amylase $2(A M Y 2 A B)$ and carbonic anhydrase $2(C A 2)$ and the endocrine marker genes glucokinase $(G C K), K I R 6.2$, SUR1 and GLUT2. Data are means \pm SEM, $\mathrm{n}=2-4$. Data are normalized to housekeeping genes and $\mathrm{d} 15$ samples scaled to 1 . 


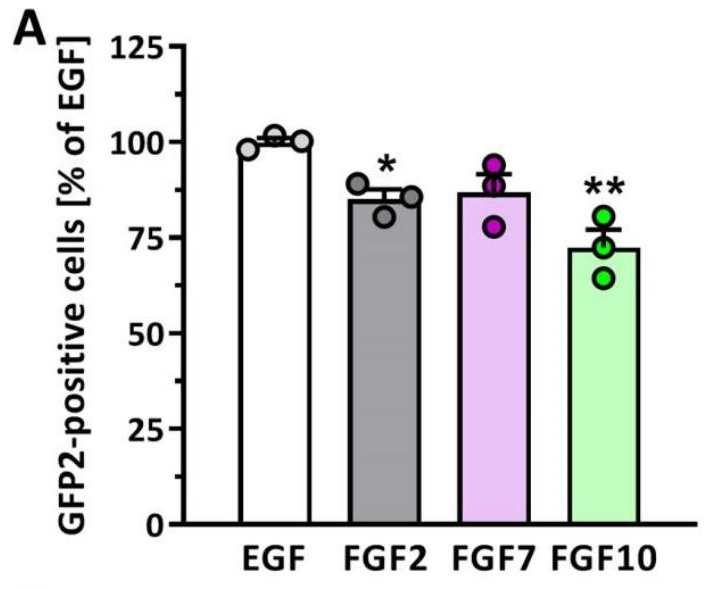

C

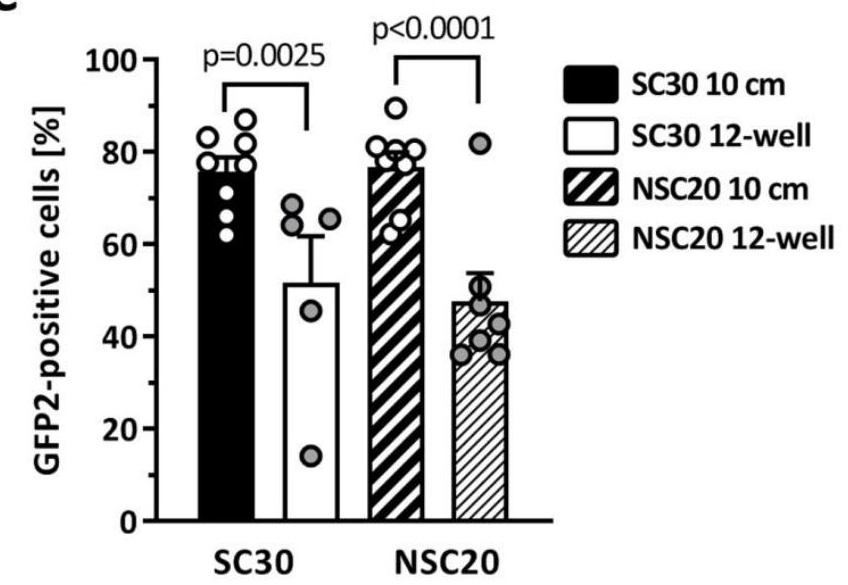

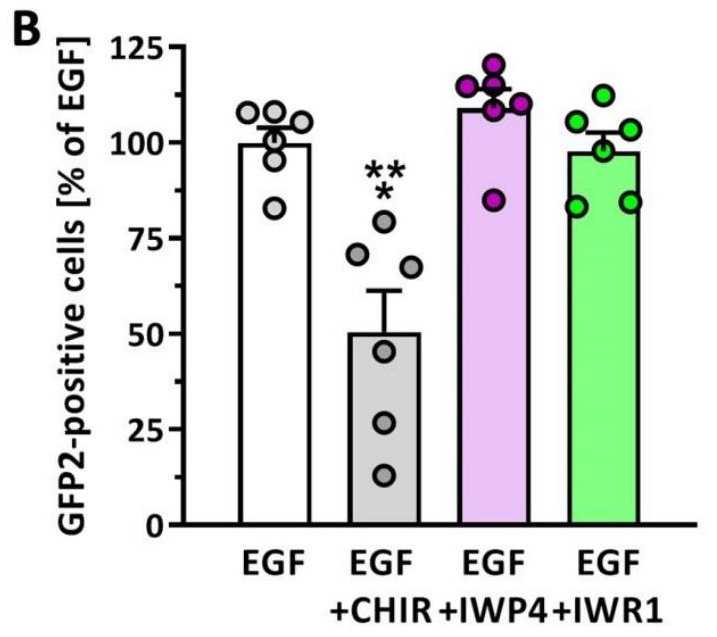

Supplementary figure 6. Effect of growth factors, Wnt/beta-catenin signaling and upscaling on the generation of GFP2+ pancreatic progenitors.

(A) Effect of different growth factors each used at $100 \mathrm{ng} / \mathrm{ml}$ on GFP2 expression in NSC20 cells. Data are means \pm SEM. $\mathrm{n}=3$, two-tailed Student's t-test, $* * \mathrm{p}<0.01, * \mathrm{p}<0.05$. (B) Effect of canonical Wnt-signaling on GFP2 expression in NSC20 cells. The pathway was activated by CHIR $(3 \mu \mathrm{M})$ or inhibited by IWP4 $(1 \mu \mathrm{M})$ or IWR-1 $(2 \mu \mathrm{M})$. Data are means \pm SEM, $\mathrm{n}=6$, two-tailed Student's t-test, *** $\mathrm{p}<0.001$ (C) Flow cytometric quantification of GFP+ pancreatic progenitors from the cell lines SC30 and NSC20 at d12 of differentiation differentiated in 12 -well plate cavities or $10 \mathrm{~cm}$ cell culture dishes. Data are means \pm SEM, $\mathrm{n}=8-11$. Two-tailed Student's t-test, *** $\mathrm{p}<0.001, * * \mathrm{p}<0.01$. 

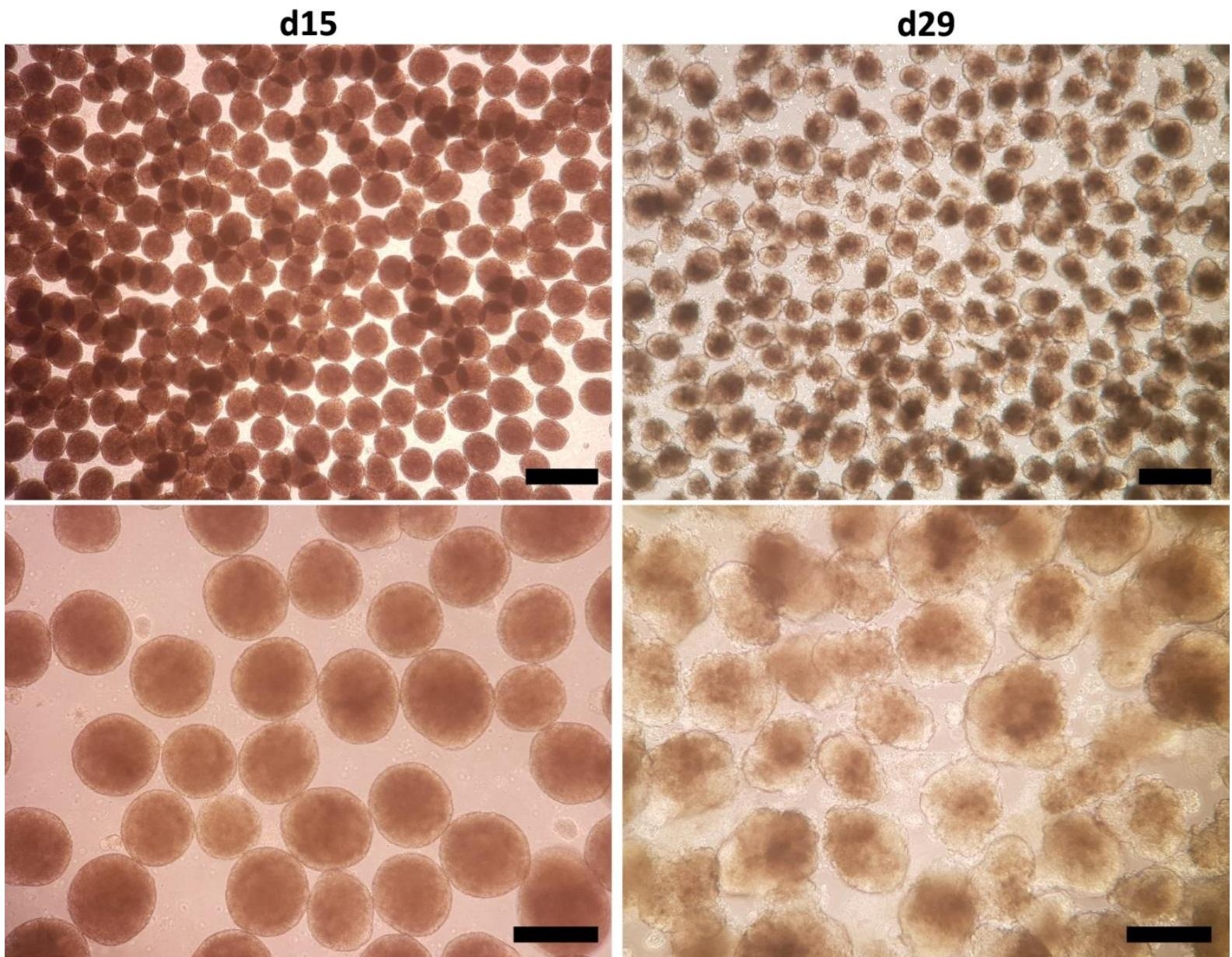

Supplementary figure 7. Generation of pancreatic spheroids (left images) and stem cellderived organoids (right images) by 3D shaking culture. Shown are representative images of cell spheroids 3 days (left) and organoids 17 days (right) after transfer from 2D adherent culture to 3D orbital suspension culture at $100 \mathrm{rpm}$. Scale bar for lower magnification image $=500 \mu \mathrm{m}$. Scale bar for higher magnification image $=200 \mu \mathrm{m}$. 

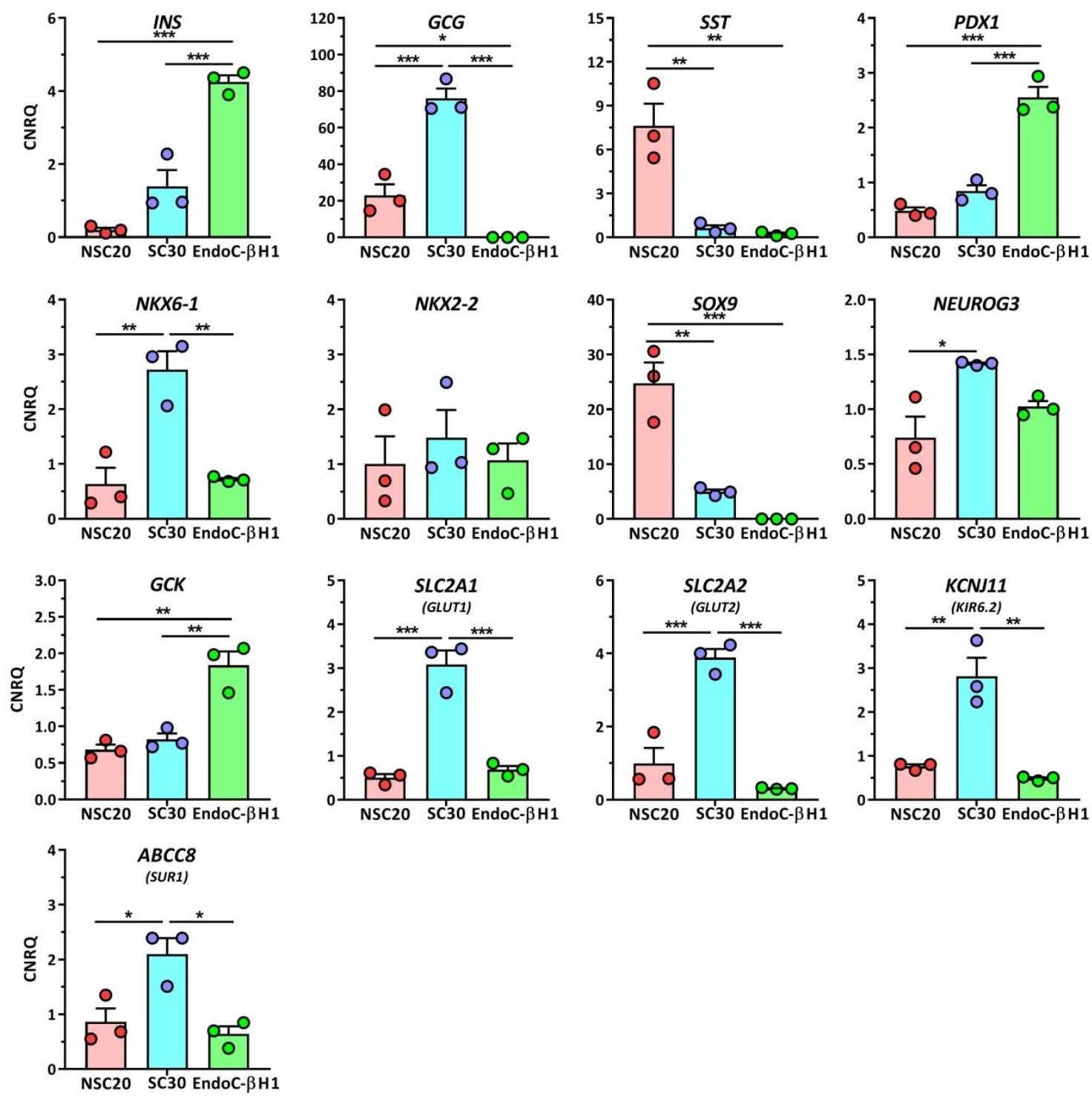

60 Supplementary figure 8. Relative gene expression of pancreatic and endocrine genes in

61 NSC20- and SC30-derived organoids after 3D differentiation compared to EndoC- $\beta$ H1

62 cells. Data are means \pm SEM, $\mathrm{n}=3$. ANOVA plus Tukey's post test, *** $\mathrm{p}<0.001$, $* * \mathrm{p}<0.01, * \mathrm{p}<0.05$. 


\section{d29}

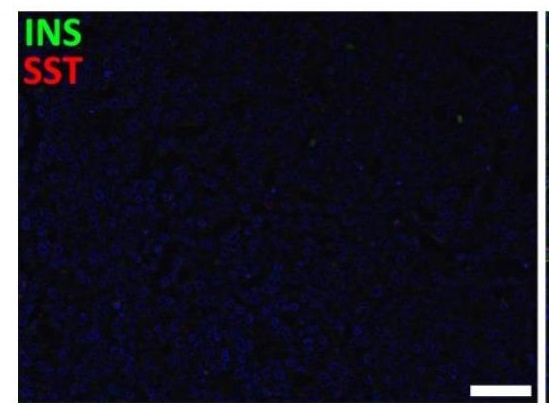

Human non-diabetic pancreas

66 Supplementary figure 9. Immunhistochemical analysis of SC-derived pancreatic organoids.

67 D15 spheroids and d29 stem cell-derived organoids derived in 3D from the SC30 clone were

68 fixed, sectioned and double-stained for somatostatin (red) and insulin (green). A human non-

69 diabetic pancreas was taken as control. Arrowheads mark polyhormonal cells. Scale $70 \quad$ Bar $=50 \mu \mathrm{m}$. 

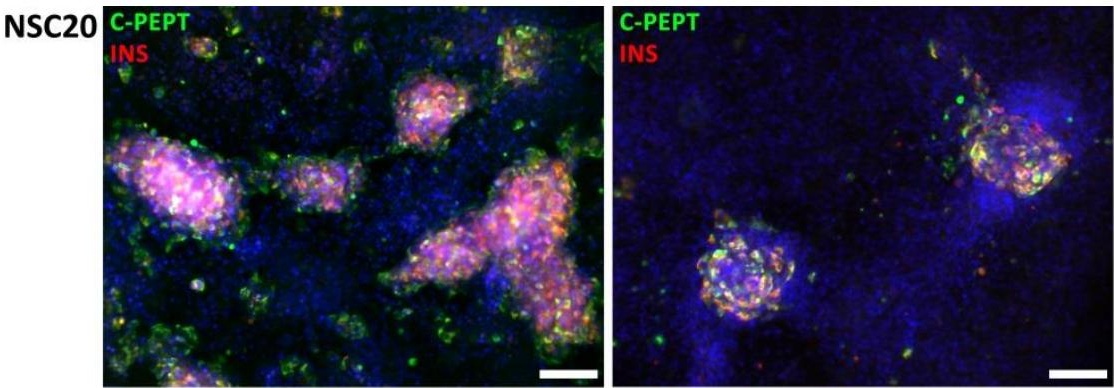

SC30
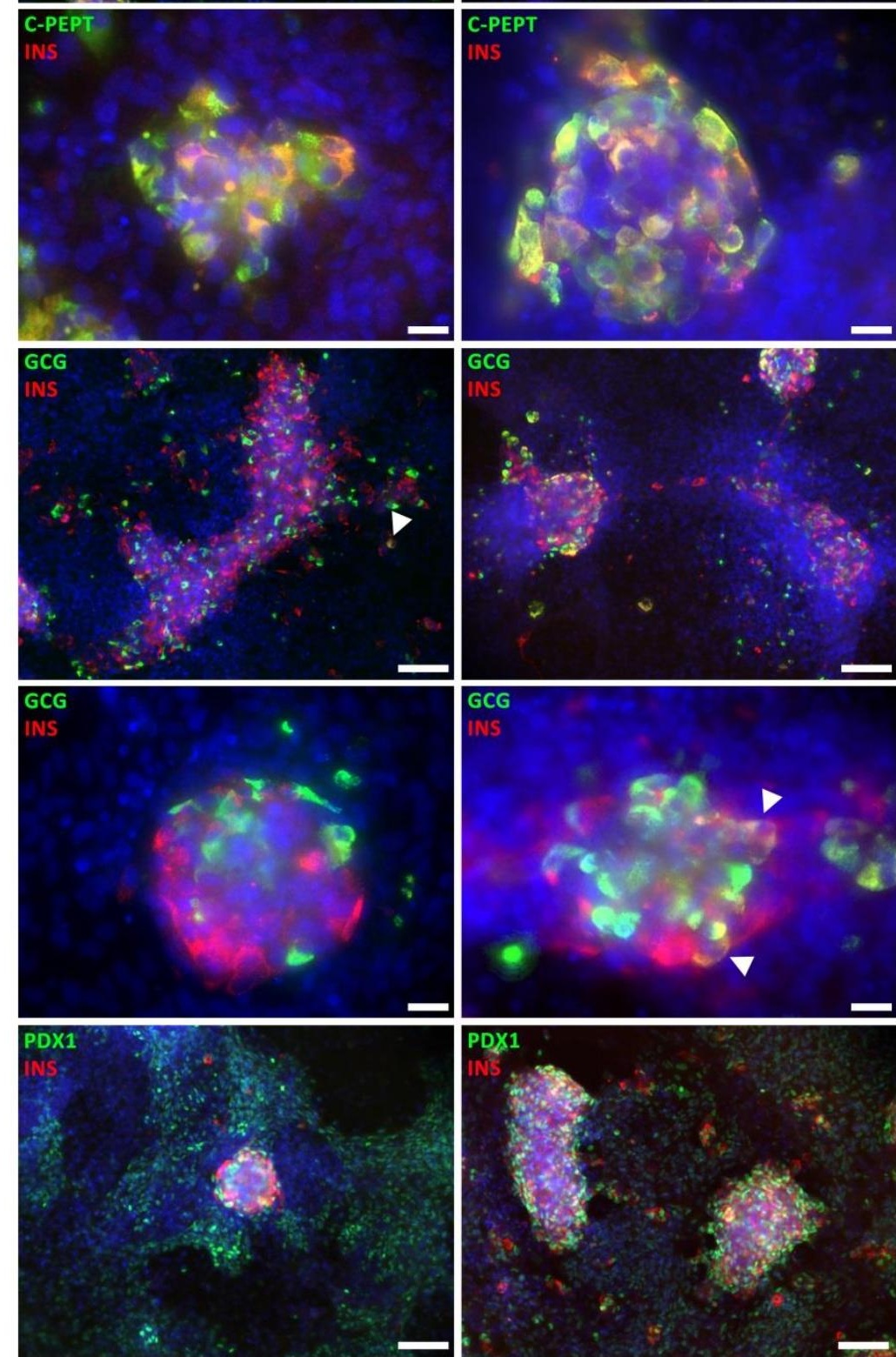

Supplementary figure 10. Immunofluorescence staining of NSC20-derived (left images) and SC30-derived (right images) pancreatic and endocrine cells at $\mathrm{d} 29$ using the production protocol in 2D. Double staining of insulin (red) and C-peptide, glucagon and PDX1 (all in green). Counterstaining with DAPI. Scale bar for lower magnification image $=100 \mu \mathrm{M}$, scale bar for higher magnification images $=20 \mu \mathrm{M}$. Arrowheads indicate polyhormonal insulin and glucagon co-expressing cells. 
80
NSC20

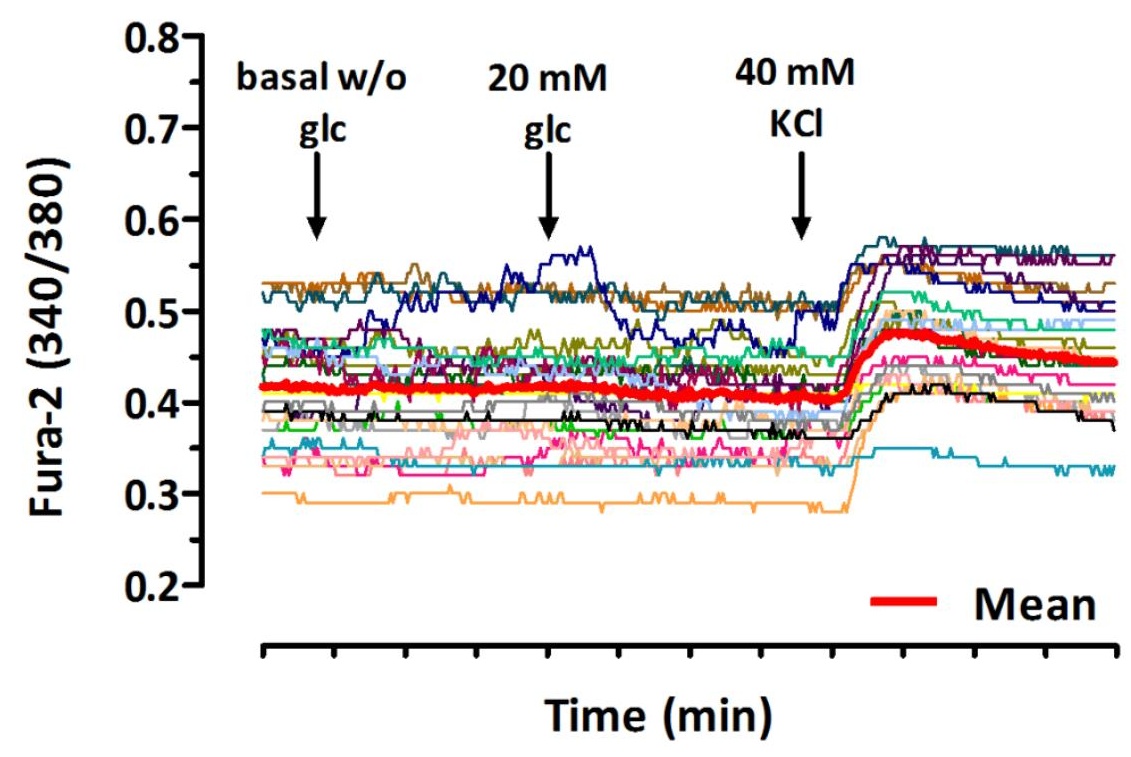

Supplementary figure 11. Recording of the Fura-2/AM emission ratio at 340 and $380 \mathbf{~ n m}$ over 13 minutes. NSC20-derived organoids were dissociated, seeded on glass slides for $24 \mathrm{~h}$ and loaded with Fura-2/AM. Then the cells were stimulated with basal KR $\varnothing$ glucose, $20 \mathrm{mM}$ glucose in $\mathrm{KR}$, basal $\mathrm{KR} \varnothing$ glucose and finally $\mathrm{KR}$ plus $40 \mathrm{mM} \mathrm{KCl}$. Mean value of all 15 cells in bold red. 
87 Supplementary Table 1: sgRNAs for HDR

\begin{tabular}{|c|c|c|}
\hline $\begin{array}{c}\text { Gene Symbol/ } \\
\text { Cas type }\end{array}$ & Orientation & Primer Sequence 5'-3' \\
\hline \multirow{2}{*}{$\begin{array}{l}\text { SOX9 } \\
\text { Cas9 } \\
\text { T5 }\end{array}$} & $\begin{array}{l}\text { Forward cloning } \\
\text { primer }\end{array}$ & CACCGACACAGCTCACTCGACCTTGAGG \\
\hline & $\begin{array}{l}\text { Reverse cloning } \\
\text { primer }\end{array}$ & AAACCAAGGTCGAGTGAGCTGTGTC \\
\hline \multirow{2}{*}{$\begin{array}{l}\text { INS } \\
\text { Cas9n } \\
\# 1 \\
\text { Nickase pair } 1\end{array}$} & $\begin{array}{l}\text { Forward cloning } \\
\text { primer }\end{array}$ & CACCGTGCAACTAGACGCAGCCCGC \\
\hline & $\begin{array}{l}\text { Reverse cloning } \\
\text { primer }\end{array}$ & AAACGCGGGCTGCGTCTAGTTGCAC \\
\hline \multirow{2}{*}{$\begin{array}{l}\text { INS } \\
\text { Cas9n } \\
\# 23 \\
\text { Nickase pair } 1\end{array}$} & $\begin{array}{l}\text { Forward cloning } \\
\text { primer }\end{array}$ & CACCGCTGGTAGAGGGAGCAGATGC \\
\hline & $\begin{array}{l}\text { Reverse cloning } \\
\text { primer }\end{array}$ & AAACGCATCTGCTCCCTCTACCAGC \\
\hline \multirow{2}{*}{$\begin{array}{l}\text { INS } \\
\text { Cas9n } \\
\# 10 \\
\text { Nickase pair } 2\end{array}$} & $\begin{array}{l}\text { Forward cloning } \\
\text { primer }\end{array}$ & CACCGCCTCCTGCACCGAGAGAGA \\
\hline & $\begin{array}{l}\text { Reverse cloning } \\
\text { primer }\end{array}$ & AAACTCTCTCTCTGGTGCAGGAGGC \\
\hline \multirow{2}{*}{$\begin{array}{l}\text { INS } \\
\text { Cas9n } \\
\# 7 \\
\text { Nickase pair } 2\end{array}$} & $\begin{array}{l}\text { Forward cloning } \\
\text { primer }\end{array}$ & CACCGAGTTGCAGTAGTTCTCCAGC \\
\hline & $\begin{array}{l}\text { Reverse cloning } \\
\text { primer }\end{array}$ & AAACGCTGGAGAACTACTGCAACTC \\
\hline
\end{tabular}

sgRNA sequences marked in bold

89

91 Supplementary Table 2: Primer pairs for gene expression analysis.

\begin{tabular}{|c|c|c|}
\hline Gene & Primer Sequence 5'-3' & Accession \# \\
\hline $\begin{array}{l}A B C C 8 \\
(S U R 1)\end{array}$ & $\begin{array}{c}\text { Fw: tcacaccgctgttcctgct } \\
\text { Rev: agaaggagcgaggacttgcc }\end{array}$ & NM_001287174.2 \\
\hline CPAl & $\begin{array}{l}\text { Fw: caggctccctctgtattggc } \\
\text { Rev: ggacttgacctccacttcgg }\end{array}$ & NM_001868.4 \\
\hline$G 6 P D$ & $\begin{array}{l}\text { Fw: aggccgtcaccaagaacattca } \\
\text { Rev: cgatgatgcggttccagcctat }\end{array}$ & NM_000402 \\
\hline$G C G$ & $\begin{array}{l}\text { Fw: aagcatttactttgtggctggatt } \\
\text { Rev: tgatctggatttctcctctgtgtct }\end{array}$ & NM_002054.5 \\
\hline$G C K$ & $\begin{array}{l}\text { Fw: cctgggtggcactaacttcag } \\
\text { Rev: tagtcgaagagcatctcagca }\end{array}$ & NM_000162.5 \\
\hline$I N S$ & $\begin{array}{l}\text { Fw: gccccgagatacatcagagg } \\
\text { Rev: ccaggtcacccaggactttac }\end{array}$ & NM_000207.3 \\
\hline $\begin{array}{l}\text { KCNJ11 } \\
(\text { KIR6.2) }\end{array}$ & $\begin{array}{l}\text { Fw: aaggaagagtctggtgggga } \\
\text { Rev: tagggcctcactgcagagtc }\end{array}$ & NM_000525.4 \\
\hline NEUROG3 & $\begin{array}{l}\text { Fw: gcgaccagaagccegctg } \\
\text { Rev: ggcgtcatcctttctaccggc }\end{array}$ & NM_020999.4 \\
\hline
\end{tabular}




\begin{tabular}{|c|c|c|}
\hline$N K X 2-2$ & $\begin{array}{l}\text { Fw: aacccettctacgacagcagcg } \\
\text { Rev: acttggagcttgagtcctgagggg }\end{array}$ & NM_002509 \\
\hline NKX6-1 & $\begin{array}{l}\text { Fw: ggcccggagtgatgcagagc } \\
\text { Rev: tcttccegtctttgtccaac }\end{array}$ & NM_006168.3 \\
\hline $\begin{array}{l}\text { ONECUT1 } \\
\text { (HNF6) }\end{array}$ & $\begin{array}{c}\text { Fw: cgctccgcttagcagcatgc } \\
\text { Rev: gtgtgttgcctctatccttcccatg }\end{array}$ & NM_004498 \\
\hline$P D X 1$ & $\begin{array}{c}\text { Fw: cgttccagctgcctttcccat } \\
\text { Rev: ccgtgagatgtacttgttgaatagga }\end{array}$ & NM_000209 \\
\hline $\begin{array}{l}S L C 2 A 1 \\
(G L U T 1)\end{array}$ & $\begin{array}{l}\text { Fw: cctgcagtttggctacaaca } \\
\text { Rev: aggatgctctccccatagcg }\end{array}$ & NM_006516 \\
\hline $\begin{array}{l}S L C 2 A 2 \\
(G L U T 2)\end{array}$ & $\begin{array}{l}\text { Fw: actgggaccctggttttca } \\
\text { Rev: ccagtggaacacccaaaaca }\end{array}$ & NM_000340 \\
\hline SOX9 & $\begin{array}{l}\text { Fw: gcggaggaagtcggtgaagaacg } \\
\text { Rev: ctgggattgccccgagtgctc }\end{array}$ & NM_000346 \\
\hline$S S T$ & $\begin{array}{l}\text { Fw: cccagactccgtcagtttc } \\
\text { Rev: tccgtctggttgggttag }\end{array}$ & NM_001048.4 \\
\hline$T B P$ & $\begin{array}{l}\text { Fw: caacagcetgccaccttacgetc } \\
\text { Rev: aggctgtggggtcagtccagtg }\end{array}$ & NM_003194 \\
\hline TUBAIA & $\begin{array}{l}\text { Fw: ggcagtgtttgtagacttggaaccc } \\
\text { Rev: tgtgataagttgctcagggtggaag }\end{array}$ & NM_006009 \\
\hline
\end{tabular}

93 Supplementary Table 3: Antibodies used in this study.

\begin{tabular}{|c|c|c|c|}
\hline Protein & Supplier & Cat \# & Dilution \\
\hline CPA1 & Origene & TA500053 & $1: 100$ \\
\hline CK19 & R\&D systems & AF3506 & $1: 300$ \\
\hline C-peptide & Thermo Fisher & MA1-19159 & $1: 400$ \\
\hline Glucagon & Abcam & ab10988 & $1: 300-1: 2000$ \\
\hline \multirow{2}{*}{ Insulin } & \multirow{2}{*}{$\begin{array}{c}\text { Agilent DAKO } \\
\text { Abcam }\end{array}$} & A564 & $1: 100$ \\
\hline & & ab7842 & $1: 100$ \\
\hline NEUROG3 & R\&D systems & AF3444 & $1: 200$ \\
\hline NKX6-1 & $\mathrm{R} \& \mathrm{D}$ systems & AF5857 & $1: 100-1: 300$ \\
\hline $\begin{array}{l}\text { ONECUT1 } \\
\text { (HNF6) }\end{array}$ & R\&D systems & AF6277 & $1: 100$ \\
\hline PDX1 & R\&D systems & AF2419 & $1: 300$ \\
\hline Somatostatin & Abcam & ab22682 & $1: 500-1: 1000$ \\
\hline SOX9 & R\&D systems & AF3075 & $1: 300$ \\
\hline
\end{tabular}


94 Supplementary Table 4: Data on the non-diabetic human pancreas organ donors

95

\begin{tabular}{ccccc}
\hline & Donor 1 & Donor 2 & Donor 3 & Donor 4 \\
\hline Age (years) & 60 & 47 & 64 & 52 \\
Gender & female & male & male & female \\
$\begin{array}{c}\text { Cause of } \\
\text { pancreas } \\
\text { removal }\end{array}$ & Donor organ & $\begin{array}{c}\text { Pancreas } \\
\text { resection }\end{array}$ & $\begin{array}{c}\text { Pancreas } \\
\text { resection }\end{array}$ & $\begin{array}{c}\text { Pancreas } \\
\text { resection }\end{array}$ \\
$\begin{array}{c}\text { Blood glucose } \\
\text { conc. (mmol/l) } \\
\text { before organ } \\
\text { collection }\end{array}$ & 5.7 & 6.2 & 5.8 & 5.3 \\
\hline
\end{tabular}

